University of Louisville

ThinkIR: The University of Louisville's Institutional Repository

Electronic Theses and Dissertations

$12-2018$

\title{
Functional consequence of PSAT1 association on PKM2's inherent enzymatic activity.
}

Alexis Avidan Vega
University of Louisville

Follow this and additional works at: https://ir.library.louisville.edu/etd

Part of the Biochemistry Commons, Bioinformatics Commons, and the Molecular Biology Commons

\section{Recommended Citation}

Vega, Alexis Avidan, "Functional consequence of PSAT1 association on PKM2's inherent enzymatic activity." (2018). Electronic Theses and Dissertations. Paper 3104.

https://doi.org/10.18297/etd/3104

This Master's Thesis is brought to you for free and open access by ThinkIR: The University of Louisville's Institutional Repository. It has been accepted for inclusion in Electronic Theses and Dissertations by an authorized administrator of ThinkIR: The University of Louisville's Institutional Repository. This title appears here courtesy of the author, who has retained all other copyrights. For more information, please contact thinkir@louisville.edu. 


\title{
FUNCTIONAL CONSEQUENCE OF PSAT1 ASSOCIATION ON PKM2'S INHERENT ENZYMATIC ACTIVITY
}

\author{
By \\ Alexis Avidan Vega \\ Biotechnology B.S., Florida Gulf Coast University, 2013
}

\author{
A Thesis \\ Submitted to the Faculty of the \\ School of Medicine \\ In Partial Fulfillment of the Requirements
}

For the Degree of

Master of Science in Biochemistry and Molecular Genetics

Department of Biochemistry and Molecular Genetics

University of Louisville

Louisville, KY

December 2018 

FUNCTIONAL CONSEQUENCE OF PSAT1 ASSOCIATION ON PKM2'S

INHERENT ENZYMATIC ACTIVITY

By
Alexis Avidan Vega
Biotechnology B.S., Florida Gulf Coast University, 2013

A Thesis approved on

October 29, 2018

By the following Thesis Committee:

Brian F. Clem, PhD, Thesis Director

Barbara J. Clark, PhD, Committee Member

Jaydev N. Dholakia, PhD, Committee Member 


\section{ACKNOWLEDGEMENTS}

I would like to begin by thanking Dr. Brian Clem for his guidance, advice, and being granted the opportunity to work in his lab. I would also like to thank Dr. Barbara Clark and Dr. Jaydev Dholakia for agreeing to serve on my committee and their aid in the development of this thesis.

Secondly, I would like to thank Rumeysa Biyik-Sit for the preliminary data, which provided the foundation for this thesis project. Also, I want to acknowledge Dr. Traci Kruer for the expression and purification of the recombinant PSAT1 protein used in this thesis. I would also like to show my appreciation to Lindsey Reynolds, Stephanie Metcalf, and Susan Dougherty for their input on the technical troubleshooting for this work.

Furthermore, I would like to extend my thanks to Dr. Lee Schmidt for his assistance in the bacterial growth protocol, Dr. William Dean for his expertise in performing the analytical ultracentrifugation, and to Robert Monsen for assisting me with ROSIE protein docking. Finally, to the Graduate Student Council for partially funding this project. 


\section{ABSTRACT \\ FUNCTIONAL CONSEQUENCE OF PSAT1 ASSOCIATION ON PKM2'S \\ INHERENT ENZYMATIC ACTIVITY}

Alexis Avidan Vega

October 29, 2018

Pyruvate kinase M2 (PKM2) is predominantly found in tumors, where it allows the cancer cell to adapt to metabolic conditions through allosteric regulation of its activity. We recently discovered that phosphoserine aminotransferase 1 (PSAT1) associates with and activates PKM2. Here, I sought to affirm PSAT1's ability to increase PKM2 activity through kinetic and association studies of wild-type or mutant PKM2 enzymes. I demonstrate that His-tagged WT and mutant PKM2 enzymes are active, exhibit different kinetics, yet cannot be activated by PSAT1. Comparison studies using untagged WT PKM2 suggest that inclusion of the Histag disrupts PSAT1 association. In support, pull-down strategies failed to demonstrate any PSAT1 interaction with the PKM2 proteins. Future studies should focus on producing the PKM2 variants, potentially in untagged form, to assess their interaction with and activation by PSAT1. These results would add to our understanding of these two crucial proteins that are believed to promote tumor progression. 
TABLE OF CONTENTS

PAGE

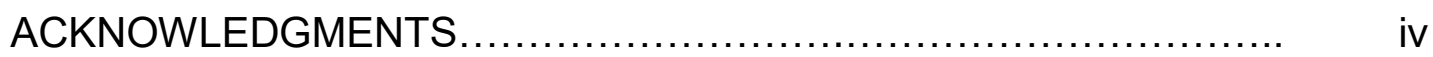

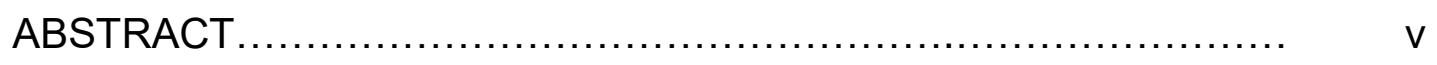

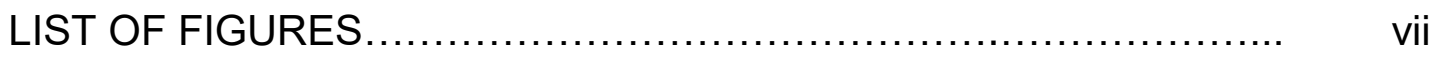

LIST OF TABLES ................................................ $\quad x$

CHAPTER ONE: INTRODUCTION..................................

Glycolysis and Intermediary Metabolism......................... 1

Glycolytic Shift in Tumor Cells...............................

Mediators of Altered Glycolysis and Tumorigenesis............. 9

PSAT1 as a Novel PKM2 activator............................. $\quad 15$

CHAPTER TWO: MATERIALS AND METHODS....................... 22

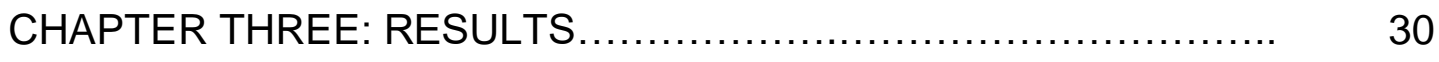

CHAPTER FOUR: DISCUSSION................................ 62

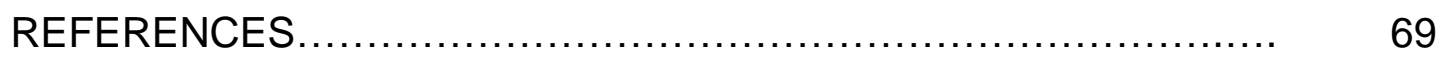

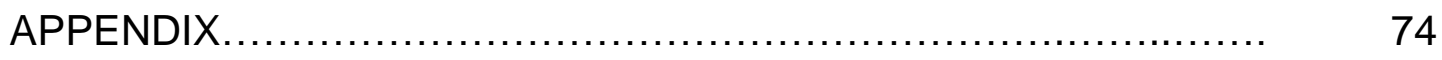

Assessment of interaction of His-PKM2 with Glutathione Beads $\quad 84$

CURRICULUM VITAE .............................................. 86 
1. Schematic of glucose carbon fates through intermediary metabolism.

2. Representation of metabolic changes upon transformation from normal to cancer cell.

3. Representation of PKM alternative splicing mechanism that produces either PKM1 or PKM2

4. Comparison between high active tetramer and low active dimer of PKM2

5. Schematic of serine metabolism.

6. Crystal structure of PKM2 and PKM1 show a potential site of interest

7. Sequence analysis of cDNA encoding WT and mutant variants of PKM2

8. Extraction of GST-PKM2 WT from bacterial lysates using ionic detergent (Sarkosyl).

9. Purification of GST-PKM2 enzymes using an alternative extraction protocol 
10. Kinetic analysis of GST-PKM2 recombinant enzymes............. 35

11. Thrombin cleavage of recombinant GST-PKM2 proteins......... 37

12. Purification of His-tagged PKM2 proteins....................... 38

13. Kinetic analysis to determine optimal PKM2 concentration........ 40

14. Kinetic analysis of WT or MT His-PKM2 enzymes................. 41

15. Vmax differences between His-PKM2 .......................... 42

16. Km differences between His-PKM2 ............................ 43

17. Cross-linking analysis to assess oligomerization of His-PKM2 46 proteins

18. Effect of PSAT1 and FBP on WT His-PKM2 activity ............... 49

19. Effect of PSAT1 and FBP on MT1 His-PKM2 activity............. 50

20. Effect of PSAT1 and FBP on MT2 His-PKM2 activity ............. 51

21. Effect of PSAT1 and FBP on MT3 His-PKM2 activity............. 52

22. Effect of PSAT1 and FBP on MT4 His-PKM2 activity ............. 53

23. Kinetic analysis of PKM2-Sigma activity in the presence of 54 PSAT1

24. Vmax differences between samples............................. 55

25. Km differences between samples............................... 56

26. Alternative analysis of recPSAT1 activation of in-house and 57

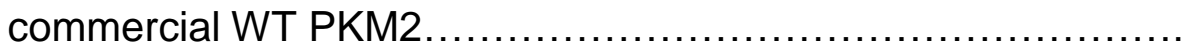

27. Analysis of PSAT1:PKM2 interaction using His-PKM2 pulldown $\quad 60$ with Ni-NTA.

28. Co-IP of recombinant PSAT1 and PKM2 
29. Effect of PSAT1 and FBP on WT His-PKM2 (Batch1) activity..... 74

30. Effect of PSAT1 and FBP on MT1 His-PKM2 (Batch1) activity.... 75

31. Effect of PSAT1 and FBP on MT2 His-PKM2 (Batch1) activity.... 76

32. Effect of PSAT1 and FBP on MT4 His-PKM2 (Batch 1) activity... 77

33. Effect of PSAT1 and FBP on WT His-PKM2 (Batch 2) activity.... 78

34. Effect of PSAT1 and FBP on MT1 His-PKM2 (Batch 2) activity... 79

35. Effect of PSAT1 and FBP on MT2 His-PKM2 (Batch 2) activity... 80

36. Effect of PSAT1 and FBP on MT4 His-PKM2 (Batch 2) activity... 81

37. Analysis of His-PKM2 association with glutathione beads........ 85 
LIST OF TABLES

PAGE

1. Abbreviations................................................... 82 


\section{CHAPTER ONE: INTRODUCTION}

Glycolysis and Intermediary Metabolism

Adenosine Triphosphate (ATP) is the energy currency that is used by cells to perform many functions, such as macromolecular synthesis and size homeostasis. In order to generate this energy, most mammalian cells metabolize sugars, notably glucose. Glucose is a six-carbon sugar that is transported into the cell through various glucose transporters, termed GLUTs. Once inside the cell, glucose carbons can be metabolized through various pathways within intermediary metabolism that gives rise to cellular components, including ATP, that is necessary for normal cell function (Figure 1). Initially, glucose enters glycolysis, which was first described by Gustav Embden, Otto Meyerhof, and Jakub Parnas, that results in the formation of pyruvic acid. Glycolysis can be divided into two sections: that requiring energy input and that resulting in energy production.

The initial reactions within glycolysis requires energy input in order to catabolize glucose. Hexokinase (HK) transfers a phosphate group from ATP to glucose to generate glucose-6-phosphate (G6P). This non-reversible step prohibits glucose from exiting the cell. Next, phosphoglucose isomerase (PGI) isomerizes G6P into fructose-6-phosphate (F6P), which subsequently is phosphorylated in a non-reversible manner by ATP-demanding phosphofructokinase-1 (PFK1). Like HK, PFK1 transfers a phosphate 


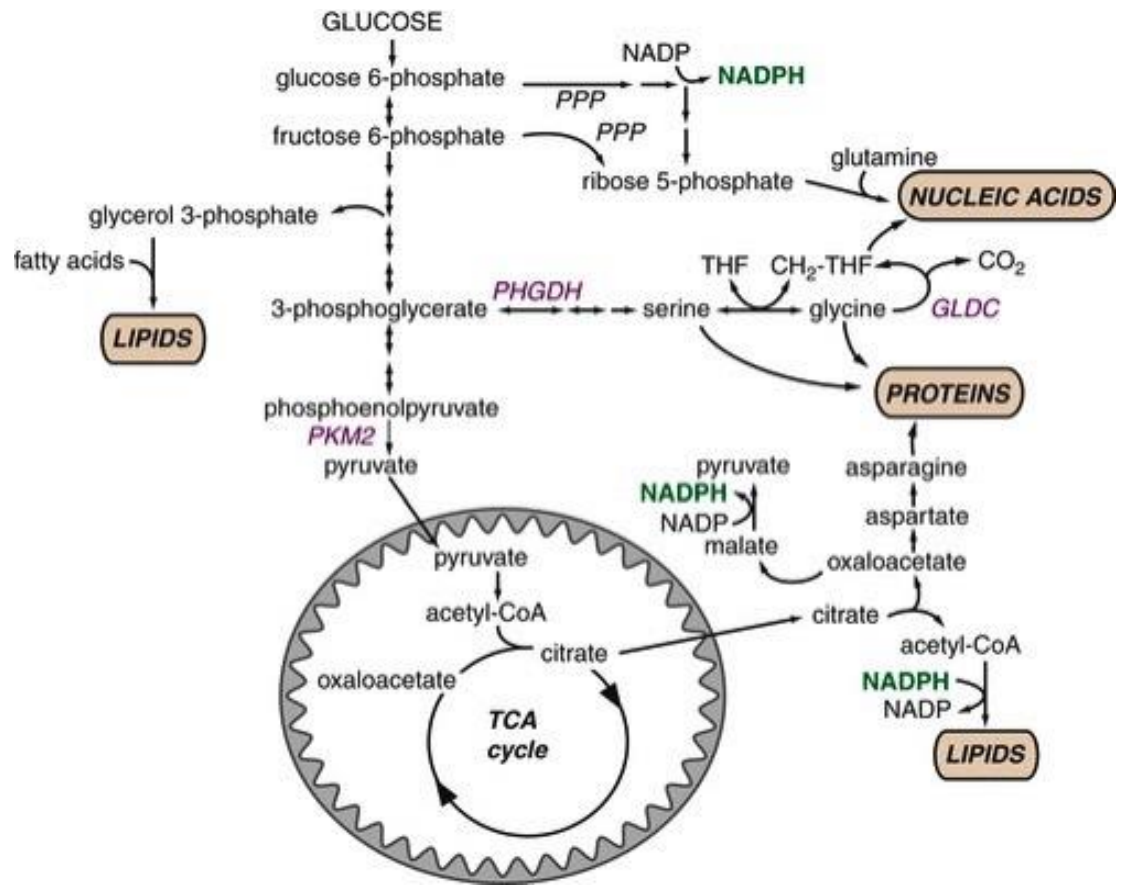

Figure 1. Schematic of glucose carbon fates through

intermediary metabolism. Glucose can be fully oxidized within glycolysis and the TCA. Glucose can also be metabolized in other pathways, such as the pentose phosphate pathway (PPP) and serine biosynthesis, to produce nucleic and amino acids for DNA/RNA and proteins, respectively. Lipids are generated through fatty acid synthesis from citrate-derived acetyl-CoA. Flux through these pathways is primarily controlled through activity of specific enzymes, including pyruvate kinase (PKM) and phosphoglycerate dehydrogenase (PHGDH).

Schematic cited from https://clinicalgate.com/the-metabolism-of-cellgrowth-and-proliferation/\#f0030 
group from ATP to F6P to generate fructose 1,6-bisphosphate (FBP). Aldolase then cleaves FBP, resulting in production of dihydroxyacetone phosphate and glyceraldehyde 3-phosphate (G3P). Dihydroxyacetone phosphate and G3P isomerize between one another through the activity of triose phosphate isomerase. This energy-requiring segment of glycolysis utilizes 2 molecules of ATP for every 1 molecule of glucose catabolized.

Subsequent to G3P are the energy producing reactions of glycolysis. Glyceraldehyde 3-phosphate dehydrogenase (GAPDH) works to oxidize G3P into 1,3-bisphosphoglycerate while also reducing nicotinamide adenine dinucleotide $\left(\mathrm{NAD}^{+}\right)$into $\mathrm{NADH}$. Phosphoglycerate kinase functions to transfer a phosphate group from 1,3-bisphosphoglycerate to adenosine diphosphate (ADP) to produce ATP and 3-phosphoglycerate. This is followed by conversion of 3phosphoglyerate into 2-phosphoglycerate by phosphoglycerate mutase. Enolase then acts to remove a water molecule from 2-phosphoglycerate to generate phosphoenolpyruvate (PEP). High energy PEP is then metabolized by pyruvate kinase $(\mathrm{PK})$ to produce pyruvate, during which the high-energy phosphate group is transferred to ADP to form ATP. Similar to HK and PFK1, PK is a non-reversible reaction and qualifies as the last step in the glycolytic pathway. Within glycolysis, metabolism of one molecule of glucose generates a net gain of 2 ATP and $2 \mathrm{NADH}$.

Under normal aerobic conditions, pyruvate is converted into acetyl-CoA by pyruvate dehydrogenase that generates $1 \mathrm{NADH}$. Acetyl-CoA can then enter the tricarboxylic acid cycle (TCA) within the mitochondrial matrix. Although the TCA contributes only one GTP molecule per turn, 3 molecules of NADH and 1 molecule 
of reduced flavin adenine dinucleotide $\left(\mathrm{FADH}_{2}\right)$ are produced. $\mathrm{NADH}$ and $\mathrm{FADH} 2$ generated from glucose-derived pyruvate oxidation act as electron donors to acceptor complexes, such as cytochrome c oxidase, throughout the electron transport chain located within the inner mitochondrial membrane. As these electrons traverse through the chain, ending in oxygen as a final acceptor, a proton gradient is formed across the mitochondrial inner membrane. This electrochemical gradient is then coupled to ATP synthesis by the flowing of protons through ATP synthase. Under physiological conditions, each NADH yields 2.5 ATP, while oxidation of each $\mathrm{FADH}_{2}$ results in 1.5 ATP. Therefore, pyruvate oxidation generates 23 ATP from oxidative phosphorylation and 2 ATP from substrate level phosphorylation within the Kreb cycle. Coupled to the 2 ATP and NADH formed in glycolysis, each molecule of glucose can yield 32 ATP under normoxic conditions. In the case where sufficient oxygen is not available for cells to fully oxidize glucose (hypoxia), pyruvate can be fermented into lactic acid by lactate dehydrogenase (LDH). Although fermentation does not contribute substrate level derived ATP, it is necessary to oxidize NADH back into $\mathrm{NAD}^{+}$to allow glycolysis to continue [1]. In addition to hypoxia, other cellular alterations or pathologies also lead to enhanced glycolytic flux that promote either enhanced cell proliferation or survival.

\section{Glycolytic Shift in Tumor Cells}

Flurodeoxyglucose positron emission tomography (FDG-PET) coupled with computed tomography (CT) is a tool used to screen for metabolically active cells in patients [2]. FDG is an analog of glucose wherein the hydroxyl located on 
carbon 2 is substituted for a radiolabeled fluorine $\left({ }^{18} \mathrm{~F}\right)$. Similar to glucose, FDG is taken in by the cells through glucose transporters and phosphorylated by $\mathrm{HK}$ that prevents it from escaping the cell. However, the fluorine inhibits the cell from metabolizing phosphorylated FDG past this step [3-5]. PET imaging is then able to detect the radioisotopic fluorine accumulating in tissues $[2,6]$. As one of the hallmarks of cancer is increased glucose metabolism, this procedure allows for diagnostic imaging in cancer patients $[7,8]$. In addition, FDG-PET/CT can be used not only to initially detect tumor lesions but also monitor tumor response during treatment [9], which is why it has become the major clinical imaging tool in oncology.

It is well established that tumor cells take up glucose at a higher rate than non-tumor cells. This change in glucose metabolism was first observed by Otto Warburg in the 1920s. In his studies, less glucose was measured in outgoing blood vessels of tumor tissues compared with that of normal tissues [7]. The increase of glucose uptake also resulted in an increase of lactate production (fermentation), even in the presence of oxygen. This ability for cancer cells to selectively metabolize glucose to lactate under normoxic conditions is termed aerobic glycolysis, or the "Warburg Effect" (Figure 2). Warburg concluded that this deviation from normal glucose metabolism was brought upon by functionally impaired mitochondria in tumor cells $[7,10]$.

Converse to Warburg's idea that mitochondrial dysfunction was the primary causal shift towards aerobic glycolysis in tumor cells, it has now been established that the vast majority of cancers maintain active mitochondria. [11, 12]. For 

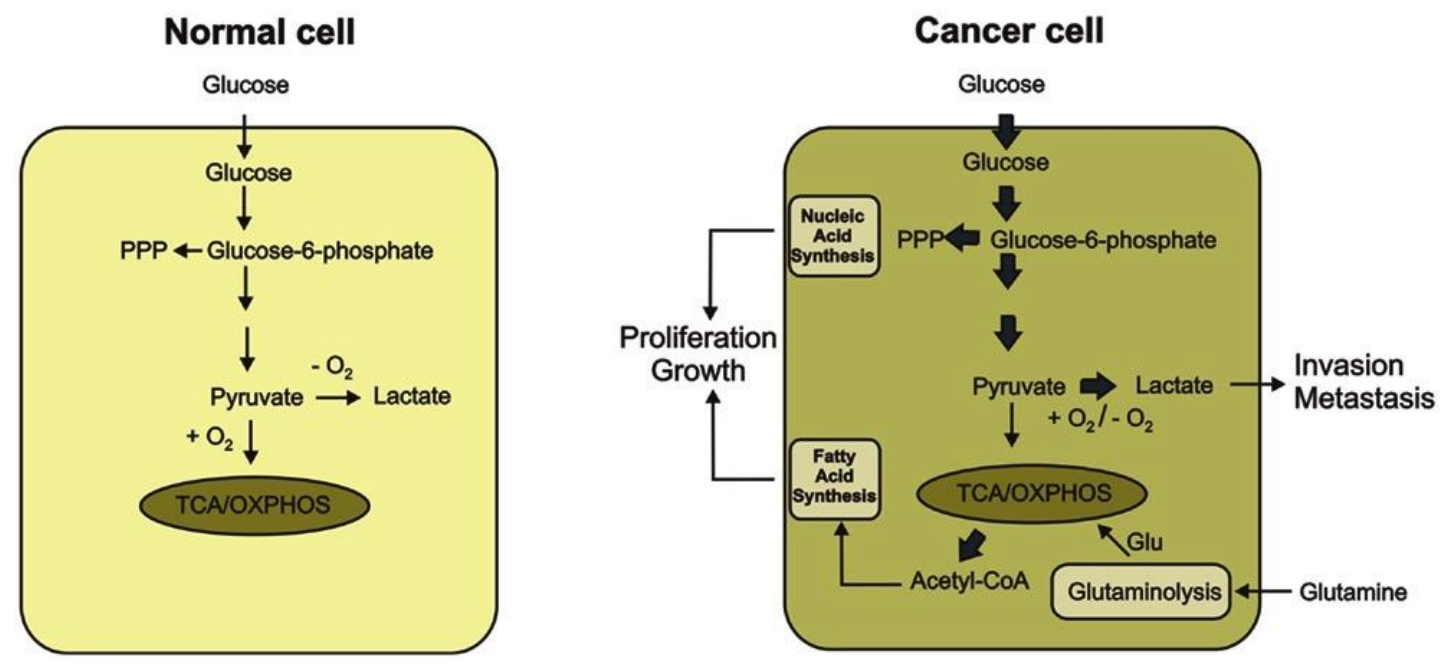

Figure 2. Representation of metabolic changes upon transformation from normal to cancer cell. Glucose is preferentially metabolized within the TCA for oxidative phosphorylation. However, cancer cells change their metabolism to increase production of macromolecules that are necessary for increased proliferation/growth. In addition, tumors secrete increased levels of lactate, even in the presence of oxygen, which helps promote invasion and metastasis.

Schematic cited from Jó'zwiak P, Forma E, Bryma,M, andKrzek and A (2014) O-GlcNAcylation and metabolic reprograming in cancer. Front.Endocrinol. 5:145. 
example, knockdown of LDH-A increased mitochondrial respiration, leading to the conclusion that LDH-A was competing with the mitochondria for glucose-derived pyruvate [11]. If the majority of tumor cells have functional mitochondria, other cellular forces must be promoting this metabolic shift towards aerobic glycolysis. One possible explanation for the Warburg effect could be the result of abnormal activation of certain genes, termed oncogenes, or inactivation of others, e.g. tumor suppressors $[9,11,13]$. Substantial work has now demonstrated the contribution of certain transcription factors or signaling pathways which control the Warburg Effect, including hypoxia inducing factor $1 \alpha(\mathrm{HIF} 1 \alpha)$, MYC, and the AKT pathway $[14,15]$. These pathways have been observed to alter the activity of certain glycolytic enzymes to increase glucose metabolism [14, 16, 17]. Among the enzymes that are direct targets of these upstream factors that increase glycolytic rate include GLUT1, HK, PFK, PK, and LDH [12, 18-24].

Despite defining mechanisms as to how tumors increase glycolysis, the question remains as to why tumor cells would use such an inefficient technique to generate ATP. It is now believed that tumor cells enhance their glycolytic rate, not for increased energy production, but because glycolytic intermediates are used to generate key components of proliferation [25]. For example, after glucose is converted into G6P in glycolysis, it can then be shunted into the Pentose Phosphate Pathways (PPP) (Figure 2). Here, G6P continues to be metabolized to ultimately generate ribonucleotides and reduced nicotinamide adenine dinucleotide phosphate (NADPH) [26-28]; both being necessary for cell proliferation [29]. The ribonucleotides produced by PPP are utilized to synthesize 
nucleic acids, while the NADPH is consumed when producing fatty acids, cholesterol, and hormones. NADPH is also required to re-establish reduced glutathione (GSH), which protects cells from reactive oxygen species (ROS) [30].

Glycolytic intermediates may also feed into the serine synthetic pathway. Specifically, 3-PG is used as a substrate to produce 3-phosphohydroxypyruvate (PHP) through the activity of phosphoglycerate dehydrogenase (PHGDH). Phosphoserine aminotransferase 1 (PSAT1), with the co-factor pyridoxal 5'phosphate (PLP), transfers an amino group from L-glutamic acid to PHP. This results in the production of phosphoserine (P-ser) and $\alpha$-ketoglutarate $(\alpha K G)$. Phosphoserine phosphatase (PSPH) can then catalyze the reaction that removes an inorganic phosphate from P-Ser to produce serine. While serine can be actively generated through this pathway, this non-essential amino acid can also be readily taken in from the extracellular environment [31].

As an amino acid, one of the functions of serine is as a component of newly synthesized proteins. In addition to this, serine can also be used to produce glycine through the transfer of one carbon to tetrahydrofolate (THF) to produce 5,10-methylene-THF [31-34]. 5,10-methylene-THF is required for the production of both purines and methionine [34]. Methionine can either continue on to be utilized as an amino acid for protein synthesis, or be used to produce S-adenosyl methionine (SAM) [31]. SAM is a substrate for methylation of DNA or RNA, as well as a precursor for production of homocysteine [35]. Homocysteine can then be used to produce GSH with the assistance of serine [31]. Given all of these cellular benefits to rapidly proliferate and protection against apoptosis, it is not surprising 
that tumor cells upregulate enzymes found in the serine synthesis pathway [36, 37].

Mediators of Altered Glycolysis and Tumorigenesis

With the increased availability of glycolytic intermediates, tumor cells can generate more biomolecular components for proliferation and cell survival. This is accomplished by altering the rate of glycolysis through certain glycolytic isoenzymes. GLUT1 is shown to be upregulated, which in turn increases the rate of glucose uptake [18]. Increased expression of HK2 in tumor cells can arise from both increased gene copy number or through direct transcriptional activation by oncogenes, such as c-Myc [24, 38]. Apart from increasing copy number or protein levels, increased glycolysis can occur through the utilization of small molecules capable of stimulating glycolytic enzymes. Fructose 2,6-bisphosphate (F26BP) is one such small molecule known to stimulate PFK1. By increasing PFK1's affinity for F6P, F26BP allows for higher levels of glucose utilization [19, 39-41]. Tumor cells also exhibit elevated expression of LDH [42], with the LDH-A isozyme being associated with metastasis and cell proliferation [11, 43, 44]. PK has also been shown to not only alter the rate of glycolysis, but also have other functions, which help facilitate the formation of tumors.

PK is known to have tissue-specific isoforms. While PKL is expressed in liver tissues and PKR in erythrocytes, variants of PKM are found in all other tissues $[45,46]$. Variants from the PKM gene can be divided into two groups: The M1 form found in the brain and skeletal muscles, and the M2 form found in remaining 
tissues as well as in undifferentiated cells, such as embryonic cells [47]. As the PKM gene is responsible for encoding both isoforms, alternative splicing dictates which isoform is translated.

Of the exons within the PKM gene, it is the inclusion of either exon 9 or 10 , and the exclusion of the other, that dictates the isoform produced (Figure 3). Both exon 9 and 10 of the PKM gene encode for 56 amino acids. Of these, 34 are identical between exons while the remaining 22 are exclusive to their respective isoform $[48,49]$. Under normoxic conditions, exon 10 is spliced out of the primary mRNA to produce PKM1. The protein that is translated from this mRNA is observed as a fully active tetrameric protein. However, under hypoxic conditions that are frequently seen within tumor cells, exon 9 is spliced out in preference for incorporation of exon 10 [48]. In addition to hypoxia, other cellular factors can promote this differential splicing. In particular, oncogenic c-Myc drives expression of heterogenous ribonucleoproteins (hnRNPs). HnRNPs are splicing factors that lead to alternative splicing for inclusion of exon 10 and expression of PKM2. Alternatively, inclusion of exon 10 can also be facilitated by other factors, including serine-argenine splice factor 3 (SRSF 3) [50-52]. These splicing mechanisms result in production of PKM2 that, in contrast to PKM1, is present as multiple oligomeric states: monomeric, dimeric, or tetrameric [46]. While discussed in more detail below, it has been demonstrated that PKM1 and PKM2 exhibit different levels of PK activity, with PKM2 being the least active. This finding has led to the postulation that tumor cells utilize the less active PKM2, due to its dimeric state, to reduce the rate of glycolysis and allow for glycolytic intermediates to accumulate 


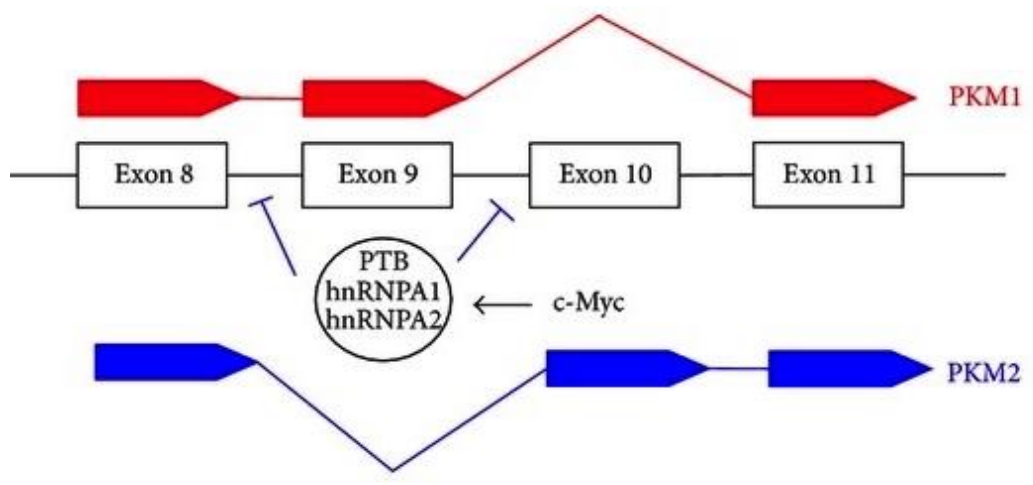

Figure 3. Representation of PKM alternative splicing mechanisms that produces either PKM1 or PKM2. Both exon 9 and exon 10 encode for 56 amino acids; of which, 34 are identical and 22 are exclusive to their respective isoforms. Inclusion of exon 9 and exclusion of exon 10 results in expression of PKM1. However, oncogenic factors, such as c-Myc promote hnRNPs expression that suppresses splicing at exon 9 and results in incorporation of exon 10 and exclusion of exon 9 from the final protein coding mRNA. Schematic cited from Nicholas Wong, Jason De Melo, and Damu Tang, ng, Tang, ng, De Melo, and Damu Tang, PKM2, a Central Point of Regulation in Cancer Metabolism . International Journal of Cell Biology, vol. 2013, Article ID 242513, 11 pages, 2013 
above the PK step (Figure 4) [38]. These glycolytic intermediates can then be shunted to different pathways, which assists in cell proliferation and survival, including nucleotide biosynthesis stemming from pentose phosphate activity and one carbon metabolism driven by increased flux through the serine synthetic pathway. Beyond expression, allosteric regulation of PKM2 allows for "metabolic tuning" in such a way to either increase or decrease its activity (tetrameric versus dimeric), depending on the needs of the tumor cell (Figure 4) [53].

In the absence of any allosteric modulator, purified human PKM2 has been recorded to have a maximum velocity $\left(\mathrm{V}_{\max }\right)$ of $166.3 \mu \mathrm{mol} / \mathrm{min}$ and a $\mathrm{K}_{\mathrm{m}}$ for PEP of $0.86 \mathrm{mM}$ [46]. In contrast, PKM1, which primarily exists in a highly-active tetramer state, exhibits a $V_{\max }$ of $345.6 \mu \mathrm{mol} / \mathrm{min}$ and $\mathrm{K}_{\mathrm{m}}$ of $0.05 \mathrm{mM}$ for PEP. One molecule that has previously been demonstrated to selectively increase PKM2 activity is the glycolytic intermediate, $\operatorname{FBP}[54,55]$. Biologically, this allows for a forward feedback loop, wherein if glycolytic intermediates are in sufficient quantity, activation of PKM2 would result in further glycolytic flux and metabolism of glucose carbon into downstream processes. The addition of FBP has been documented to promote the formation of tetrameric PKM2 from the available monomer/dimers [55]. This results in a modest increase in PKM2 activity $(213 \mu \mathrm{mol} / \mathrm{min})$ and a significant decrease in $\mathrm{Km}$ for PEP to $0.10 \mathrm{mM}$ [46]. Unlike PKM2, PKM1 activity does not increase in the presence of FBP. This is due to PKM1 being present exclusively as a tetramer. Recently, it has been found that serine can also increase the activity of PKM2 [56-58]. Similar to FBP, serine induces strong tetramer formation to enhance PKM2 activity and also functionally works as a feedback 

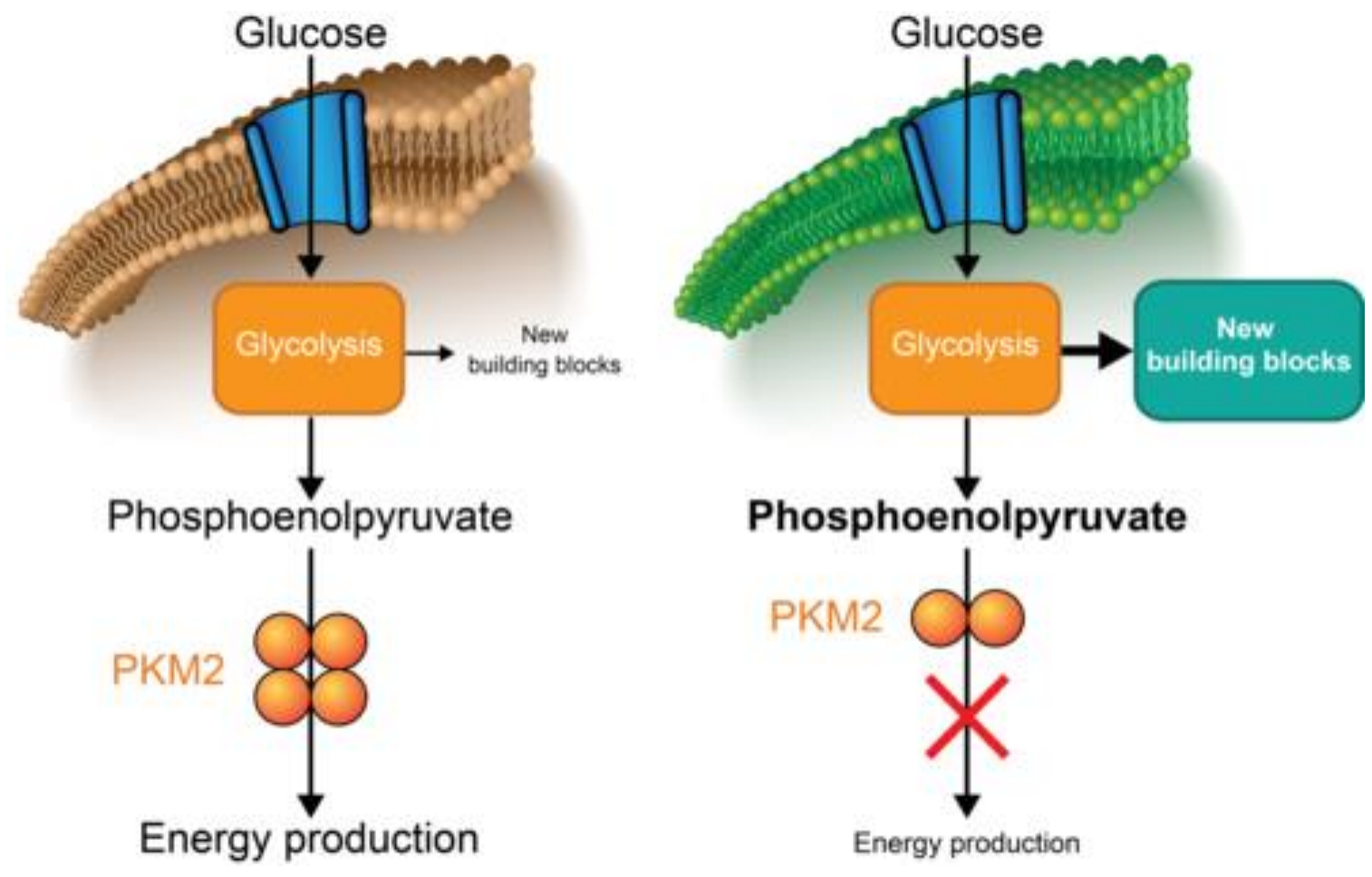

Figure 4. Comparison between high active tetramer and low active dimer of PKM2. In the tetrameric form, PKM2 catalyzes the reaction to produce pyruvate at a high rate for energy production. In the dimeric form, the reaction rate of PKM2 is lowered that leads to accumulation of glycolytic intermediates which can be shunted to increase biomass and produce biomolecules useful in proliferation.

Schematic cited from Witney, T.H., et al., PET imaging of tumor glycolysis downstream of hexokinase through noninvasive measurement of pyruvate kinase M2. Sci Transl Med, 2015. 7(310): p. 310ra169. 
mechanism. As explained earlier, serine is derived from the glycolytic intermediate 3-PG, which, if in excess, is shunted into the serine biosynthetic pathway. As serine levels become abundant in the cell, serine can activate PKM2 and lead to increased glycolysis and reduction in 3-PG levels. Although the binding pocket for serine can be found across different isoforms of PK, serine is unable to increase the activity of the M1 or L/R isoforms [56]. Contrary to FBP and serine, Christofk et al. demonstrated that phosphotyrosine peptides, of the tyrosine kinase signaling pathway, reduced the activity of PKM2 [59]. By acting as a competitor for FBP's binding site, phosphotyrosine peptides can cause the dissociation of PKM2 and FBP. The dissociation then results in PKM2 shifting back to a less active state. By doing so, the cell builds up the glycolytic intermediates to be shunted to multiple different pathways that can be used to facilitate proliferation.

A substantial amount of work has been done on defining the metabolic characteristics of PKM2, particularly as it relates to its pro-tumorigenic effects. Yet, more recently, studies have demonstrated that PKM2 exhibits non-metabolic functions that also may contribute to tumorigenesis. Outside of glycolysis, PKM2 can act as a specific protein kinase or interact with other proteins. Although normally located in the cytoplasm where it functions in glycolysis, PKM2 has also been seen to translocate into the nucleus [60]. While functioning as a protein kinase, PKM2 can phosphorylate Histone $\mathrm{H} 3$ on tyrosine 11 (H3T11) $[60,61]$ that leads to changes in gene expression, including Bub-3 for cell-cycle control [62], and B-cell lymphoma 2 (BCL-2) to prevent apoptosis [63]. In addition, nuclear PKM2 directly associates with $\beta$-catenin and assists in transactivating downstream 
target genes, such as c-Myc and CCND1 (encodes for cyclin D1) [60, 61]. Within the nucleus, PKM2 can also interact with several other proteins such as HIF-1 $\alpha$, octamer-binding transcription factor 4 (Oct-4), and suppressor of cytokine signaling 3 (SOCS3) to act as a coactivator for gene expression [60, 64-66]. Taken together, prior studies have emphasized the relevance of PKM2 in contributing to tumorigenic growth, not only from its altered activity within glycolysis, but as an important mediator in promoting gene expression through its non-canonical protein kinase and protein:protein interactions. Therefore, identifying additional binding partners may provide further insight into the unique function of PKM2 in cancer.

PSAT1 as a Novel PKM2 activator

Activity within multiple biochemical pathways are changed in response to tumor initiation and progression. Among these, enhanced flux within serine metabolism has been demonstrated in tumors from various tissue types. Previous studies have attempted to understand the pro-tumor advantage for increased serine production in various cancers, such as breast and lung [67, 68]. Serine metabolism provides amino acids for protein synthesis and promotes one carbon metabolism through formation of methyl-tetrahydrofolate (mTHF) from the conversion of serine to glycine. mTHF is a precursor required for novel nucleotide production, which is necessary for rapidly proliferating cells. In addition, the aminotransferase reaction of PSAT1 promotes glutamine metabolism as a source of anaplerotic carbon for the TCA cycle through the conversion of glutamate to 
aKG [67]. This elevated serine biosynthetic activity observed in tumors is accomplished through increased expression of enzymes within this pathway, including PSAT1 (Figure 5).

Prior attempts to understand the relevance of serine synthetic enzymes, including PHGDH and PSAT1, in tumor progression has been done using knockdown strategies in tumor cells. Within breast cancer cells, reduction of either PSAT1 or PHGDH reduced cell proliferation, which could be partially rescued by addition of downstream metabolites, such as aKG, non-essential amino acids, and nucleosides to the culture medium [69]. Yet, this result is somewhat surprising in that serine can be actively taken up from the outside environment and presumed to be utilized in an identical manner as synthesized serine. While some progress has been made in identifying requirements for serine synthesis in promoting tumor progression, the relevance for this pathway is not completely understood. Multiple metabolic enzymes, such as enolase and PKM2, have been identified to have alternative functions, including protein-protein interactions. We postulated that enzymes within the serine biosynthetic pathway, specifically PSAT1, may have unknown binding partners. In addition to its role in serine production, these interactions may also promote pro-tumor activities.

To identify potential protein: protein associations with PSAT1, the Clem lab performed a pull-down experiment incorporating protein lysates from A549 lung cancer cells and GST-tagged PSAT1 bound to a glutathione bead column. Mass spectrometry analysis of specific associating proteins identified PKM as a new interacting protein of PSAT1. As the peptide fragments did not distinguish between 
PKM1 or PKM2 (coverage only in identical amino acid regions of both proteins), co-immunoprecipitation (Co-IP) analysis was done using purified commercially available (Sigma) untagged purified PKM1 (PKM1-Sigma) and PKM2 (PKM2Sigma) with untagged PSAT1 that was produced and purified within the Clem lab.

To understand a potential biological effect of this interaction, in-vitro enzymatic assays were done to determine if this interaction had any effect on pyruvate kinase enzyme activity. Activity of PKM1-Sigma and PKM2-Sigma were done in the absence or presence of PSAT1 using an end-point activity assay (Kinase ADP Glo). As PK generates ATP from ADP, ATP generates light, through luciferase-mediated conversion of luciferin to oxyluciferin, which is presented as relative light units. Using this approach, addition of PSAT1 resulted in a dosedependent increase in PKM2-Sigma activity up to four-fold activation in the presence of 400nM PSAT1. PSAT1 failed to increase PKM1-Sigma activity at any concentration. To address whether the native PSAT1:PKM2 interaction is promoting the increase in activity, an aliquot of PSAT1 was boiled to denature the protein before addition to the enzyme assay. Loss of native formation of PSAT1 failed to activate PKM2-Sigma, suggesting that it is the protein-protein interaction selectively with PKM2 that is promoting pyruvate kinase activity.

To initially understand which domains or amino acids within PKM2 may be responsible for interacting with PSAT1, a computational comparison was done between the crystal structures for both PKM2 and PKM1. The 22 amino acid 
changes between incorporation of exon 9 (PKM1) or exon 10 (PKM2) are localized within a loop structure on the external region of the PKM protein (Figure 6A, illustrated in cyan on left side of crystal structure). This suggested that this site may be the region responsible for the PKM2:PSAT1 interaction. To test the amino acids within this region that may contribute to PSAT1 interaction, we randomly mutated separate amino acids within the non-synonymous region to those amino acids found in PKM1 (Figure 6B). Four distinct site-specific mutants were constructed: Mutant 1 (MT1) containing L391R and Q392K, Mutant 2 (MT2) containing P402S and $1403 \mathrm{H}$, Mutant 3 (MT3) containing P402S, 1403H, and R398V, and Mutant 4 (MT4) containing R398V. To avoid the potential for dramatic changes in the PKM2 structure upon mutation, the amino acid modifications were constructed in order to revert those amino acids to those found in PKM1. FLAG-tagged constructs encoding WT or the mutant PKM2 proteins were expressed in HEK293T cells and immunoprecipitated using anti-FLAG antibody conjugated sepharose beads. Immunoblot analysis of immunoprecipitated complexes found that while PKM2 Wild-Type (WT), MT1, MT2 and MT4 interacted with PSAT1, amino acid changes in MT3 resulted in loss of PSAT1 association.

We hypothesize that PKM2 mutations will abolish activation by PSAT1 through disruption of the PSAT1:PKM2 interaction. However, these data do not exclude the possibility that the point mutations change the overall structure of PK and contribute to the loss of binding. Furthermore, it is plausible that the mutations, alone, could alter the activity of PK in such a way to differ from the wild-type enzyme. For this, we will determine recombinant WT and MT(1-4) PKM2 activity 


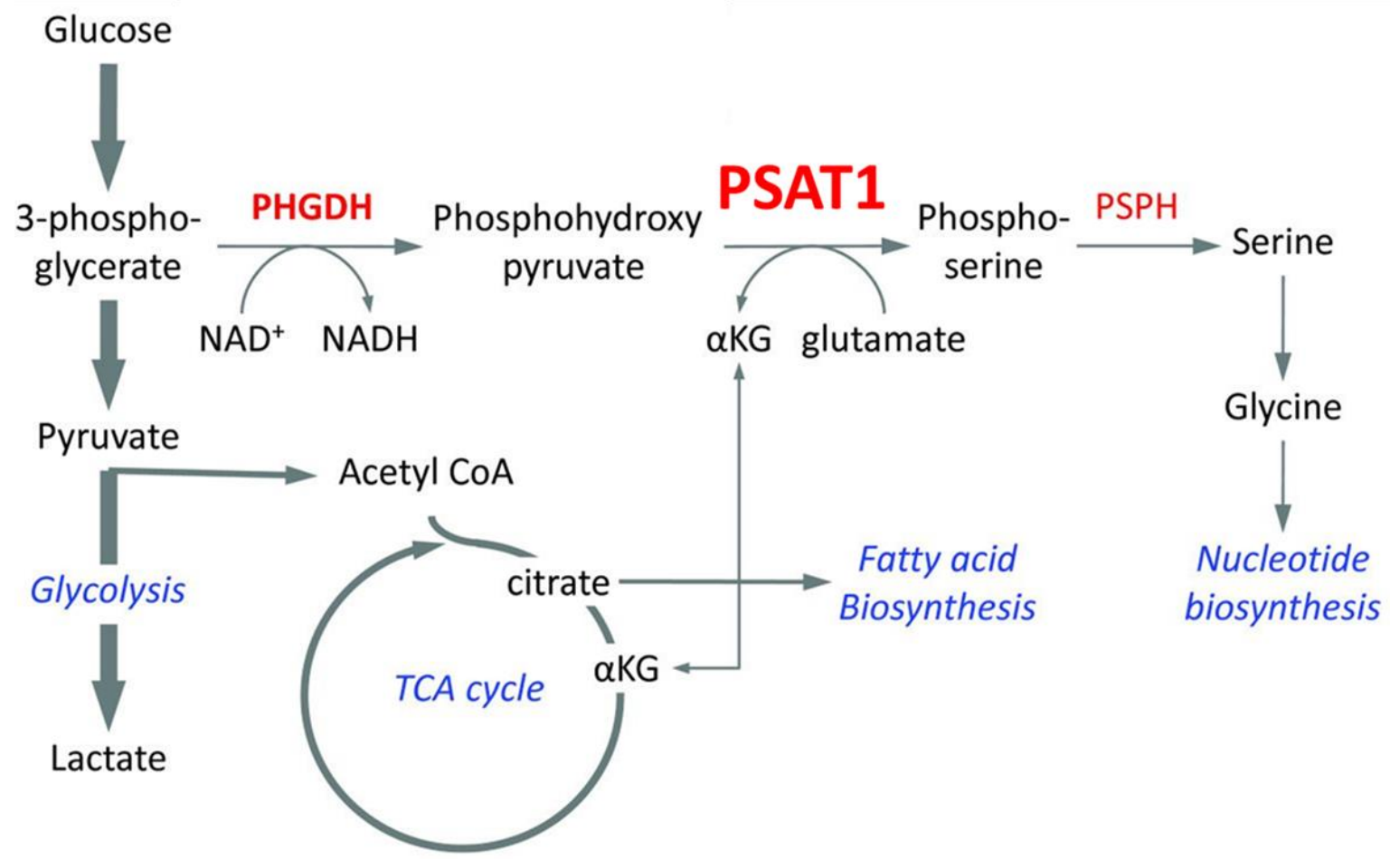

Figure 5. Schematic of serine metabolism. Serine is be synthesized from the glycolytic intermediate 3Phosphoglycerate. Synthesis of serine leads to the production of alpha Ketogluterate, which can go on to enter the carboxylic acid cycle. Serine can also be metabolized by cells to synthesize nucleotides. Schematic edited from: Cancer's sweet tooth for serine. Breast Cancer Res. 2011;13(6):317. 


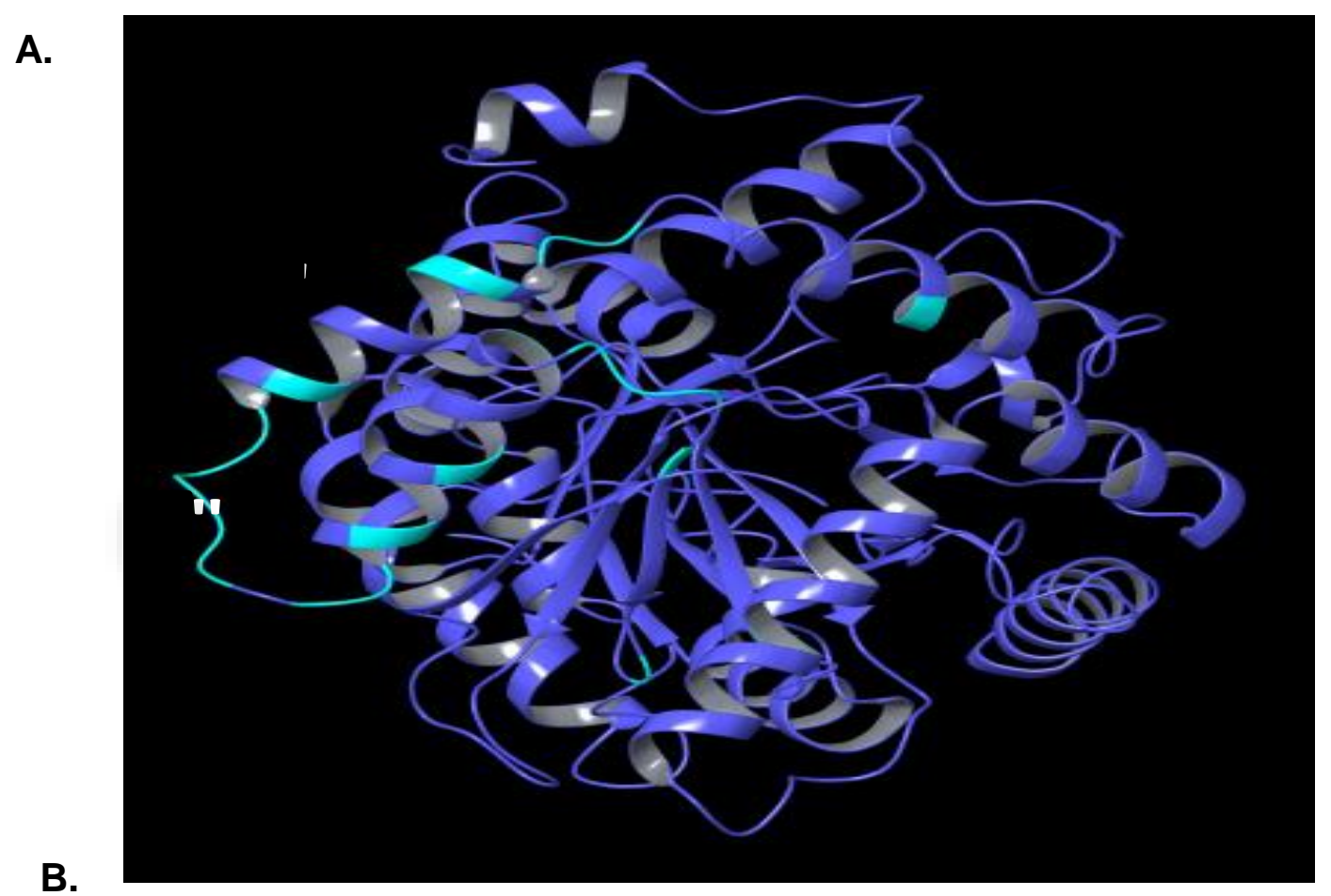

PKM1 AAMFHRKLFEELVRASSHSTD
||$::|.:||||| . \mid . . .::$ ।
PKM2 AAIYHLQLFEELRRLAPITSD

AAIYHRKLFEELRRLAPITSD MT1
AAIYHLQLFEELRRLASHTSD MT2
AAIYHLQLFEELVRLASHTSD MT3
AAIYHLQLFEELVRLAPITSD MT4

Figure 6. Superimposed crystal structures of PKM2 and PKM1 identify region of divergent sequence. A) Crystal structure of PKM2 (cyan) overlaid atop the crystal structure of PKM1 (blue). PKM2 contained an outer looped region (") that was not shared with PKM1. B) Mutations on PKM2, reverting the amino acid on PKM2 WT to those seen in PKM1. Mutation sites colored in red and highlighted in gray 
in the presence or absence of PSAT1 (Aim1) and assess the direct interaction with recombinant WT and MT(1-4) PKM2 with PSAT1 (Aim2). Completion of these studies aims to define the kinetic parameters of WT and MT(1-4) PKM2, PSAT1's effect on their activity, and confirm that PSAT1's effects on activity is due to direct association. 
CHAPTER TWO: MATERIALS AND METHODS

\section{Vector Generation}

Plasmids containing CDNA encoding WT or mutant PKM2 was generously provided by Rumeysa Biyik-Sit for construction of these expression vectors. cDNAs for PKM2-WT, -MT1, -MT2, -MT3, or -MT4 were sub-cloned from the provided pcDNA3.1 vector into either the pGEX-4T-1 (GST-fusion) or pET30a (Hisfusion) expression plasmids. Briefly, $1 \mu \mathrm{g}$ of plasmid was incubated at $37^{\circ} \mathrm{C}$ for 15 minutes in a solution containing $2 \mu \mathrm{L}$ of Fast Digest Buffer, $1 \mu \mathrm{L}$ of BamHI, $1 \mu \mathrm{L}$ of EcoRI, and brought up to $20 \mu \mathrm{L}$ with Nuclease-Free water. Subsequently, the digestion reactions were loaded onto a 1\% agarose gel and ran for 30 minutes at 100V. Bands corresponding to cut destination plasmids (pGEX-4T-1 or pET30a) or PKM2 cDNA were excised from the gel and centrifuged through a Gen Elute Agarose Spin Column (Sigma Cat\#56500) at 18,000 x g for 10 minutes. The elute was then ethanol precipitated by addition of $1 \%$ of $3 \mathrm{M}$ sodium acetate at $\mathrm{pH} 5.2$ and $2.5 \times$ volume of absolute ethanol and incubated for 20 minutes at $-80^{\circ} \mathrm{C}$. The solution was centrifuged for 20 minutes at $4^{\circ} \mathrm{C}$ and $12,000 \mathrm{rpm}$. The supernatant was removed, and the pellet was washed with $500 \mu \mathrm{L}$ of $70 \%$ ethanol. Centrifuge was repeated to remove the supernatant and any excess ethanol. The pellet was resuspended in $10 \mu \mathrm{L}$ of Nuclease-Free water. The concentration of DNA was taken by nanodrop. Molar ratio of 1:1.73 insert to vector DNA was incubated 
overnight at $4^{\circ} \mathrm{C}$ in a solution containing $1 \mu \mathrm{L}$ of ligase buffer, 1 unit of T4 DNA Ligase, and brought up to $10 \mu \mathrm{L}$ with water.

\section{Transformation of bacterial cells}

$1 \mu \mathrm{L}$ of ligation mixture was added to one vial of TOP $10 \mathrm{DH} 5 \alpha$ competent cells and incubated on ice for 30 minutes. Cells were then heat-shocked for 30 seconds at $42^{\circ} \mathrm{C}$ and immediately transferred to ice and incubated for an addition 2 minutes. $250 \mu \mathrm{L}$ of S.O.C medium was added to the bacterial solution and incubated at $37^{\circ} \mathrm{C}$ for 1 hour. Bacterial cells were spread onto LB plate containing appropriate antibiotics and incubated overnight at $37^{\circ} \mathrm{C}$. Cells transformed with pGEX4T-1 were spread onto a plate containing ampicillin; cells transformed with $\mathrm{pET30a}$ were spread onto a plate containing kanamycin.

\section{Construct Verification}

A single bacterial colony was harvested from the transformed LB agar plate and grown in $5 \mathrm{~mL}$ of $\mathrm{LB}$ containing appropriate antibiotic overnight at $37^{\circ} \mathrm{C}$. Bacterial cells were pelleted by centrifugation for 3 minutes at 8,000 rpm, and plasmid DNA was purified using plasmid miniprep kit following the manufacturer's protocol (Qiagen Cat\#27106) [ref: QIAprep® Miniprep Handbook 2nd Edition. May 2012.

Available: https://www.qiagen.com/us/resources/resourcedetail?id=89bfa021-7310-4c0f$90 \mathrm{e} 0-6 \mathrm{a} 9 \mathrm{c} 84 \mathrm{f} 66 \mathrm{cee} \&$ lang $=\mathrm{en}$.$] .$

Plasmid DNA was then sequenced to verify incorporation of WT or MT PKM2. For PGEX4T-1 vectors, 250ng of plasmid DNA was combined with either $2 \mu \mathrm{L}$ of $\quad$ Forward Sequencing Primer 
GATCGAATTCATGTCGAAGCCCCATAGTGAAG-3') or $2 \mu \mathrm{L}$ of Reverse Sequencing Primer (5'-CTGGGGATCCTCACGGCACAGGAACAACACGC-3'). Samples were then sent to Eurofins Genomics to be sequenced. For pET30a vectors, 250ng of plasmid DNA was sent to Eurofins Genomics to be sequenced using company provided T7 and T7 Terminator primers. Sequences were then assessed through a BLAST search to verify presence of the respective PKM2 cDNAs and to ensure that each was incorporated into the plasmid in the correct orientation and in-frame.

\section{Expression of Recombinant GST-PKM2 Proteins}

A single colony of transformed bacteria was grown in a sterile Erlenmeyer flask, containing $100 \mathrm{~mL}$ of $\mathrm{LB}$ and $100 \mathrm{ug} / \mathrm{mL}$ of Ampicillin, and incubated overnight at $37^{\circ} \mathrm{C}$. $100 \mathrm{~mL}$ of fresh $\mathrm{LB}$ and ampicillin was added to the starter culture and incubated at $37^{\circ} \mathrm{C}$ for an additional 3 hours. When the bacterial culture reached an $\mathrm{OD}_{600}$ of $\sim 0.7$, IPTG was added to final concentration of $1 \mathrm{mM}$ and incubated at $37^{\circ} \mathrm{C}$ for additional 4 hours. Bacterial cells were then pelleted and stored, overnight, in $-80^{\circ} \mathrm{C}$. The pellet was thawed and resuspended with $4 \mathrm{~mL}$ of B-PER lysis buffer (Pierce, containing $2 \mu \mathrm{L}$ of lysozyme, $2 \mu \mathrm{L}$ of DNase I, and $10 \mu \mathrm{L}$ of Protease Inhibitors for every $1 \mathrm{~mL}$ of B-PER buffer) for every gram of bacterial pellet. The resuspended pellet was incubated for 15 minutes at room temperature followed by centrifugation for 5 minutes at $15,000 \times \mathrm{g}$ in $4^{\circ} \mathrm{C}$ to obtain bacterial lysate.

GST-PKM2 Protein Purified by Affinity Chromatography 
Glutathione sepharose containing spin-columns were washed twice with $1 \mathrm{X}$ PBS and centrifuged at $700 \times \mathrm{g}$ for 2 minutes at $4^{\circ} \mathrm{C}$. Bacterial lysates were added to columns and incubated for 60 minutes at $4^{\circ} \mathrm{C}$ on a rocking platform, followed by centrifugation at $700 \times \mathrm{g}$. The flow-through was collected and saved for further analysis. Columns were washed 3 additional times with PBS, with an aliquot of each wash being saved for future analysis. $1 \mathrm{~mL}$ of Glutathione Elution buffer (50mM Tris $\mathrm{HCl}, 10 \mathrm{mM}$ reduced glutathione, and adjusted to $\mathrm{pH} 8.0$ ) was added to each column and incubated overnight at room temperature. Columns were centrifuged to collect eluted protein and repeated $2 x$ using fresh elution buffer. The reduced glutathione was removed from the elution fraction through dialysis with $1000 \mathrm{X}$ volume of buffer containing: $25 \mathrm{mM}$ of Tris $\mathrm{HCl}$ at $\mathrm{pH} 7.4,100 \mathrm{mM}$ of $\mathrm{KCl}$, $5 \mathrm{mM}$ of $\mathrm{MgCl}_{2}$, and $10 \%$ glycerol for 2 hours at $4{ }^{\circ} \mathrm{C}$. The buffer was changed, and dialysis was continued for an additional 16 hours at $4^{\circ} \mathrm{C}$.

\section{Expression and purification of His-tagged PKM2 Proteins}

Expression and purification of His-tagged PKM2 variants was performed following the same procedure as that for GST-tagged PKM2 with minor modifications. Briefly, the frozen pellet was thawed at room temperature for 15 minutes followed by incubation in $5 \mathrm{~mL}$ of Binding Buffer $(50 \mathrm{mM}$ Tris $\mathrm{HCl} \mathrm{pH} 8.0$, $10 \mathrm{mM} \mathrm{MgCl} 2,300 \mathrm{mM} \mathrm{NaCl}, 5 \mathrm{mM}$ Imidazole, $10 \%$ Glycerol) containing $10 \mu \mathrm{L}$ lysosome and $10 \mu \mathrm{L}$ of DNase for 15 additional minutes. Lysates were then sonicated $3 X$ in 15 second intervals and added to pre-washed Ni-NTA beads overnight in $4^{\circ} \mathrm{C}$. Poly prep chromatography columns were washed the following day $2 \mathrm{X}$ with $5 \mathrm{~mL}$ of Washing Buffer $(50 \mathrm{mM}$ Tris, $10 \mathrm{mM} \mathrm{MgCl} 2,300 \mathrm{mM} \mathrm{NaCl}$, 
$30 \mathrm{mM}$ Imidazole, $10 \%$ glycerol) prior to the addition of lysate/bead mixture. The resin was washed 4 times with Wash Buffer followed by incubating columns at room temperature with $1 \mathrm{~mL}$ of Elution Buffer $(50 \mathrm{mM}$ Tris, $10 \mathrm{mM} \mathrm{MgCl} 2,250 \mathrm{mM}$ $\mathrm{NaCl}, 250 \mathrm{mM}$ Imidazole, and $10 \%$ glycerol) for 1 hour. Aliquots of starting lysate, washes and elutions were collected and stored for future analysis. Imidazole was removed from elutions through dialysis using $50 \mathrm{mM}$ Tris, $10 \mathrm{mM} \mathrm{MgCl} 2,25 \mathrm{mM}$ $\mathrm{NaCl}$, and $10 \%$ glycerol overnight at $4{ }^{\circ} \mathrm{C}$. Protein concentration was determined by Nanodrop, and subsequently aliquoted, flash-frozen in $\mathrm{LN}_{2}$, and stored in $-80^{\circ} \mathrm{C}$.

\section{Coomassie Stain}

Aliquots from bacterial lysates, column washes, and dialyzed elutions were assessed for protein content and purity by Coomassie stain. Samples were loaded onto $10 \%$ SDS-Polyacrylamide Gel Electrophoresis (PAGE) gel and ran for 30 minutes at 200V. The SDS-PAGE gel was then stained with Coomassie Brilliant Blue R250 Stain for 30 minutes. The stained gel was then washed with a de-stain solution containing $10 \%$ acetic acid, $20 \%$ methanol.

\section{Immunoblotting}

Protein samples were mixed 1:1 with 2X SDS-sample buffer and separated by $10 \%$ SDS-PAGE at $200 \mathrm{v}$ for 30 minutes. Proteins were then transferred to PVDF membrane in transfer buffer for one hour at 200v. Membranes were incubated in blocking buffer (5\% non-fat dry milk in TBS-Tween) for one hour. Primary antibodies at defined dilutions were placed on membranes overnight at $4^{\circ} \mathrm{C}$ with constant rocking. After $3 \mathrm{X}$ washes with TBS-Tween, membranes were 
incubated with appropriate secondary antibodies and protein was detected using ECL chemiluminescent reagent.

\section{Antibodies}

For Western blot analysis, membranes were probed with 1:1000 anti-HIS (Cell Signaling; 12698S), anti-PKM2 (Cell Signaling; 4053S), or anti-PSAT (ProteinTech; 20180-1-AP). Anti-rabbit HRP-linked secondary antibody (1:5000; Thermo; 31460) was used to detect proteins.

\section{Protein Cross-Linking}

Disuccinimidyl suberate (DSS) cross-linking agent was reconstituted to 25mM in DMSO. 50ng of recombinant His-PKM2 WT, MT1, MT2, MT3, or MT4

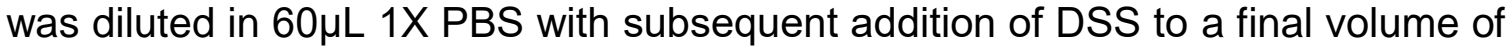
10 or $20 \mu \mathrm{M}$. Samples were then incubated for 15 minutes at $37^{\circ} \mathrm{C}$. To stop the cross-linking reaction, Tris $(\mathrm{pH} 7.4)$ was added to a final concentration of $50 \mathrm{mM}$ and incubated for 15 minutes at room temperature. $60 \mu \mathrm{L}$ of $2 \mathrm{X}$ sample buffer was added to the reaction and heated for 5 minutes at $95^{\circ} \mathrm{C} .30 \mu \mathrm{L}$ of sample was separated by SDS-PAGE and oligomeric state of PKM2 was determined by immunoblot analysis.

\section{PKM2 Kinetics Assay}

Enzyme kinetics of PKM2 WT and mutant proteins were determined using an LDH enzyme coupled assay. PKM2-derived pyruvate is rapidly converted by $\mathrm{LDH}$ to lactate with equimolar oxidation of $\mathrm{NADH}$ to $\mathrm{NAD}^{+}$. For the assay, a $10 \mathrm{x}$ Reaction Buffer stock was made containing $500 \mathrm{mM}$ Tris $\mathrm{HCl} \mathrm{pH} \mathrm{8.0,500mM} \mathrm{KCl,}$ and $50 \mathrm{mM} \mathrm{MgCl} 2$. Assay master mixes were generated containing a final 
concentration of $1 \mathrm{X}$ Reaction Buffer, $0.6 \mathrm{mM}$ ADP, $0.54 \mathrm{mM} \mathrm{NADH}, 0.016 \mu \mathrm{g} / \mathrm{uL}$ $\mathrm{LDH}$, and different concentrations of PEP ranging from 0.025 to $4 \mathrm{mM}$. $100 \mu \mathrm{L}$ of assay solution was then aliquoted into a 96-well plate in triplicate for each PEP concentration. Separately, PKM2 enzymes were incubated with or without 400nM PSAT1 or $500 \mu \mathrm{M} \mathrm{FBP}$ in $1 \mathrm{X}$ reaction buffer for 30 minutes at $37^{\circ} \mathrm{C}$. To initiate the kinetic reaction, PKM2 samples were then added to the assay solution to a final concentration of 2.5nM PKM2. NADH absorbance was recorded at $340 \mathrm{~nm}$ every 30 seconds for 10 minutes using a Biotek spectrophotometer plate reader. Absorbance readings were plotted against time and rates of $\mathrm{NADH}$ consumption $(\mathrm{OD} / \mathrm{min})$ at each PEP concentration were determined by the slope of linear equation. Rates were then converted to $\mu \mathrm{mol} / \mathrm{min}$ using the $\mathrm{NADH}$ extinction coefficient $\left(6220 \mathrm{M}^{-1} \mathrm{~cm}^{-1}\right)$. Initial velocities were then plotted against each PEP concentration and kinetic parameters $\left(\mathrm{V}_{\max }\right.$ and $\left.\mathrm{K}_{\mathrm{M}}\right)$ of each PKM2 protein with or without PSAT1 or FBP were determined by non-linear regression analysis using Prism software.

\section{Pulldown Assay using His-PKM2}

500 ng of PSAT1 was incubated with 50ng of WT or mutant His-PKM2 in $500 \mu \mathrm{L}$ of Binding Buffer for 45 minutes at $4^{\circ} \mathrm{C}$. $30 \mu \mathrm{L}$ of Ni-NTA sepharose bead slurry was washed with Washing Buffer, reconstituted in $0.1 \%$ BSA and incubated for 1 hour at $4^{\circ} \mathrm{C}$. Beads were then added to the His-PKM2:PSAT1 solution and incubated overnight at $4^{\circ} \mathrm{C}$. Ni-NTA beads were centrifuged and washed twice. $30 \mu \mathrm{L}$ of $1 \mathrm{x}$ Laemmli Sample Buffer was added to the Ni-NTA beads and heated at $95^{\circ} \mathrm{C}$ for 5 minutes The supernatant was then loaded onto an SDS-PAGE and 
presence of PSAT1 and PKM2 were analyzed by immunoblotting using anti-His or anti-PSAT1 antibodies.

\section{Co-Immunoprecipitation of His-PKM2:PSAT1}

50ng of PSAT1 and 500ng WT or mutant His-PKM2 was incubated in 500 $\mu \mathrm{L}$

of Lysis Buffer at room temperature for 45 minutes. $1 \mu \mathrm{g}$ of anti-PSAT1 antibody or control IgG was added to the protein mixture and incubated overnight at $4^{\circ} \mathrm{C}$. Protein G Dynabeads (Invitrogen) $(50 \mu \mathrm{L}$ per immunoprecipitation) were washed twice in $250 \mu \mathrm{L}$ of $\mathrm{Ab}$ Wash Buffer, resuspended in Antibody binding buffer (Invitrogen) and added to protein samples for 45 minutes at room temperature with end-over-end rocking. Immunocomplexes were collected by placement on Magnarack (Invitrogen) and subsequently washed 3 times with $200 \mu \mathrm{L}$ of Wash Buffer. $25 \mu \mathrm{L}$ of $1 \times$ Laemmli Buffer was added to the beads and incubated at $95^{\circ} \mathrm{C}$ for 3 minutes. Solution was placed back on Magnarack for 2 minutes, and protein supernatant was separated by SDS-PAGE. Presence of PSAT1 and PKM2 were assessed by immunoblotting using anti-PSAT1 or anti-His antibodies. 
CHAPTER THREE: RESULTS

\section{Expression of GST-PKM2}

The initial objective of these studies was to recombinantly express and purify PKM2 WT and PKM2 variants harboring the mutations indicated in Figure 7. Previous reports have demonstrated that utilizing a GST-fusion system could assist in properly folding proteins that are prone to aggregation [70]. I chose to express PKM2 as a GST-fusion protein utilizing the pGEX4T-1 vector system that encodes a GST-tag on the N-terminus of the fusion protein. cDNAs encoding WT, MT1, MT2, or MT3 were previously generated within the lab using site-directed mutagenesis and sequenced to verify correct mutational status (Figure 7A-D). Each cDNA was sub-cloned into the pGEX4T-1 vector and underwent DNA sequencing and subsequent BLAST search to ensure correct orientation and presence of mutations.

\section{Purification of GST-PKM2}

Plasmids that had been verified to encode WT or mutant GST-PKM2 were transformed into BL21(DE3) cells. Following the protocol outlined by Park et al. to increase yield of GST-fusion proteins [72], I initially attempted to purify WT GSTPKM2 using a Sarkosyl: Triton X100 buffer for bacterial extraction [73]. PKM2 has a molecular weight of $56 \mathrm{kDa}$, and with the addition of the GST-(27kDa), the fusion protein is expected to have a molecular weight of $\sim 80 \mathrm{kDa}$. While I was able to extract proteins from both un-induced and IPTG-induced bacteria, no specific 
A. Chain A, Human M2 Pyruvate Kinase In Complex With Fructose 1-6 Bisphosphate And Oxalate. Sequence ID: gil400260539|3SRD A Length: 551 Number of Matches: 1

$\triangleright$ See 7 more title(s)

\begin{tabular}{|c|c|c|c|c|c|c|}
\hline \multicolumn{2}{|l|}{ Score } & \multirow{2}{*}{$\begin{array}{l}\text { Expect } \\
0.0\end{array}$} & \multirow{2}{*}{$\begin{array}{l}\text { Method } \\
\text { Compositional matrix adjust. }\end{array}$} & \multirow{2}{*}{$\begin{array}{l}\text { Positives } \\
302 / 302(100 \%)\end{array}$} & \multirow{2}{*}{$\begin{array}{l}\text { Gaps } \\
0 / 302(0 \%)\end{array}$} & \multirow{2}{*}{$\begin{array}{l}\text { Frame } \\
-1\end{array}$} \\
\hline $624 \mathrm{bi}$ & $s(1608)$ & & & & & \\
\hline Query & 960 & \multicolumn{3}{|c|}{$\begin{array}{l}\text { KFGVEQDVDMVF ASF IRKASDVHEVRKVLGEKGKNIKIISKIENHEGVRRFDE ILEASDG } \\
\text { KFGVEQDVDMF ASFIRKASDVHEVRKVLGEKKNIKIISKIENHEGVRRFDEILEASDG }\end{array}$} & 781 & \\
\hline Sbjet & $250 \mathrm{~K}$ & \multicolumn{3}{|c|}{ KFGVEQDVDMVFASFIRKASDVHEVRKVLGEKGKNIKIISKIENHEGVRRFDEILEASDG } & 309 & \\
\hline Query & 780 I & \multirow{2}{*}{\multicolumn{3}{|c|}{$\begin{array}{l}\text { IMVARGDLGIEIPAEKVFLAQKMMIGRCNRAGKPVICATQMLESMIKKPRPTRAEGSDVA } \\
\text { IMVARGDLGIEIPAEKVFLAQKMMIGRCNRAGKPVICATQMLESMIKKPRPTRAEGSDVA } \\
\text { IMVARGDLGIEIPAEKVFLAQKMIGRCNRAGKVICATQMLESMIKKPRPTRAEGSDVA }\end{array}$}} & 601 & \\
\hline Sbjet & 310 & & & & 369 & \\
\hline Query & $600 \mathrm{~N}$ & \multicolumn{3}{|c|}{$\begin{array}{l}\text { NAVLDGADCIML SGETAKGDYPLEAVRMQHLIAREAEAAIYHLQLFEELRRLAPITSDPT } \\
\text { NAVLDGADCIML SGETAKGDYPLEAVRMQHLIAREAEAAIYHLQLFELRRLAPITSDPT }\end{array}$} & 421 & \\
\hline Sbjet & 370 & \multicolumn{3}{|c|}{ NAVLDGADCIML SGETAKGDYPLEAVRMQHLIAREAEAAI YHLQLFEELRRLAPITSDPT } & 429 & \\
\hline Query & $420 \quad \mathrm{E}$ & \multicolumn{3}{|c|}{ 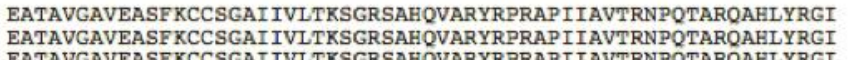 } & 241 & \\
\hline Sbjot & $430 \mathrm{E}$ & \multicolumn{3}{|c|}{ EATAVGAVEASF KCCSGAI IVLTKSGRSAHQVARYRPRAPI IAVTRNPQTARQAHLYRGI } & 489 & \\
\hline Query & $240 \quad F$ & \multicolumn{3}{|c|}{$\begin{array}{l}\text { FPVLCKDPVQEAWAEDVDLRVNFAMNVGKARGFFKKGDVIVLTGWRPGSGFTNTMRVVP } \\
\text { FPVLCKDPVQEAWAEDVDLRVNFAMNVGKARGFFKKGDVIVLTGWRPGSGFTNTMRVVP }\end{array}$} & 61 & \\
\hline Sbjet & 490 & \multicolumn{3}{|c|}{ FPVLCKDPVQEAWAEDVDLRVNFAMNVGKARGFFKKGDVVIVLTGWRPGSGFTNTMRVVP } & 549 & \\
\hline Query & 60 & $\begin{array}{l}\text { VP } \\
\text { VP }\end{array}$ & & & & \\
\hline Sbjet & 550 & VP $\quad 551$ & & & & \\
\hline
\end{tabular}

B.

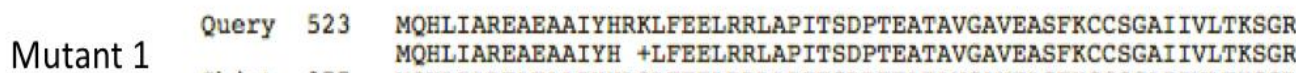
Sbjet 377 MQHLIAREAEAAIYHLQLFEELRRLAPITSDPTEATAVGAVEASFKCCSGAIIVLTKSGR

C.

$\begin{array}{llll}\text { Mutant } 2 \text { Query } 508 & \text { IAREAEAAIYHLLLFELRRLASHTSDPTEATAVGAVEASFKCCSGAIIVLTKSGRSAHQ } \\ \text { IAREAEAAIYHLLFELRRLA TSDPTEATAVGAVEASFKCCSGAIVLTKSGRSAHQ }\end{array}$ Sbjet 441 IAREAEAAIYHLQLFEELRRLAPITSDPTEATAVGAVEASFKCCSGAIIVLTKSGRSAHQ

D.

Mutant 3 Query 603 NAVLDGADCIMLSGETAKGDYPLEAVRMQHLIAREAEAAIYHLQLFEELVRLASHTSDPT NAVLDGADCIMLSGE TAKGDYPLEAVRMQHLIAREABAAIYHLQLFEEL RLA TSDPI Sbjet 350 NAVLDGADCIMLSGETAKGDYPLEAVRMQHLIAREAEAAIYHLQLFEELRRLAPITSDPT

E.

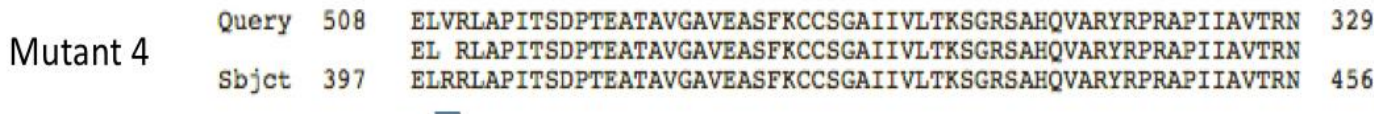

Figure 7. Sequence analysis of cDNA encoding WT and mutant variants of PKM2 Plasmid DNA was commercially sequenced by Eurofins Genomics. Computational BLAST analysis revealed correct orientation and inclusion of cDNA encoding (A) WT, (B) MT1, (C) MT2, (D) MT3, (E) MT4 PKM2. 
GST-PKM2 was collected from the glutathione beads as demonstrated by SDSPAGE and Coomassie stain (Figure 8). I then attempted an alternative strategy for protein purification using the Tris-based B-PER solution (Bacterial Protein Extraction Reagent, ThermoFisher). Utilizing this bacterial lysis protocol followed by glutathione bead affinity chromatography, I was able to recover GST-PKM2 WT, MT1, MT2, and MT3 (Figure 9).

\section{Enzymatic Activity of GST-PKM2}

To determine whether the GST-PKM2 enzymes had activity, I utilized an enzyme-coupled assay incorporating LDH-mediated consumption of NADH (Figure 10A). As PKM2 generates pyruvate from PEP, LDH subsequently metabolizes pyruvate to lactate while simultaneously converting NADH to NAD+, in an equal mole to mole ratio. Loss of NADH absorbance in a linear fashion allows for the indirect measurement of PKM2 activity. Using this approach, I recorded no enzymatic activity above background with any of the GST-PKM2 enzymes (WT, MT1, M2 or M3) at $0.5 \mathrm{mM} \mathrm{PEP} \mathrm{(Figure} \mathrm{10B).} \mathrm{To} \mathrm{ensure} \mathrm{the} \mathrm{functionality} \mathrm{of} \mathrm{the}$ enzyme assay, I included untagged PKM2-Sigma as a positive control. As shown in Figure 11B, PKM2-Sigma exhibits pyruvate kinase activity based on the linear consumption of NADH. The lack of activity of the GST-PKM2 proteins suggest that

the addition of the large GST tag at the N-terminus of PKM2 may be inhibiting the catalytic activity of the enzyme.

\section{Thrombin Cleavage of GST-tag from PKM2 Protein}




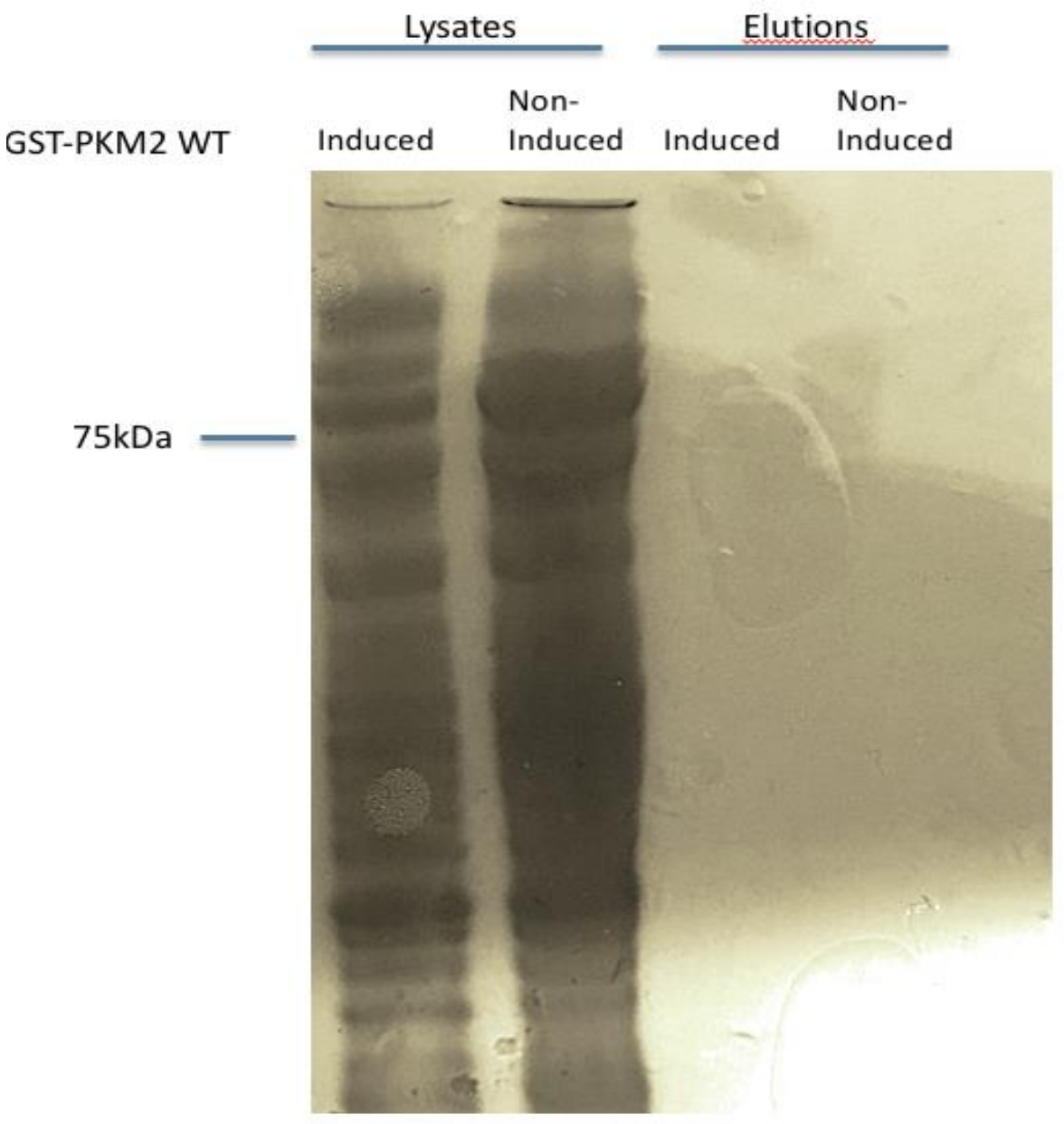

Figure 8. Extraction of GST-PKM2 WT from bacterial lysates using ionic detergent (Sarkosyl). Wild-type GSTPKM2 expression in transformed BL21 cells was induced with IPTG as described in the materials and methods. Cell pellet was then extracted using Sarkosyl-Triton X-100 buffer and proteins purified by glutathione elution from glutathione linked sepharose beads. Lysates or elutions from induced and non-induced bacteria were subjected to SDS-PAGE and Coomassie staining. 


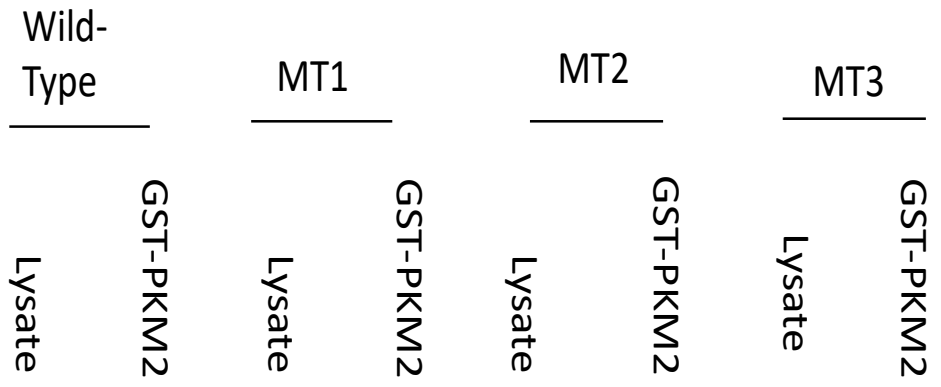

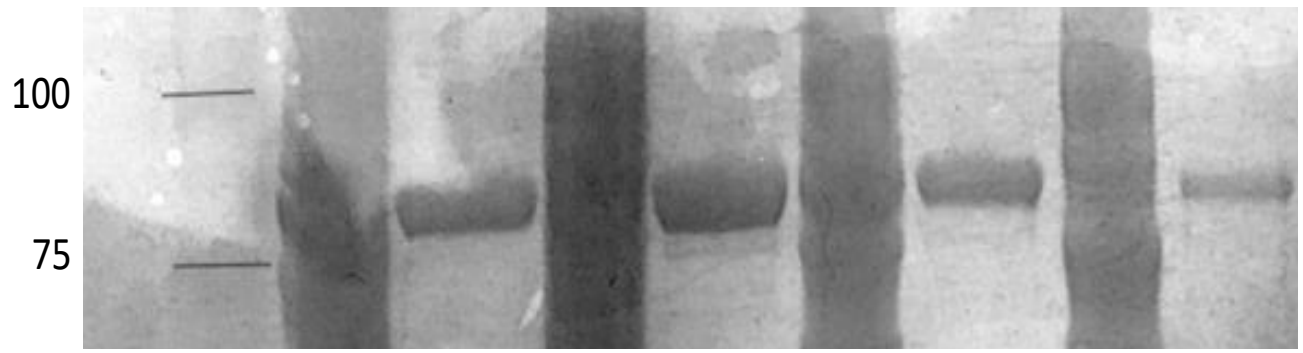

Figure 9. Purification of GST-PKM2 enzymes using an alternative extraction protocol. Expression of fusion GST-PKM2 proteins in transformed BL21 cells was induced by IPTG as described in the materials and methods. Proteins were extracted using B-PER buffer (Thermo Fischer) with addition of DNase and lysozyme. GST-PKM2 proteins were purified by glutathione elution from glutathione-linked sepharose beads. Lysates and elutions (GST-PKM2) were subjected to SDS-PAGE and Coomassie stain. Expected molecular weight of GST-PKM2 proteins is $80 \mathrm{kDa}$. 
A.

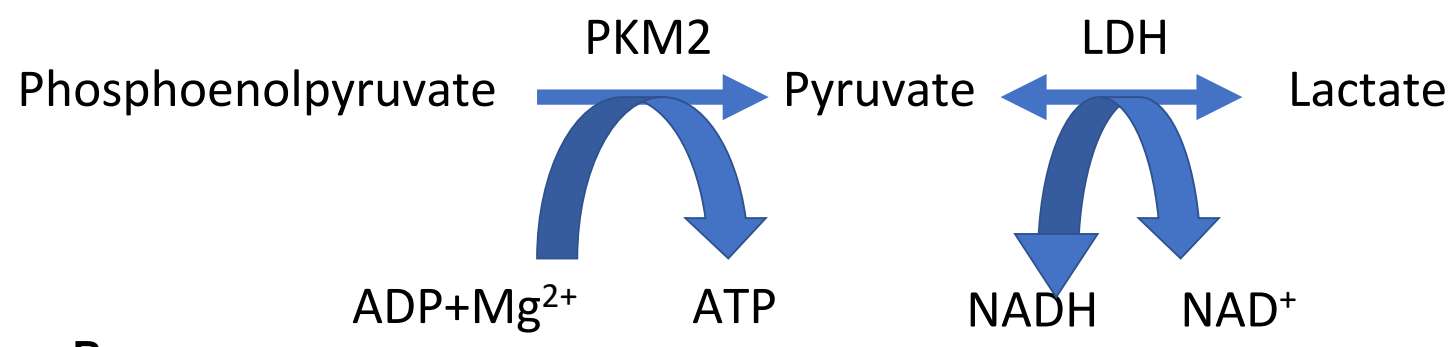

B.

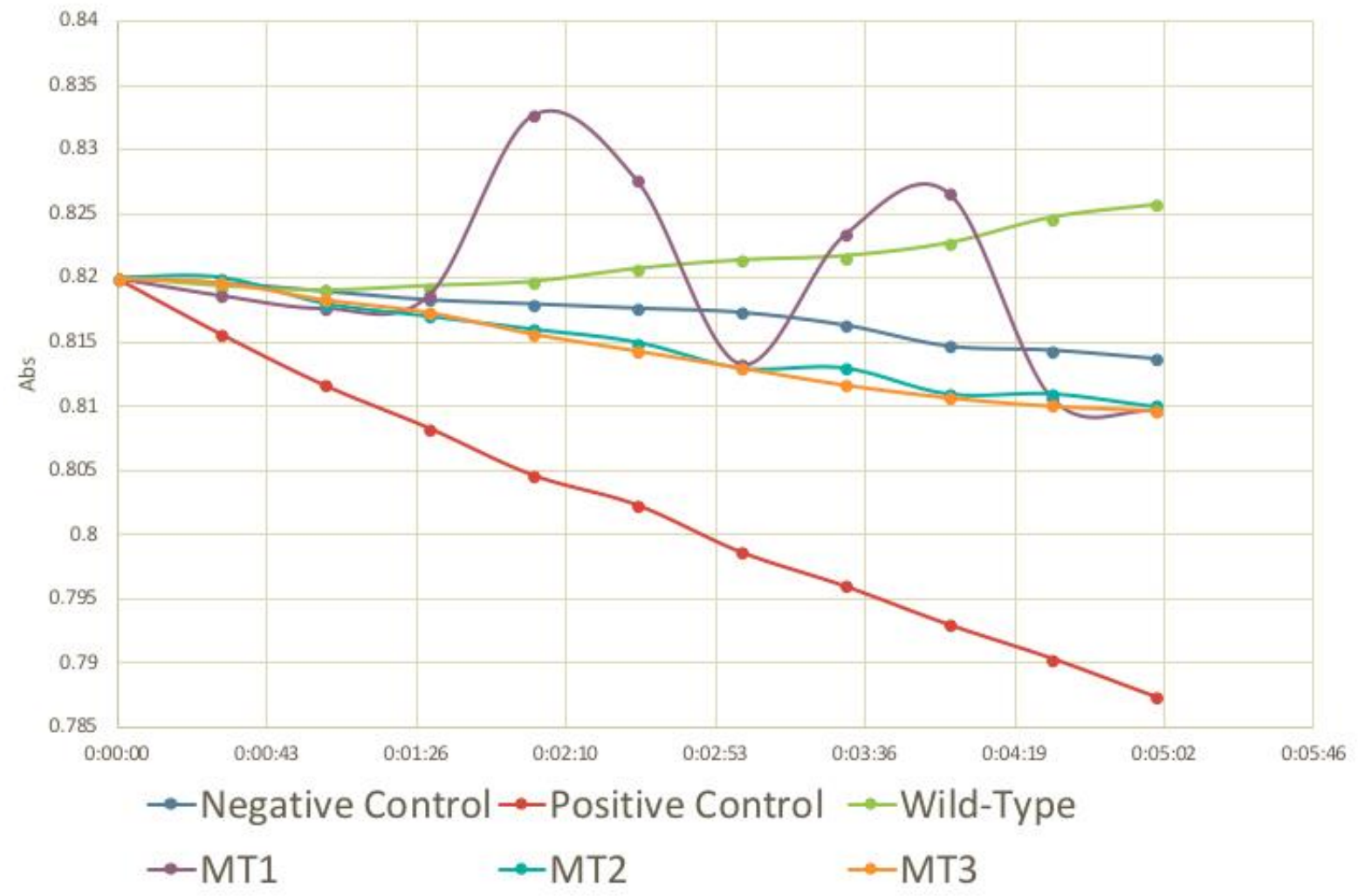

Figure 10. Kinetic analysis of GST-PKM2 recombinant enzymes. (A) Scheme of the LDH-coupled assay used to measure PKM2 activity through consumption of NADH, which is assessed by loss of NADH absorbance at $340 \mathrm{~nm}$. (B) Representative kinetic assay comparing WT, MT1, MT2, and MT3 GST-PKM2 at 4nM protein concentration and 0,5mM PEP. Data is demonstrated as loss of absorbance of NADH at $340 \mathrm{~nm}$ over time. Addition of water was used as negative control and positive control represents addition of untagged PKM2-Sigma. 
To determine whether the GST-tag was responsible for the inactivity of PKM2, I attempted to purify PKM2 from induced GST-PKM2 bacteria lysates through removal of GST-tag by thrombin cleavage. The pGEX-4T-1 vector encodes a thrombin cleavage site between the GST-tag and the N-terminal amino acid of PKM2. After the final wash during glutathione-sepharose purification, I incubated protein-bound beads for 45 minutes at room temperature with Thrombin protease to release cleaved PKM2 from the bead matrix. SDS-PAGE and Coomassie stain analysis of cleaved elutions revealed no recovery of PKM2 protein (Figure 11). Together, these data indicate that while my experimental conditions are sufficient to express WT and MT GST-PKM2 proteins, they are inactive and thrombin cleavage under these conditions is ineffective in recovering PKM2 enzymes.

\section{PKM2 was sub-cloned into a pET vector encoding a smaller fusion tag}

To circumvent the potential issue of the large GST tag affecting PKM2 activity, I decided to use a different protein fusion expression system. The PKM2 cDNAs were sub-cloned into the pET30a vector, which encodes for a small $6 x$ Histag at the $\mathrm{N}$-terminal end of the fusion protein ( $1 \mathrm{kDa}$ compared to $27 \mathrm{kDa}$ GSTtag). Initially, I utilized the extraction protocol for the GST-fusion proteins discussed above (ie buffer conditions) in conjunction with affinity purification with imidazole elutions from Ni-NTA beads. SDS-PAGE analysis demonstrated large amounts of non-specific proteins within the imidazole elution fractions (Figure 12A) and was 


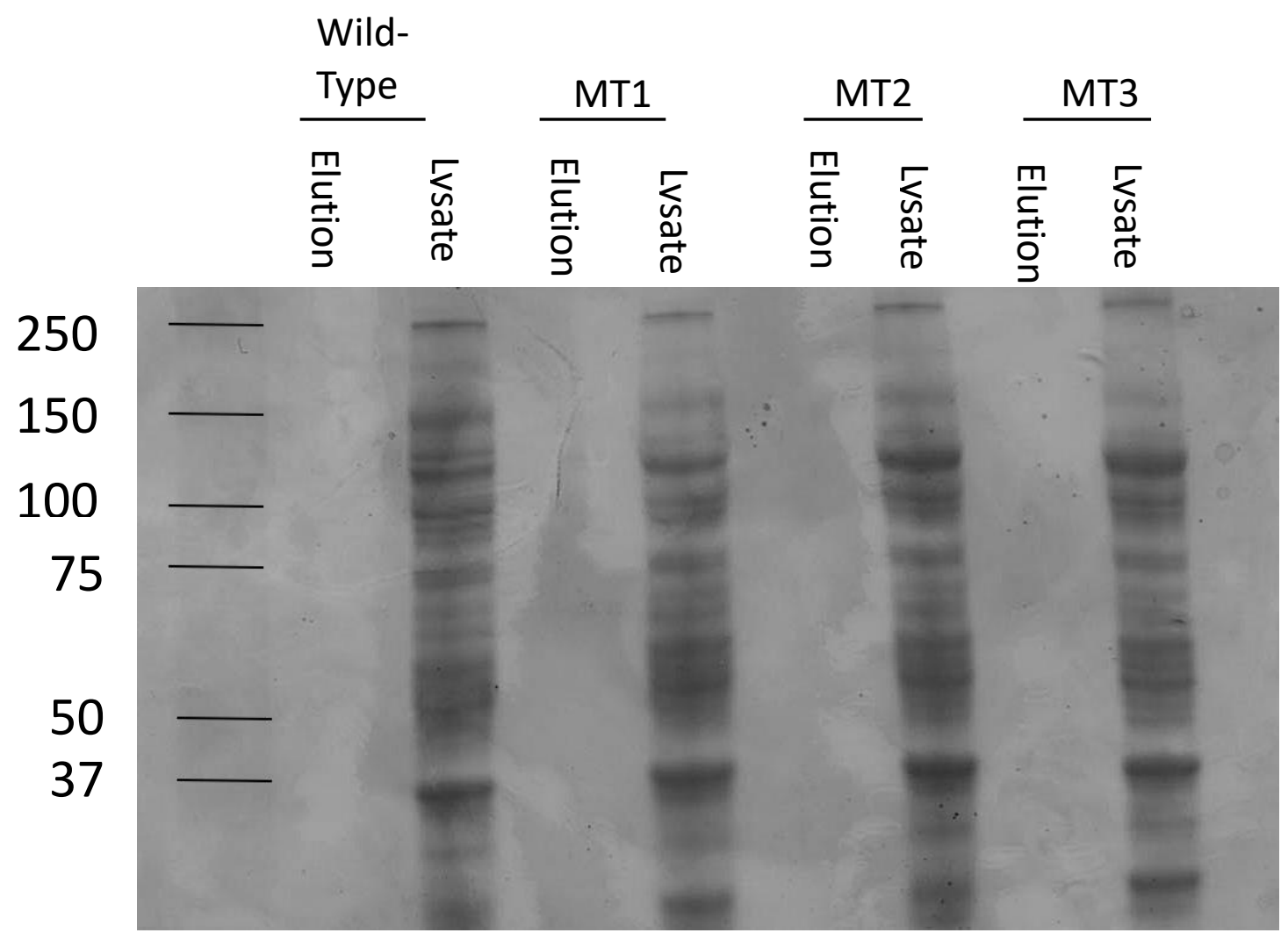

Figure 11. Thrombin cleavage of recombinant GST-PKM2 proteins. Bacterial lysates induced for GST-PKM2 WT, MT1, MT2, and MT3 were incubated with glutathione sepharose. Immobilized GST-PKM2 enzymes were treated with thrombin in order to cleave the GST-tag from the recombinant protein and result in PKM2 elution from the column matrix. Bacterial lysates or elutions following thrombin cleavage were subjected to SDS-PAGE and Coomassie staining. 


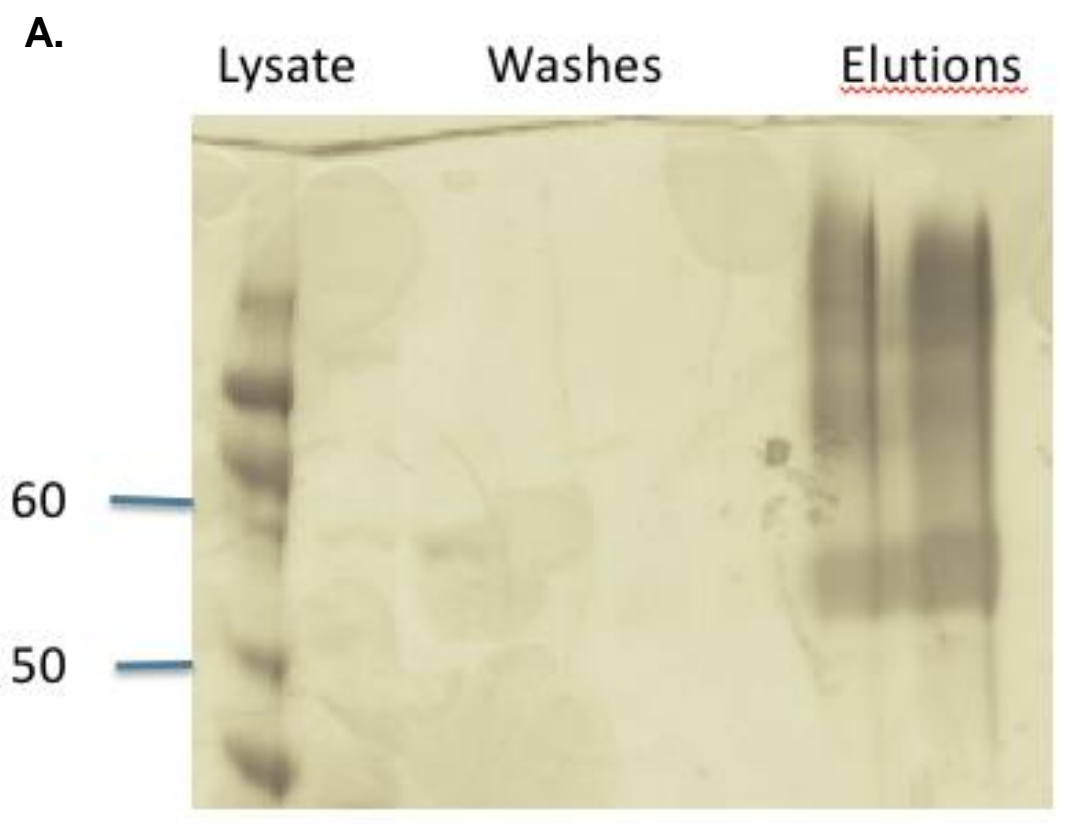

B.

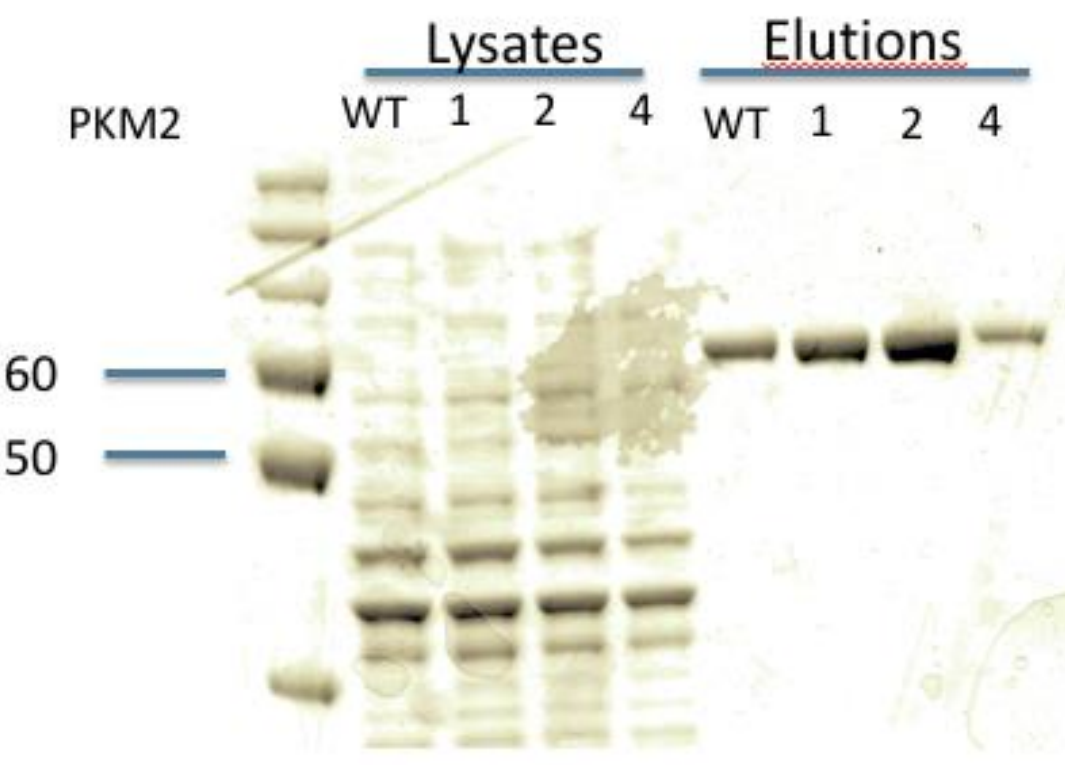

Figure 12. Purification of His-tagged PKM2 proteins. (A) Initial purification of His-WT PKM2 from IPTG-induced BL21 cells with Ni-NTA sepharose resulted in the presence of higher molecular weight proteins upon elution with imidazole. (B) Optimization of expression/extraction protocol led to purification WT, MT1, MT2, and MT4 His-PKM2 from Ni-NTA sepharose. Aliquots from lysates, washes, or imidazole elutions were subjected to SDSPAGE and Coomassie staining. Expected molecular weight of His-PKM2 is approximately $60 \mathrm{kDa}$. 
unable to discern the presence of any His-PKM2 protein. I further developed the purification protocol for the His-PKM2 proteins by changing the extraction/binding buffers and the addition of sonication to the bacterial lysates. After optimization, I was able to recover His-PKM2 WT, MT1, MT2, MT3, and MT4 to greater than 95\% purity (Figure 12B, only WT, MT1, MT2, and MT4 are shown). I have noticed that His-PKM2-MT4 consistently resulted in lower yield compared to the other samples, but this may be due to lower overall extracted proteins in bacteria (Figure 12B).

\section{Kinetic Analysis of His-PKM2 Enzymes}

To determine that the protein concentration to be used in the kinetic analysis would be within a linear relationship of initial velocity and enzyme concentration, I first measured initial velocities ( $\mathrm{mOD}$ absorbance / min) within a range of HisPKM2 concentrations, from 1.0 to $4.0 \mathrm{nM}$ of the enzyme. Unlike the GST-PKM2 enzymes, I found that His-PKM2 proteins showed activity within the LDH coupled assay (Figure 13 A-C; data shown for PKM2 MT1, MT2, and MT4). From these studies, I selected $2.5 \mathrm{nM}$ as an optimal concentration for kinetic characterization of these enzymes (Figure 13A-C). Western blot analysis was also performed comparing His-PKM2 proteins across separate preparations [Batch 1 (B1) or Batch $2(B 3)]$ to ensure that they were similar across all samples (Figure $14 \mathrm{~A}-\mathrm{B}$ ).

I next proceeded to measure His-PKM2 activity, using $2.5 \mathrm{nM}$ of each enzyme, across multiple concentrations of PEP, ranging from $0.025 \mathrm{mM}$ to $4 \mathrm{mM}$. Using the NADH extinction coefficietny, the initial linear slope of NADH consumption ( $\mathrm{mOD} / \mathrm{min}$ ) can be converted to an initial velocity kinetic rate for PKM2 of $\mathrm{nmol} / \mathrm{min}$ of PEP at a specified PEP concentration. The average initial 
A.

$.5 \mathrm{mM}$ PEP

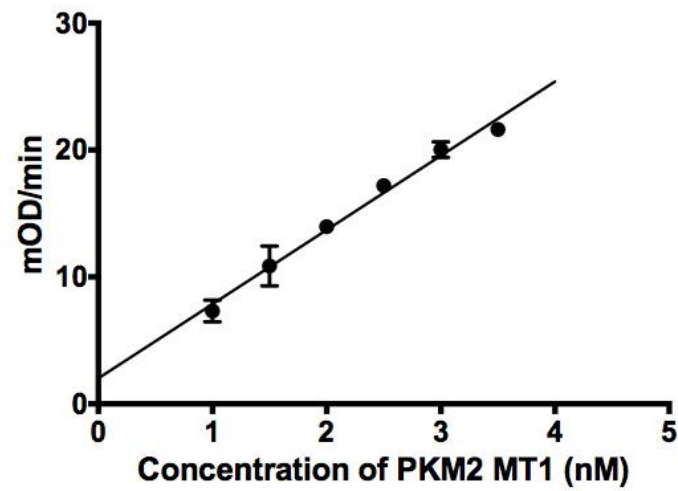

C.

$.5 \mathrm{mM}$ PEP

C.
B.

$.5 \mathrm{mM}$ PEP

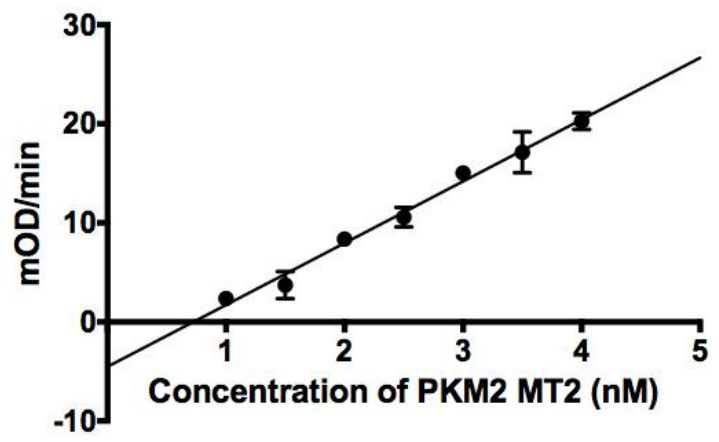

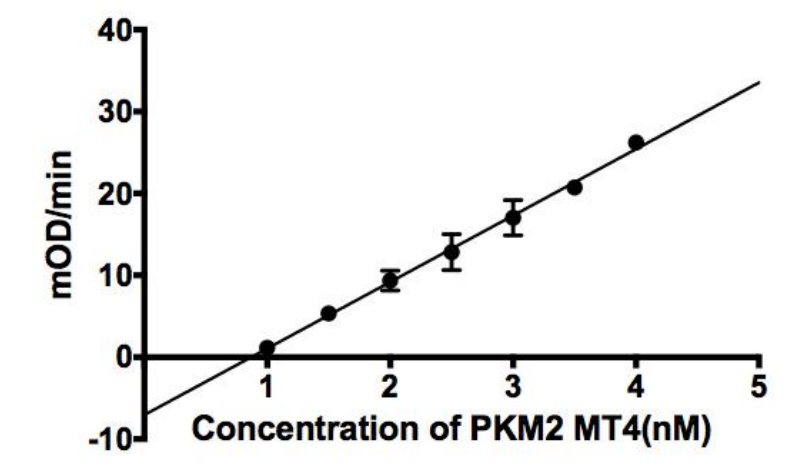

Figure 13. Kinetic analysis to determine optimal PKM2

concentration. Rates of NADH consumption was measured under increasing concentrations of His-PKM2. Depicted are the reads from MT1 (A) MT2 (B) and MT4 (C). Points were plotted based on $\mathrm{mOD} / \mathrm{min}$ and were fit to linear regression analysis. 
A.

B1. His-PKM2

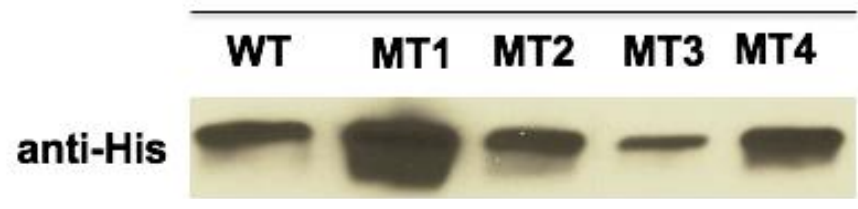

B.2 His-PKM2

B.

\section{WT MT1 MT2 MT3 MT4}

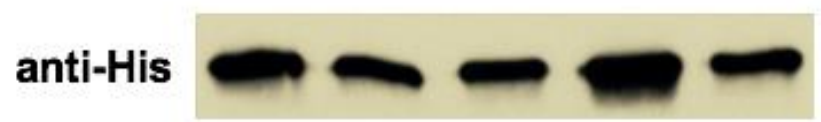

$\mathrm{H}$ is - P K M 2

c.
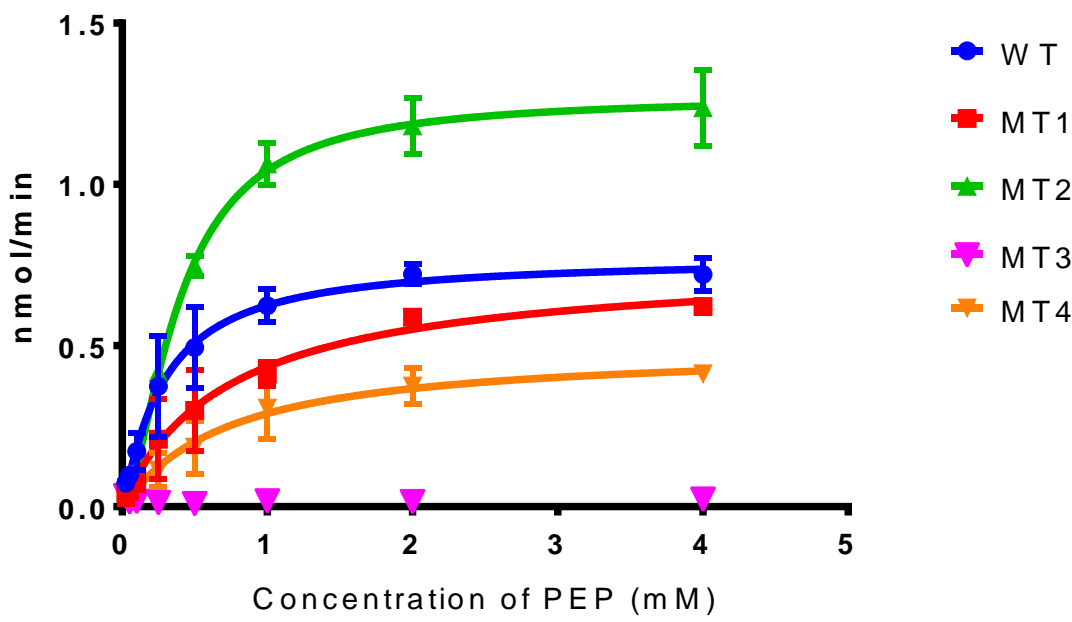

His-PKM2

Wild-Type

Mutant 1

Mutant 2

Mutant 3

Mutant 4

$\mathrm{V}_{\max }$
(nmol/min)
$\mathrm{K}_{\mathrm{m}}$

0.7733

0.7634

1.272

(0.1001)

0.2816

0.7517

$(0.05274)$

(0.264)

$(0.02924)$

0.3915

$\mathrm{N} / \mathrm{A}$

0.4893

$(0.06719)$

(mM)

$(0.02123)$

N/A

0.705

(0.2489)

Figure 14. Kinetic analysis of WT or MT His-PKM2 enzymes. His-tagged WT, MT1, MT2, MT3, and MT4 PKM2 were purified using Ni-NTA as described in the materials and methods (A \& B) Western blots of His-PKM2 proteins from Batch 1 and 2 were performed to aid in concentration adjustments for the kinetic assays. (C) Average initial velocities of the His-PKM2 proteins $(2.5 \mathrm{nM})$ in the presence of increasing concentrations of PEP. Data is represented as $\mathrm{nmol} / \mathrm{min}$ and fitted to a non-linear regression analysis. Results are an average of two experiments using protein preparations from either batch 1 or batch 2 that incorporate two technical replicates. Average kinetic parameters $\left(V_{\max }\right.$ and $\left.\mathrm{Km}\right)$ for each enzyme is detailed within the table with the standard deviations indicated within the parentheses. 


\section{PKM2 Vmax Differences}

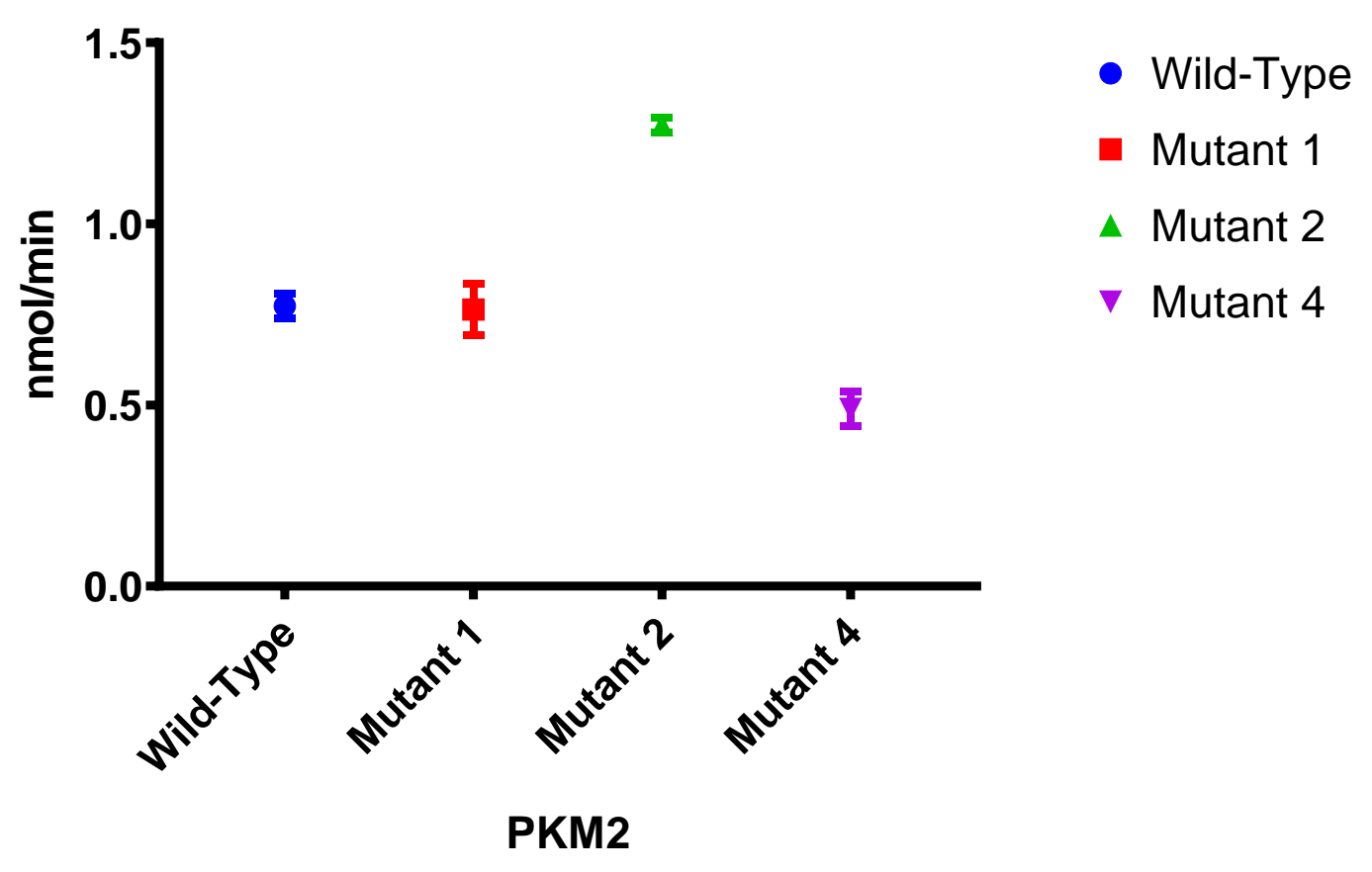

Figure 15. $\mathbf{V}_{\max }$ differences between His-PKM2.

Comparison of calculated $V_{\max }$ values across wild-type or different mutant His-PKM2 enzymes. 


\section{PKM 2 K m Differences}

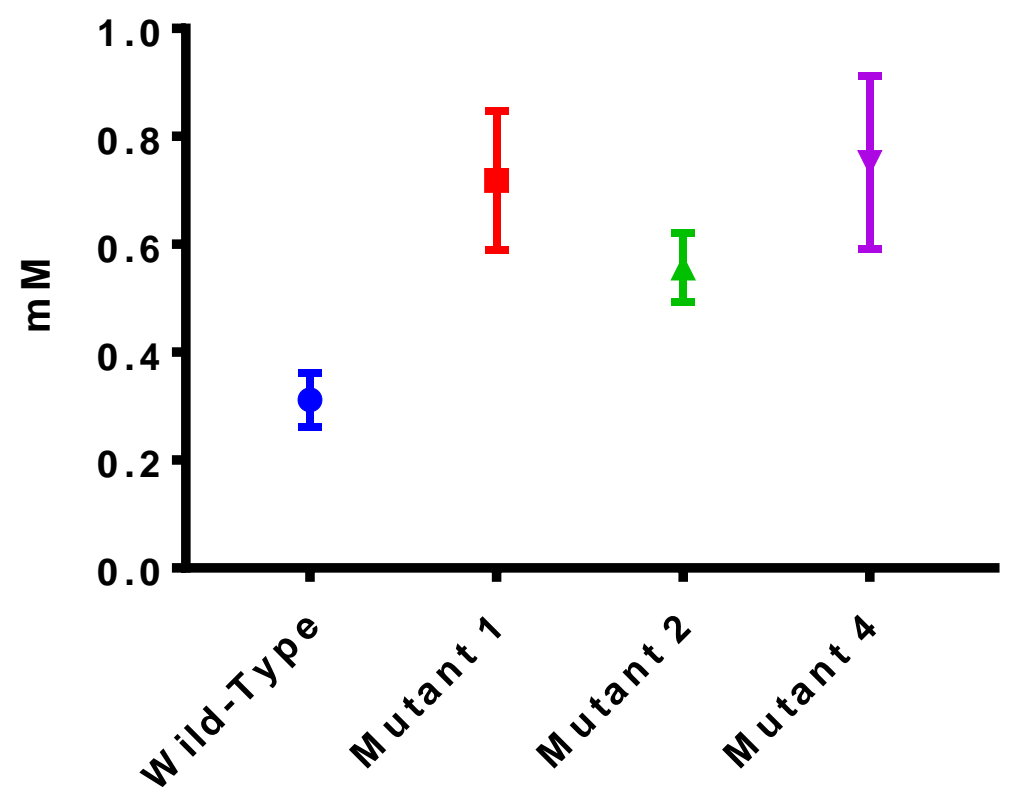

- W ild-Type

- Mutant 1

- Mutant 2

$\nabla$ Mutant 4

\section{P K M 2}

Figure 16. $\mathrm{K}_{\mathrm{m}}$ differences between His-PKM2. Calculated

$\mathrm{K}_{\mathrm{m}}$ values of His-PKM2 WT, MT1, MT2, and MT4. 
velocities (nmol / min) were plotted versus PEP concentration for the WT and MT His-PKM2 proteins from both preparations (Figure 14C; plots for each individual enzyme are shown in Appendix Figures 29-36). Non-linear regression analysis was used to determine both the maximum velocity $\left(\mathrm{V}_{\max }\right)$ and Michaelis-Menten constant $\left(\mathrm{K}_{\mathrm{m}}\right)$ for each enzyme. The calculated average $\mathrm{V}_{\max }$ for WT, MT1, MT2, and MT4 His-PKM2 were $0.77,0.76,1.3$, and 0.49 (nmol / min), respectively. The $\mathrm{K}_{\mathrm{m}}$ values for $\mathrm{WT}, \mathrm{MT1}$, MT2, and MT4 His-PKM2 were determined to be 0.28 , $0.75,0.39,0.70 \mathrm{mM}$ (Figure 14C), respectively. No activity was detected for HisPKM2 MT3 across any concentrations of PEP. The specific activity of human WT PKM2 has been previously reported as $116 \mu \mathrm{mol} / \mathrm{min} / \mathrm{mg}$ protein [47]. His-PKM2 WT used in these studies exhibited a specific activity of $55 \mu \mathrm{mol} / \mathrm{min} / \mathrm{mg}$. Comparison of activity of His-PKM2 WT to mutant enzymes indicate that mutations within MT1 did not alter $V_{\max }$, yet amino acid changes within MT2 led to an increase in $V_{\max }$ (Figure 15). In addition, mutation of a single amino acid in His-PKM2 MT4 resulted in decreased activity. While not significant, mutations in either His-PKM2 MT1 or MT4 appeared to increase the $\mathrm{K}_{\mathrm{m}}$ for PEP compared to WT (0.28 vs. $0.75 \mathrm{mM}$ or $0.70 \mathrm{mM}$, respectively) (Figure 14B-C\&16). To assess the effect of these mutations on the overall catalytic efficiency of PKM2, we calculated the $\mathrm{K}_{\mathrm{cat}} / \mathrm{K}_{\mathrm{m}}$ of $1.83 \times 10^{5}, 6.7 \times 10^{4}, 2.16 \times 10^{5}$, and $4.6 \times 10^{4} \mathrm{M}^{-1} \mathrm{sec}^{-1}$ for the WT, MT1, MT2, and MT4 enzymes, respectively. Mutations within MT1 and MT4 led to a decrease in enzyme efficiency of 60 and $75 \%$ compared to WT PKM2, while mutations in MT2 caused a $20 \%$ increase in $\mathrm{K}_{\mathrm{cat}} / \mathrm{K}_{\mathrm{m}}$. Surprisingly, combining amino acid changes in MT2 and MT4 within MT3, completely abolished any detectable 
PKM2 function within the LDH-coupled assay. Taken together, these data suggest that these amino acid changes can either increase (MT2) or decrease (MT1 and MT4) the kinetic activity of PKM2, particularly its catalytic efficiency, while the combination of mutations within MT2 and MT4 abolish all activity (MT3).

\section{Examination of Oligomer States of His-PKM2 Proteins}

PKM2 can exist as a monomer, dimer, and tetramer and these varying oligomer states can influence enzymatic activity. As I observed differences in enzymatic activity in mutant His-PKM2 proteins, particularly complete loss in MT3, I next wanted to determine if the mutations changed the oligomerization of PKM2. For this, 50ng aliquots of His-PKM2 enzymes (study performed with proteins purified from batch 2) were incubated with disuccinimidyl suberate (DSS), which is a non-cleavable, cell permeable protein cross-linker. Enzymes were then subjected to SDS-PAGE and immunoblot analysis. Under these conditions, DSS cross-linking resulted in the formation of dimer and tetramer states for the PKM2 enzymes (Figure 17). As a positive control, FBP was added 30 minutes before DSS crosslinking, which resulted in greater tetramer formation of WT His-PKM2 (Figure 17, compare lanes $1 \&$ 8). Cross-linking of His-PKM2 MT3 revealed the presence of large molecular weight aggregates $(\sim 300 \mathrm{kDa})$ beyond dimer and tetramer forms of PKM2. The presence of these aggregates may explain the lack of activity of MT3 within the kinetics assay, as aggregation may have limited the concentration of potentially active protein within the assay.

Influence of PSAT1 on His-PKM2 Enzymes 


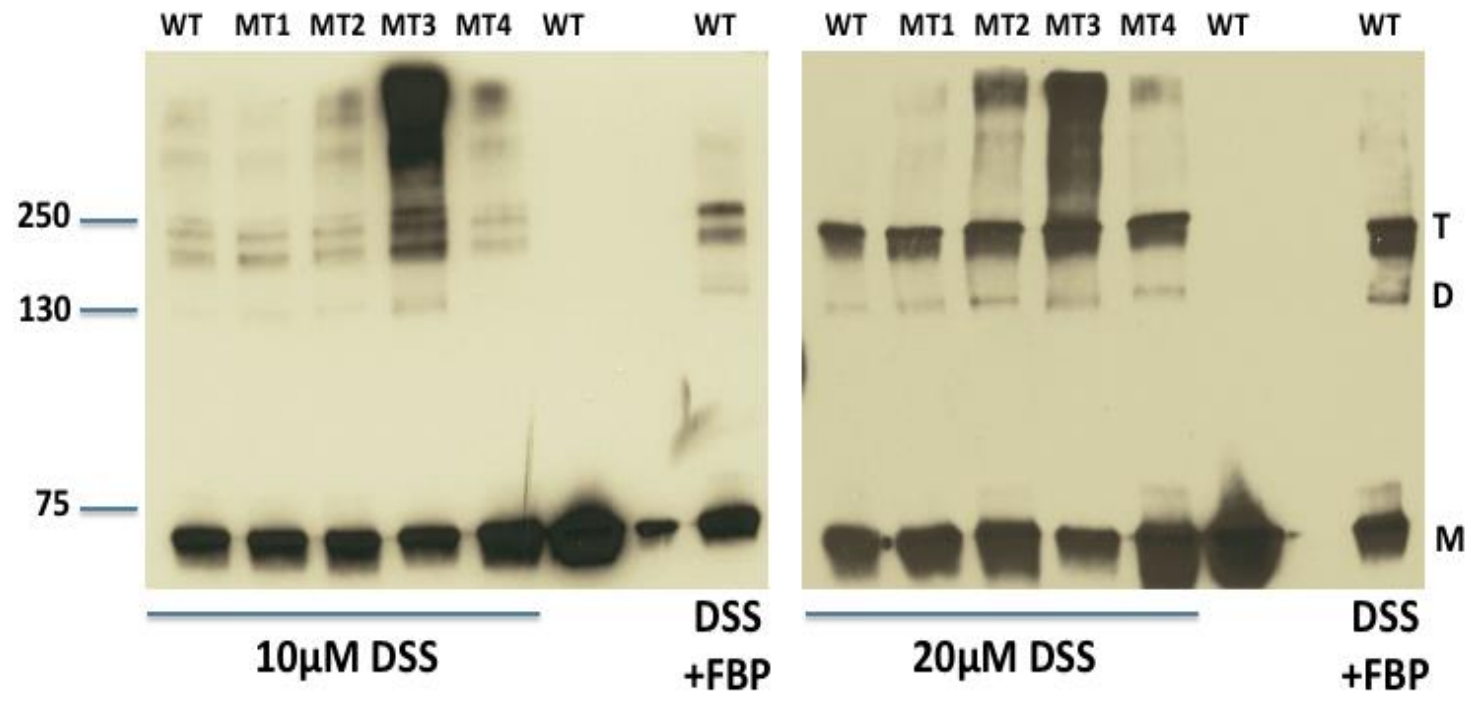

Figure 17. Cross-linking analysis to assess oligomerization of His-

PKM2 proteins. 50ng aliquots of His-PKM2 WT and MT proteins (Batch 2) were cross-linked with DSS (left: $10 \mu \mathrm{M}$; right: $20 \mu \mathrm{M}$ ) as described in the materials and methods. Samples were then subjected to SDS-PAGE and immunblotted for His. Additional preparations of WT PKM2 without DSS or in

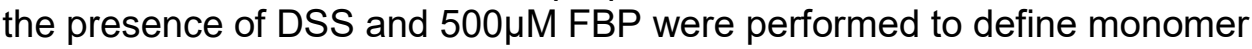
PKM2 and assess FBP on tetramer formation, respectively. Shown are representative Western blots of two separate experiments. 
After defining the kinetic activity of His-PKM2 WT, MT1, MT2, MT3, and MT4, I next assessed the effect of PSAT1 on the activity of each enzyme. Using the kinetic protocol described above, 400nM PSAT1 was incubated with the HisPKM2 proteins before initiation of the LDH-coupled kinetics assay. Unlike what was previously observed in the preliminary studies using untagged PKM2-Sigma, I found that addition of PSAT1 was unable to increase the activity of any of the HisPKM2 enzymes (Figure 18-22; plots for each enzyme from both batches is shown in Figures 29-36 in the Appendix). In addition, there was no significant change in the $\mathrm{K}_{\mathrm{m}}$ for PEP of any of the His-PKM2 proteins in the presence of PSAT1 (Figure 25). To ensure that the His-PKM2 enzymes were capable of responding to external stimulus, I added $500 \mu \mathrm{M}$ of FBP before initiating the kinetic assays. For all of the active His-PKM2, FBP was found to considerably decrease the $\mathrm{K}_{\mathrm{m}}$ for PEP (Figures 18-22). This shift in $\mathrm{K}_{\mathrm{m}}$ is not unexpected as this has previously been reported for PKM2 and the crosslinking experiments showed an increase in the tetrameric state of, at least, His-PKM2 WT, in the presence of FBP (Figure 17). These results indicate that, unlike the preliminary data utilizing untagged PKM2Sigma within the ADP-glo assay, PSAT1 was unable to increase His-PKM2 activity, even though these His-tagged enzymes still possessed the ability to be activated by FBP.

\section{Direct Comparison of His-PKM2 and untagged PKM2-Sigma}

To determine whether this discrepancy is due to the use of different assays, I directly compared the effect of PSAT1 addition on PKM2-Sigma within both the LDH-coupled assay as well as His-PKM2 WT within the ADP-glo. I first performed 
Western blot analysis to demonstrate that the protein levels of both His-PKM2 and PKM2-Sigma were similar, and that PKM2-Sigma does not contain a His-tag (Figure 23A). Analysis of PKM2-Sigma within the LDH-coupled assay determined a $V_{\max }$ of $0.77 \mathrm{nmol} / \mathrm{min}$, similar to that observed with His-PKM2. Unlike HisPKM2, upon incubation with PSAT1, PKM2-Sigma exhibited an increase in $V_{\max }$ $(0.95 \mathrm{nmol} / \mathrm{min})$, a decrease in the $\mathrm{K}_{\mathrm{m}}$ to $0.38 \mathrm{mM}$, and an 2.2 fold increase in catalytic efficiency (Figure 23B). To verify this result and determine whether HisPKM2 may be stimulated in other assays, I repeated the ADP-glo protocol with both His-PKM2 WT and PKM2-Sigma. Similar to that observed with the LDHcoupled assay, PSAT1 failed to enhance the activity of His-PKM2 compared to PKM2-Sigma (Figure 26). Together these data suggest that while His-PKM2 proteins maintain enzymatic activity that can be stimulated with known allosteric activators, something inherent in these recombinant proteins is precluding activation by PSAT1. Direct comparison with PKM2-Sigma suggests that the presence of the His-tag on the His-PKM2 proteins may disrupt the association with PSAT1 that is observed with un-tagged PKM2-Sigma.

\section{ASSESSMENTS FOR INTERACTION BETWEEN WILD-TYPE AND MUTANT HIS-PKM2 ENZYMES AND PSAT1}

\section{PSAT1 associates non-specifically to Ni-NTA beads}

To determine whether the His-PKM2 proteins were able to associate with PSAT1, I performed a pull-down assay using His-PKM2 WT and Ni-NTA sepharose beads. As a negative control, a separate sample was added that contained PSAT1 and Ni-NTA beads without His-PKM2. After pulldown with Ni-NTA, recovered proteins 


\section{His-PKM2 WT}

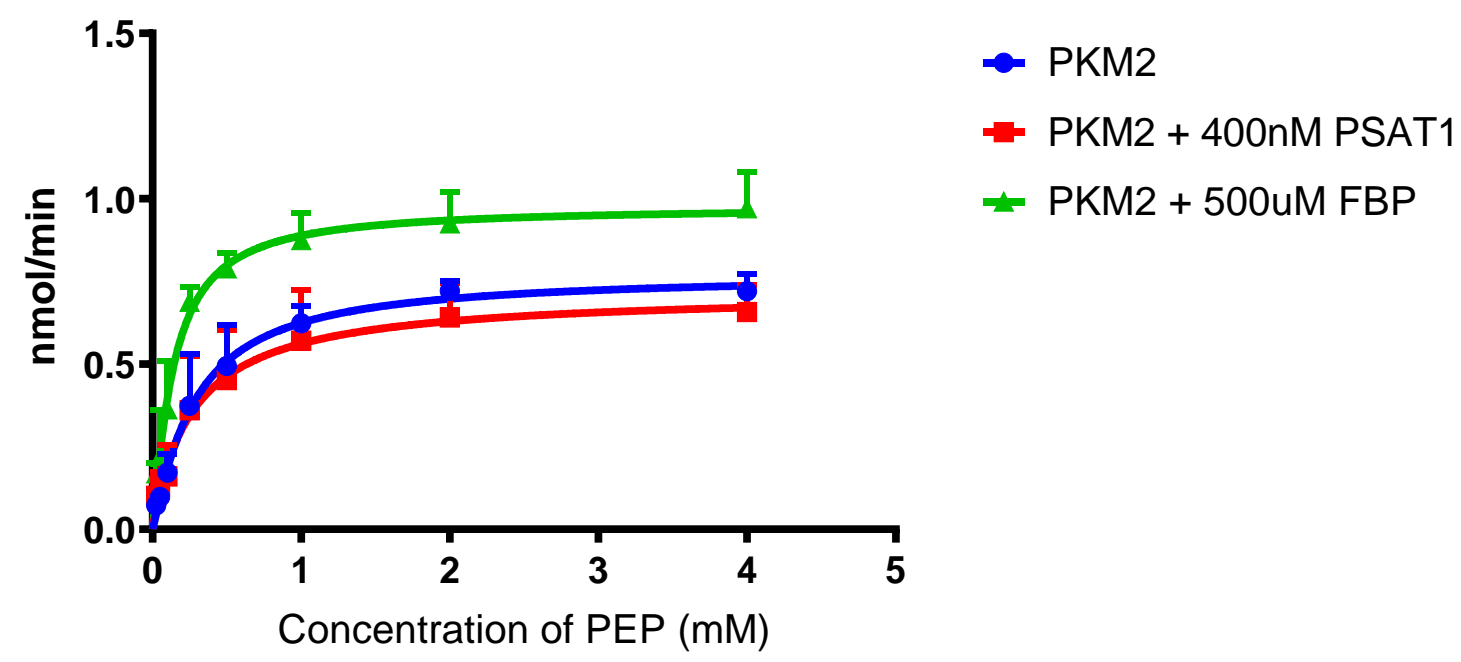

\begin{tabular}{l|ccc} 
His-PKM2 WT & + & $\stackrel{+}{+}$ & $\begin{array}{c}+ \\
+\end{array}$ \\
& & + 400nM PSAT1 & + 500uM FBP \\
\hline $\boldsymbol{V}_{\max }$ & 0.7733 & 0.719 & 0.9751 \\
& $(0.04974)$ & $(0.08552)$ & $(0.04388)$ \\
\hline$K_{m}$ & 0.2816 & 0.273 & 0.1388 \\
& $(0.05274)$ & $(0.1005)$ & $(0.0205)$ \\
\hline
\end{tabular}

Figure 18. Effect of PSAT1 and FBP on WT His-PKM2 activity. Enzymatic activity of WT His-PKM2 (2.5nM) was measured by an enzymecoupled assay with increasing concentrations of PEP in the presence or absence of PSAT1 or FBP. Data is represented as $\mathrm{nmol} / \mathrm{min}$ and fitted to a non-linear regression analysis. Results are an average of two experiments using protein preparations from either batch 1 or batch 2 that incorporate two technical replicates. Table depicts average kinetic parameters $\left(\mathrm{V}_{\max }\right.$ and $\left.\mathrm{Km}\right)$ for each condition with standard deviation indicated within the parentheses. 


\section{His-PKM2 MT1}

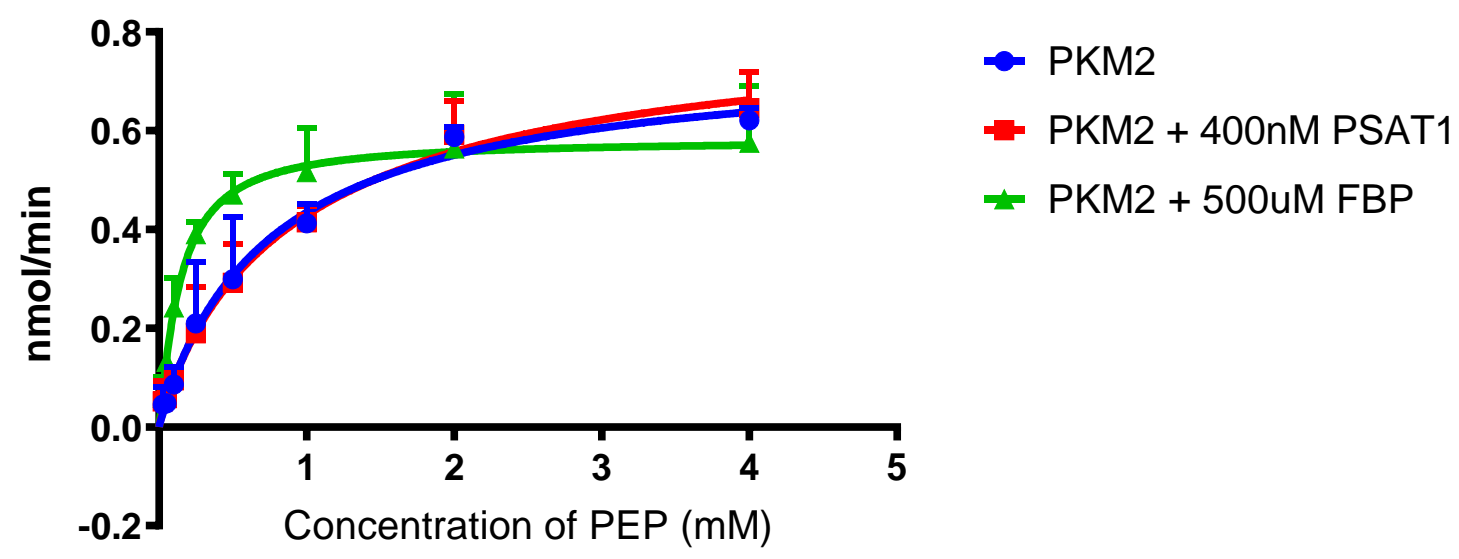

\begin{tabular}{l|c|c|c} 
His-PKM2 MT2 & + & + & + \\
& & + +400nM PSAT1 & $+\mathbf{+ 5 0 0 u M ~ F B P ~}$ \\
\hline $\boldsymbol{V}_{\max }$ & 0.7634 & 0.8434 & 0.5817 \\
& $(0.1001)$ & $(0.1184)$ & $(0.03007)$ \\
\hline$K_{m}$ & 0.7517 & 0.962 & 0.1397 \\
& $(0.264)$ & $(0.365)$ & $(0.02415)$ \\
\hline
\end{tabular}

Figure 19. Effect of PSAT1 and FBP on MT1 His-PKM2 activity. Enzymatic activity of MT1 His-PKM2 (2.5nM) was measured by an enzymecoupled assay with increasing concentrations of PEP in the presence or absence of PSAT1 or FBP. Data is represented as $\mathrm{nmol} / \mathrm{min}$ and fitted to a non-linear regression analysis. Results are an average of two experiments using protein preparations from either batch 1 or batch 2 that incorporate two technical replicates. Table depicts average kinetic parameters $\left(\mathrm{V}_{\max }\right.$ and $\left.\mathrm{Km}\right)$ for each condition with standard deviation indicated within the parentheses. 


\section{His-PKM2 MT2}

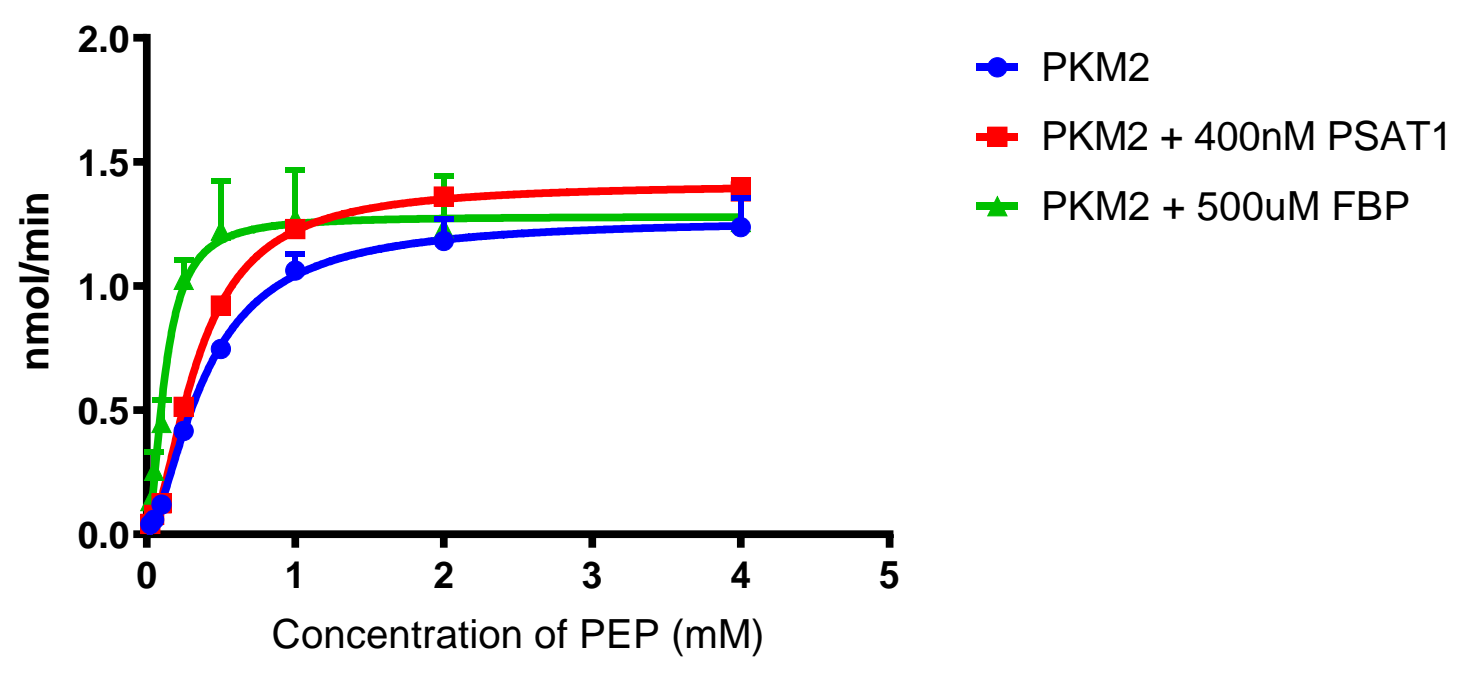

\begin{tabular}{l|ccc} 
His-PKM2 MT2 & + & + & + \\
& & + 400nM PSAT1 & $\mathbf{+}$ +500uM FBP \\
\hline $\boldsymbol{V}_{\max }$ & 1.272 & 1.412 & 1.281 \\
& $(0.02924)$ & $(0.01489)$ & $(0.04464)$ \\
\hline $\boldsymbol{K}_{\boldsymbol{m}}$ & 0.3915 & 0.3455 & 0.1237 \\
& $(0.02123)$ & $(0.008683)$ & $(0.01375)$ \\
\hline
\end{tabular}

Figure 20. Effect of PSAT1 and FBP on MT2 His-PKM2 activity. Enzymatic activity of MT2 His-PKM2 (2.5nM) was measured by an enzymecoupled assay with increasing concentrations of PEP in the presence or absence of PSAT1 or FBP. Data is represented as $\mathrm{nmol} / \mathrm{min}$ and fitted to a non-linear regression analysis. Results are an average of two experiments using protein preparations from either batch 1 or batch 2 that incorporate two technical replicates. Table depicts average kinetic parameters $\left(\mathrm{V}_{\max }\right.$ and $\left.\mathrm{Km}\right)$ for each condition with standard deviation indicated within the parentheses. 
H is-PKM 2 M T 3

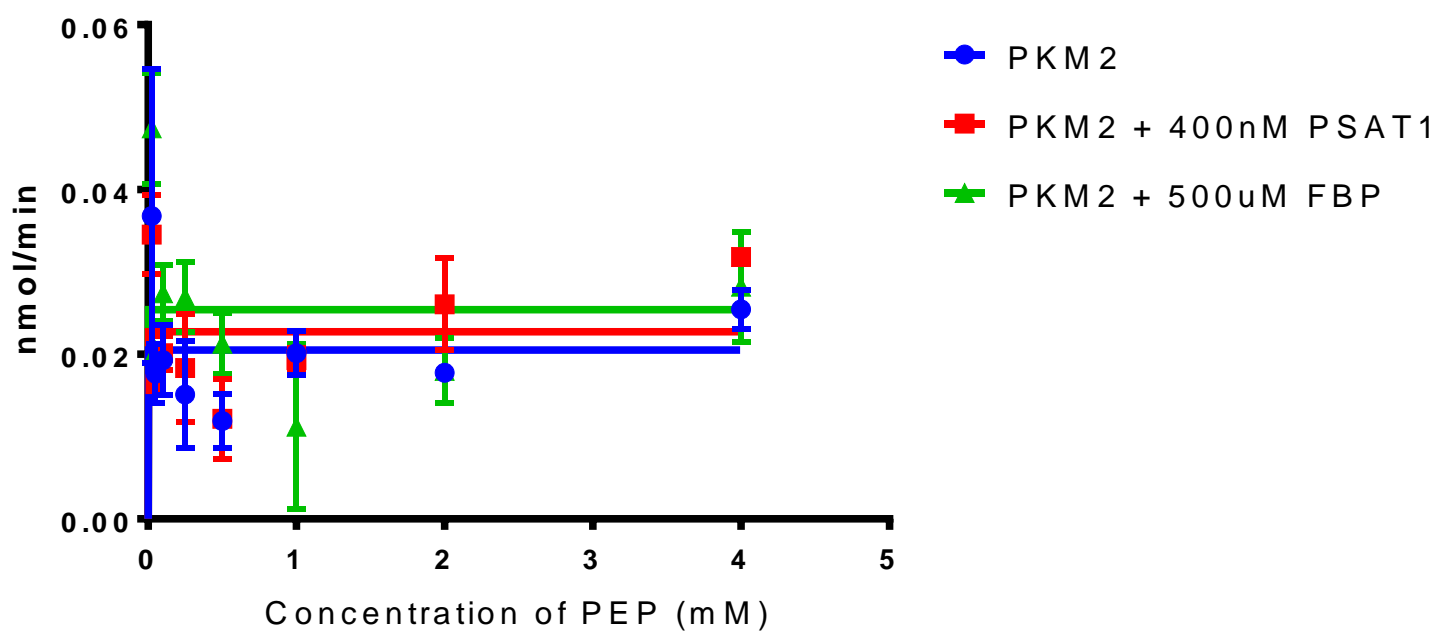

Figure 21. Effect of PSAT1 and FBP on MT3 His-PKM2 activity.

Enzymatic activity of MT3 His-PKM2 (2.5nM) was measured by an enzymecoupled assay with increasing concentrations of PEP in the presence or absence of PSAT1 or FBP. Data is represented as $\mathrm{nmol} / \mathrm{min}$ and fitted to a non-linear regression analysis. Results are an average of two separate experiments incorporating two technical replicates. 


\section{His-PKM2 MT4}

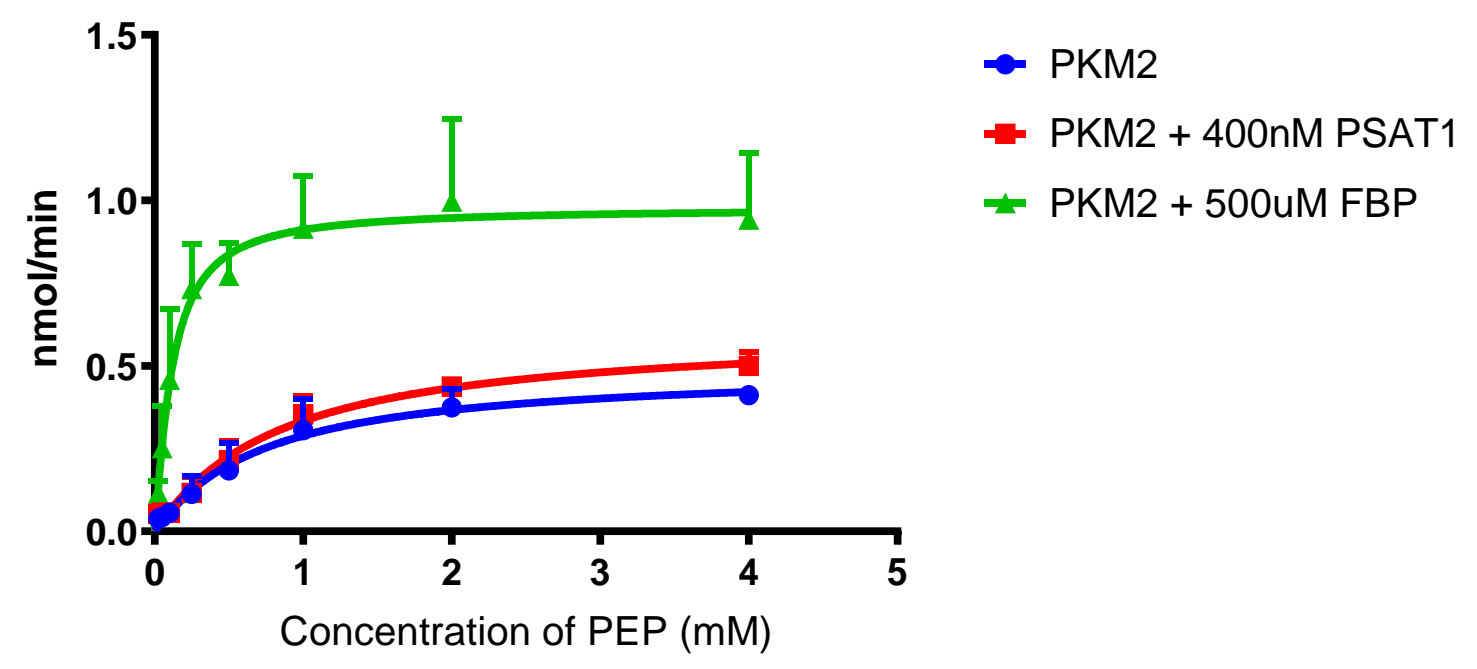

\begin{tabular}{l|ccc} 
His-PKM2 MT4 & + & + & + \\
& & + 400nM PSAT1 & $+\mathbf{+}$ 500uM FBP \\
\hline $\boldsymbol{V}_{\max }$ & 0.4893 & 0.6056 & 0.9758 \\
& $(0.06719)$ & $(0.06349)$ & $(0.06354)$ \\
\hline $\boldsymbol{K}_{\boldsymbol{m}}$ & 0.705 & 0.822 & 0.1158 \\
& $(0.2489)$ & $(0.2173)$ & $(0.002574)$ \\
\hline
\end{tabular}

Figure 22. Effect of PSAT1 and FBP on MT4 His-PKM2 activity.

Enzymatic activity of MT4 PKM2 (2.5nM) was measured by an enzyme- coupled assay with increasing concentrations of PEP in the presence or absence of PSAT1 or FBP. Data is represented as $\mathrm{nmol} / \mathrm{min}$ and fitted to a non-linear regression analysis. Results are an average of two experiments using protein preparations from either batch 1 or batch 2 that incorporate two technical replicates. Table depicts average kinetic parameters $\left(\mathrm{V}_{\max }\right.$ and $\left.\mathrm{Km}\right)$ for each condition with standard deviation indicated within the parentheses. 
A.

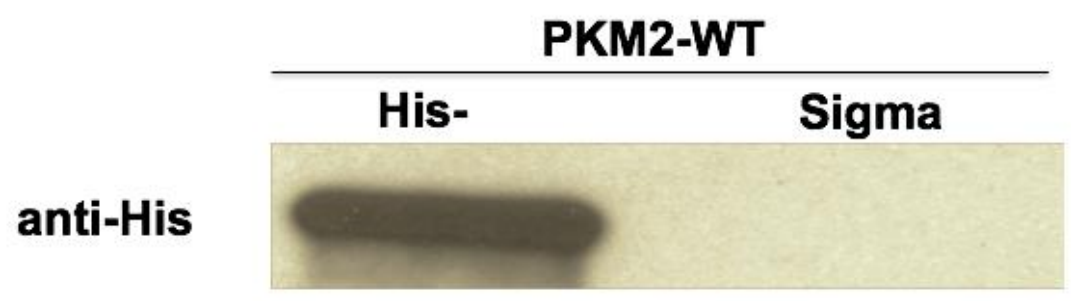

\section{anti-PKM2}

B.

PK M 2-Sig m a

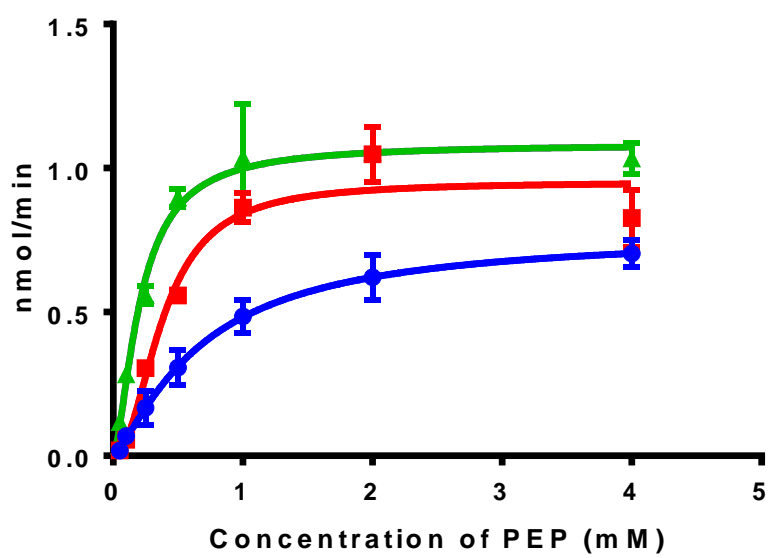

$$
\begin{aligned}
& - \text { PKM2 } \\
& - \text { PKM2 + } 400 \text { nM PSAT1 } \\
& =\text { PKM2 + 500uM FBP }
\end{aligned}
$$

\begin{tabular}{|c|c|c|c|}
\hline PKM2-Sigma & + & $\stackrel{+}{+}$ & $\stackrel{+}{+} \stackrel{+}{+500 \mathrm{MM}_{\mathrm{MBP}}}$ \\
\hline$V_{\max }$ & $\begin{array}{c}0.7747 \\
(0.05403)\end{array}$ & $\begin{array}{c}0.9512 \\
(0.04297)\end{array}$ & $\begin{array}{c}1.083 \\
(0.04105)\end{array}$ \\
\hline$K_{m}$ & $\begin{array}{c}0.6815 \\
(0.1079)\end{array}$ & $\begin{array}{c}0.3827 \\
(0.03783)\end{array}$ & $\begin{array}{c}0.2101 \\
(0.02278)\end{array}$ \\
\hline
\end{tabular}

Figure 23. Kinetic analysis of PKM2-Sigma activity in the presence of PSAT1. (A) Representative Western blot comparing purified His-PKM2 WT with PKM2-Sigma. 50ng of enzyme was separated by SDS-PAGE and immunobloted using His or PKM2 specific antibodies. (B) Enzymatic activity of PKM2-Sigma (2.5nM) was measured by enzyme-coupled assay with increasing concentrations of PEP in the presence or absence of PSAT1. Data is represented as $\mathrm{nmol} / \mathrm{min}$ and fitted to a non-linear regression analysis. Results are an average of two separate experiments incorporating two technical replicates. Table depicts average kinetic parameters $\left(\mathrm{V}_{\max }\right.$ and $\left.\mathrm{Km}\right)$ for each condition with standard deviation indicated within the parentheses. 


\section{Vmax differences}

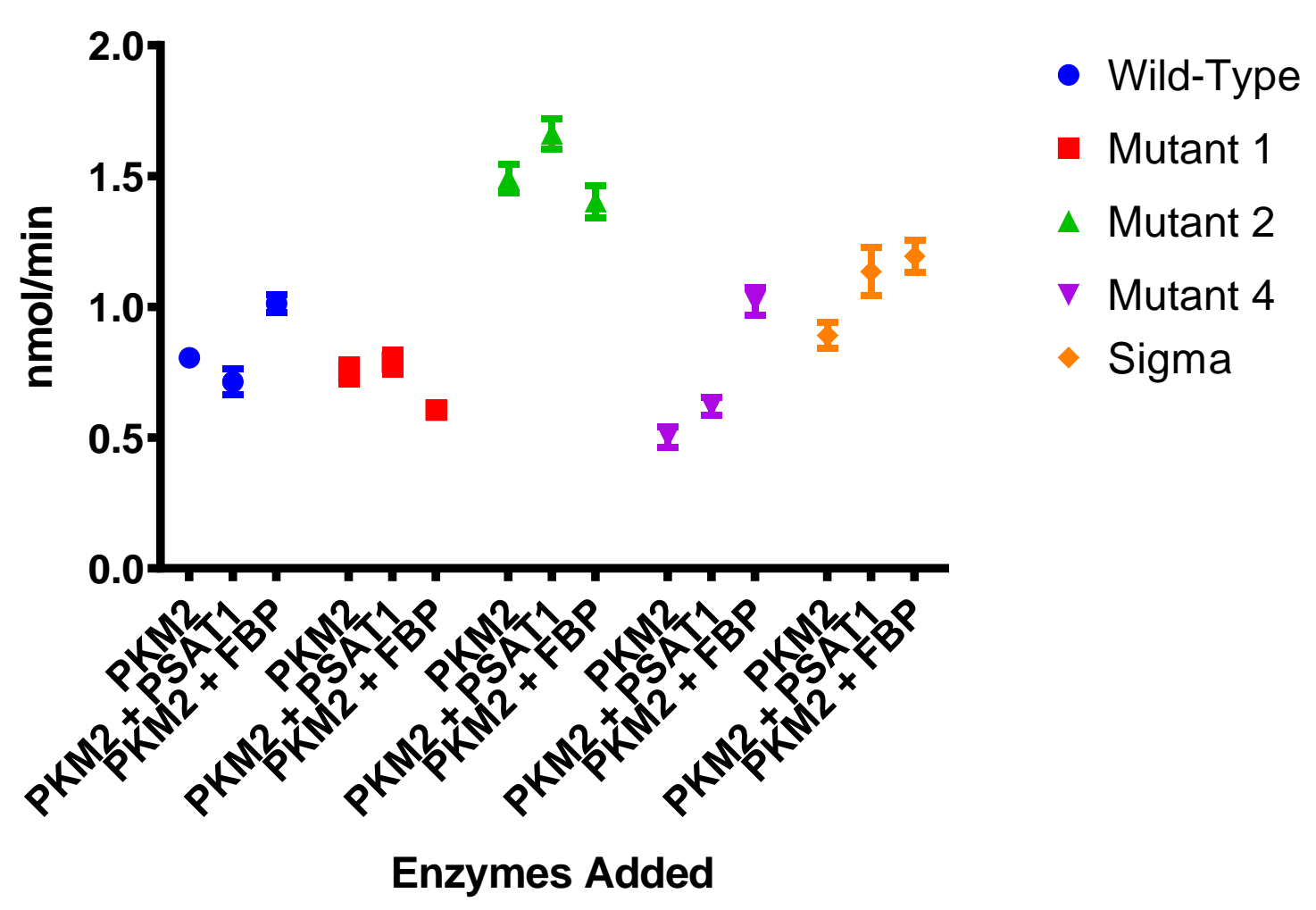

Figure 24. $\mathbf{V}_{\max }$ differences between samples Graph representing the differences in $\mathrm{V}_{\max }$ among the recPKM2 in the presence of either PSAT1 or FBP $(n=2)$. 
K m Differences

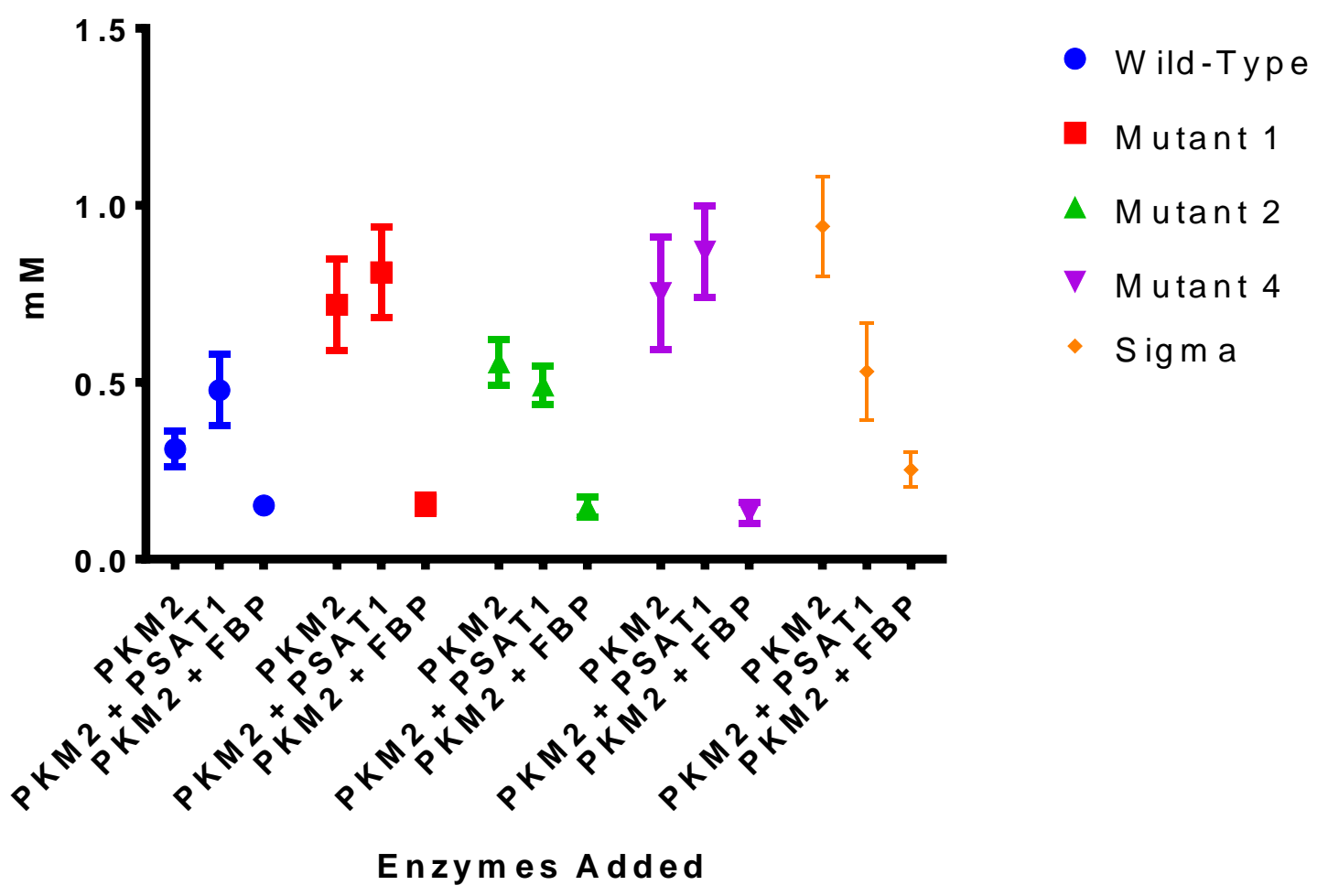

Figure 25. $\mathrm{K}_{\mathrm{m}}$ differences between samples Graph representing the differences in $\mathrm{K}_{\mathrm{m}}$ among the recPKM2 in the presence of either PSAT1 or FBP $(n=2)$. 


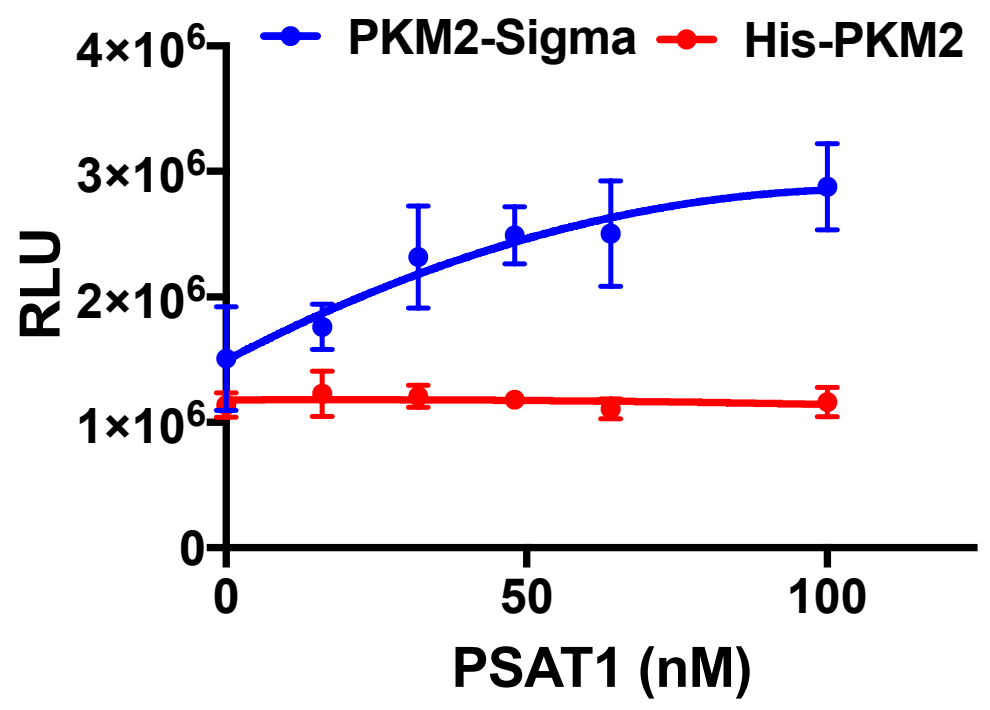

Figure 26. Alternative analysis of recPSAT1 activation of inhouse and commercial WT PKM2. Both recPKM2 enzymes were incubated with increasing concentrations of PSAT1 and pyruvate kinase activity was measured by AD-Glo as described in the materials and methods. Data at each PSAT1 concentration is represented as average $\%$ RLU change from activity observed without PSAT1. Shown is mean \pm SD from two separate experiments incorporating two technical replicates. 
were separated by SDS-PAGE and PSAT1 interaction was assessed by Western blot. First, I was able to successfully pull-down His-PKM2 WT from the protein mixture (Figure 27A, Lane 2-4; input of His-PKM2 for reference in Lane 5). However, while there was a significant level of PSAT1 observed in the His-PKM2 pull-down sample (Figure 27A, Lanes 2-3; input of PSAT1 for reference in Lane 1), I also found that PSAT1 appeared to be non-specifically binding to the Ni-NTA beads in the absence of His-PKM2 (Figure 27A, lane 6). To ensure that PSAT1 did not contain an unexpected His-tag that was mediating its binding to the $\mathrm{Ni}$ beads, I incubated PSAT1 with beads alone and performed Western blot using antibodies specific for His- tag or PSAT1. As illustrated in Figure 27B, PSAT1 does, in fact, interact with Ni-NTA bead matrix and does so without a His-tag, as the anti-His Western blot failed to show any PSAT1 in samples containing PSAT1 and Ni-NTA. Together, these data suggest that use of Ni-NTA pulldown protocol is not compatible to assess PKM2:PSAT1 interaction due to PSAT1's non-specific binding to the nickel beads.

\section{Co-immunoprecipitation of PSAT1 and PKM2}

Due to the complications that were seen using PSAT1 and Ni-NTA, I decided to perform co-immunoprecipitation analysis to examine the interaction with PSAT1 and WT or MT His-PKM2 proteins. This approach was used to demonstrate the selective association of PSAT1 with un-tagged PKM2-Sigma within the preliminary studies. Immunoblot analysis for PSAT1 demonstrated that the anti-PSAT1 antibody was able to significantly precipitate PSAT1 from the protein mixture (Figure 28, compare lanes 1-5 to lanes 6-10 for lgG control). However, Western 
blot for His-tagged PKM2 failed to show any enrichment of the His-PKM2 proteins with precipitation of PSAT1 (Figure 28). These indicate that unlike PKM2-Sigma that was found to directly interact with PSAT1, His-PKM2 enzymes fail to associate with PSAT1. While it is unclear as to why these enzymes fail to interact with PSAT1 (certain hypothesis will be discussed below), these data may explain the lack of activation of these proteins in the presence of PSAT1. 
A.

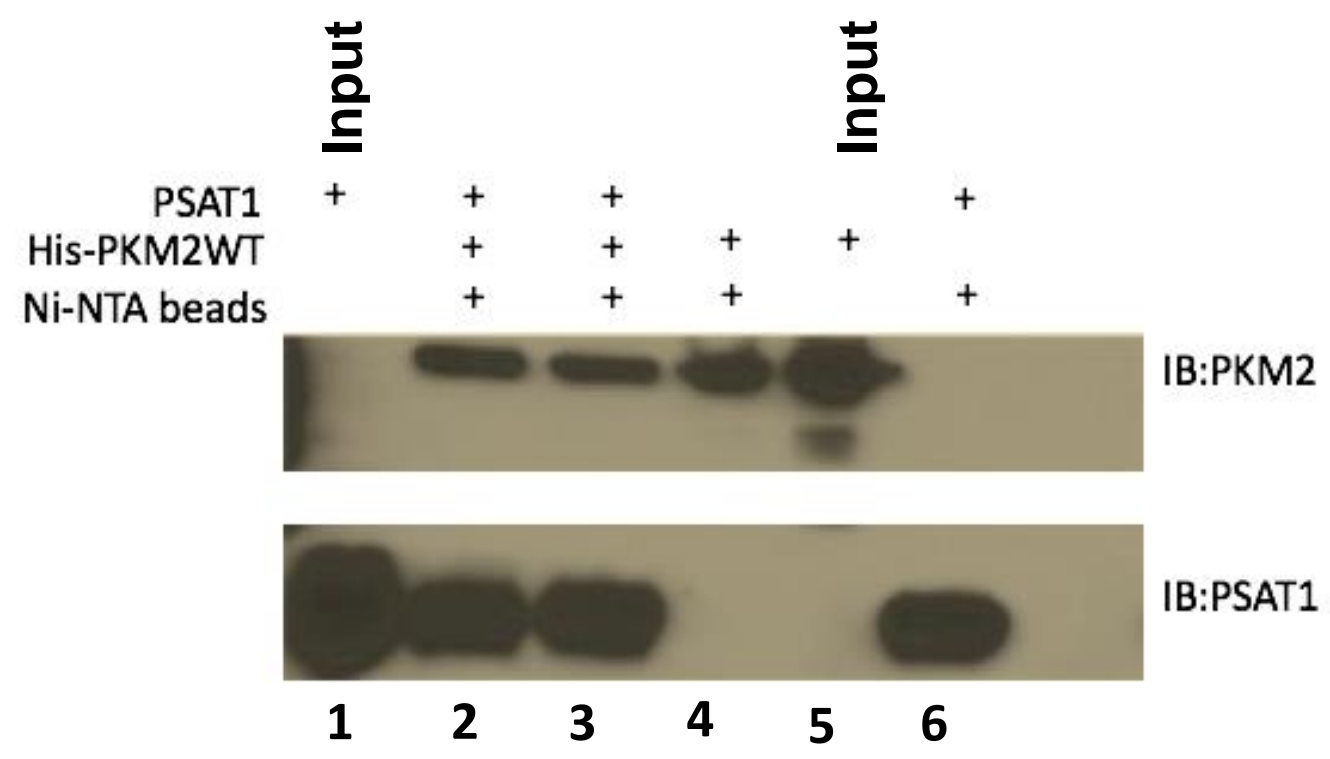

B.

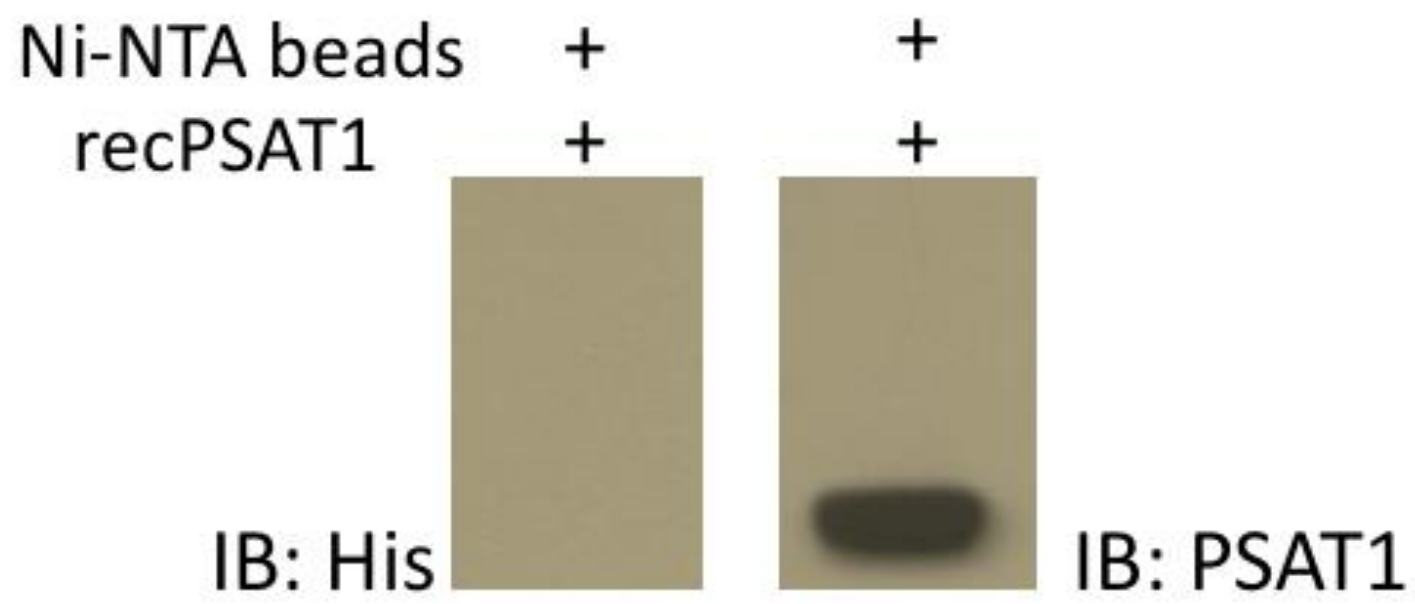

Figure 27. Analysis of PSAT1:PKM2 interaction using His-PKM2 pulldown with Ni-NTA. (A) 50ng of His-PKM2 WT was incubated with 500ng of PSAT1. Ni-NTA beads were used to pulldown complex and elutions were analyzed by immunoblot analysis. Shown is representative Western blot using specific His (PKM2) or PSAT1 antibodies. Input lanes have been labeled in addition to lane numbers. (B) PSAT1 was incubated with Ni-NTA alone and elutions were analyzed by Western blot using anti-His or anti-PSAT1 antibodies. 


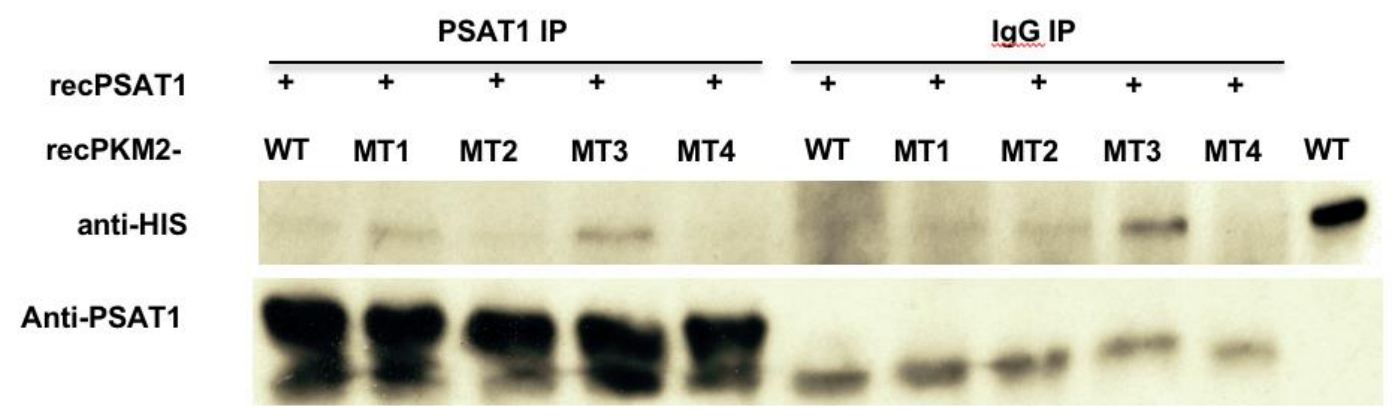

Figure 28. Co-IP of recombinant PSAT1 and PKM2. Co-IP analysis was done on mixture of PSAT1 (50ng) and 500ng of His-PKM2 proteins. Co-IP was performed using anti-PSAT1 or normal rabbit lgG (negative control). Shown is a representative Western blot of immunocomplexes using anti-His (PKM2) or antiPSAT1 antibodies. 


\section{CHAPTER FOUR: DISCUSSION}

The goal of this project was to define the consequence of PSAT1 association on the enzymatic activity of PKM2. This was based on preliminary studies that performed mass spectrophotometry on PSAT1 to identify novel binding partners and found PKM2 among the list of possible interacting proteins. Through an ADP-Glo kinase assay it was shown that addition of PSAT1 led to increased PKM2-Sigma activity. Further, site-directed mutations identified specific amino acids that suggested contribution to the interaction between both proteins. These findings led to my hypothesis that the direct association of PSAT1 was necessary for PKM2 activation and that loss of interaction between PSAT1 and PKM2 due to these PKM2 mutations would prevent PSAT1 activation of PKM2. I aimed to test this hypothesis by defining the activity of WT and MT forms of PKM2, determining the effect of PSAT1 on their activity, and assessing their interaction with PSAT1. To initiate these experiments, I first needed to express and purify recombinant proteins by incorporation of a fusion tag.

Tags encoded by expression vectors differ in their size and the matrix that is used to purify the fusion proteins. Included among these are histidine and GST tags that can be purified using nickel or glutathione-linked sepharose, respectively. Experimental end-point, as well as effects on the solubility of the fusion protein, are factors to be considered when selecting a specific tag. PKM2 can be challenging to express recombinantly, but others have reported that the inclusion of a GST tag assists in proper protein folding [73]. Thus, I began by sub-cloning the cDNAs encoding WT, MT1, MT2, and MT3 PKM2 into a pGEX4T-1 vector. 
After cloning, GST-PKM2 was purified under non-denaturing ionic conditions, as others have demonstrated that this method increases protein yield [72]. Initial attempts utilizing this Sarkosyl:Triton X100 procedure resulted in no GST-PKM2 purification (Figure 9), leading me to optimize my expression protocols (different lysing methods) to obtain significant yield (Figure 10).

One potential issue with using fusion-tagged proteins is the effect of the tag on the activity of the enzyme. Using an enzyme-coupled assay to measure PKM2 activity, I found that the GST-PKM2 WT and MT proteins displayed no pyruvate kinase activity (Figure 10). As I had performed the preparation protocol under nondenaturing conditions and Coomassie staining revealed little to no contaminating proteins, I concluded that the large GST tag was inhibiting enzymatic activity. The lack of activity could be potentially due to either changing the overall structure of PKM2, preventing oligomerization, or inhibiting substrate binding. In order to remove the tag, I decided to utilize the thrombin cleavage site that is encoded between the GST tag and PKM2. However, no PKM2 protein was recovered following thrombin cleavage; making it unfeasible to assess enzyme activity. Due to these experimental issues, I decided use a separate expression system to purify the WT and MT PKM2 proteins.

Purification using a His-fusion expression system has been shown to result in active pyruvate kinase [55]. After optimizing the purification protocol (Figure 13), I was able to produce active His-PKM2, as assessed in the LDH-coupled assay. The calculated specific activity of my purified His-PKM2 WT (55 $\mu \mathrm{mol} / \mathrm{min} / \mathrm{mg}$ ), which is half of what has been previously published by others $(116 \mu \mathrm{mol} / \mathrm{min} /$ 
mg) [47]. As point mutations have been previously reported to alter PKM2 activity [55], I proceeded to define the kinetics of all four mutant His-PKM2 forms.

In my studies, the introduction of the separate mutations resulted in different kinetics for His-PKM2. While mutations in MT1 did not appear to alter activity compared to WT; MT2 His-PKM2 demonstrated an increase in $V_{\max }$. Yet, these amino acid changes within MT2 did not significantly alter the $\mathrm{K}_{\mathrm{m}}$ for PEP. This suggests that these mutations may modify the protein structure in such a way as to distort the active site, resulting in lower activation energy and increased pyruvate formation. Conversely, MT4 exhibited a slight decrease in $V_{\max }$, indicating that these mutations negatively affect enzyme activity. However, amino acid changes in MT3 His-PKM2 entirely abolished pyruvate kinase activity.

The complete lack of activity is surprising in that MT3 is a combination of mutations found in MT2 and MT4 His-PKM2. As other site-specific mutations have previously been shown to affect dimer/tetramer formation of PKM2, cross-linking studies were done to assess effects on the oligomerization of His-PKM2. I found that MT3 forms high molecular weight aggregates under native conditions compared to WT and other MT His-PKM2 proteins. From this, it still needs to be determined whether these mutations abolish activity due to inducing His-PKM2 misfolding and aggregation. The cross-linking experiments also showed that there were no adverse effects on dimer/tetramer formation between WT, MT1, MT2, or MT4 suggesting that the differences observed in activity may not be a result of changes in oligomer formation. 
Next, I determined the effect of PSAT1 on the activity of all forms of HisPKM2. While the preliminary studies demonstrate that PSAT1 stimulates PKM2Sigma, PSAT1 failed to activate any of the His-PKM2 proteins. To determine whether these enzymes respond to other activators, I added FBP and observed either significant increases in enzyme activity, lowering of $\mathrm{Km}$ for PEP, or both as has been previously described for FBP. This is supported, at least with His-PKM2 WT, that addition of FBP leads to greater tetramer formation, which is well established to increase PKM2 activity. Lastly, to determine whether it was a difference in assays that were leading to the discrepancy in the ability of PSAT1 to activate His-PKM2, I repeated both the LDH-coupled assay and the ADP-Glo using both PKM2-Sigma and His-PKM2 WT. I observed that PSAT1 was able to stimulate PKM2-Sigma in both assays, while His-PKM2 WT failed to show any increase. Together, these data suggest that the His-tag on the PKM2 enzymes was inhibiting the transactivation potential of PSAT1, potentially through blocking the association between PSAT1 and the His-PKM2 proteins.

Since the preliminary data suggested that PSAT1's interaction with PKM2Sigma allows for activation, I performed association studies to determine the amino acid requirement for PSAT1:PKM2 interaction. However, I was unable to observe interaction with any of the active His-PKM2 enzymes. Both Ni-NTA pulldown and co-immunoprecipitation studies demonstrated a lack of specific interaction between PSAT1 and His-PKM2. Attempting to pull-down PSAT1 using HisPKM2:Ni-NTA chromatography proved to be ineffective, as PSAT1 was found to bind non-specifically to the nickel beads. Also, co-immunoprecipitation analysis 
using a PSAT1 antibody, similar to that used in the preliminary studies with PKM2Sigma, failed to enrich levels of His-PKM2 above that of the IgG negative control. Together, my interaction experiments suggest that His-PKM2 proteins are unable to associate with PSAT1. While not conclusive, this could explain the lack of activation of His-PKM2 upon addition of PSAT1.

As demonstrated by Western blot, PKM2-Sigma does not contain a His-tag. While unexpected, cumulatively, my data indicate that the His-tag within the HisPKM2 enzymes is affecting the interaction with PSAT1. Yet, another possible reason relates to potential differences in the purification scheme used to produce both the PKM2-Sigma and His-PKM2 proteins. Buffers used to lyse, wash, elute, and even dialyze PKM2 could lead to differences in the ability to interact with PSAT1. A shift in pH between two separate buffers could be a determining factor as to whether proteins associate. Lastly, PSAT1 requires a co-factor, PLP, for its enzymatic activity and in theory optimal tertiary structure. I did not add this cofactor to either the His-PKM2 enzymatic or associating assays. However, I do not believe that this contributed to the lack of effect, as the preliminary data using PKM2-Sigma also did not add exogenous PLP.

Future studies related to this project should be focused on identifying other purification schemes to purify the PKM2 enzymes. As thrombin cleavage was inefficient in obtaining PKM2 enzymes, cDNA can be sub-cloned into other GSTfusion vectors that contain cleavage sites for other enzymes, such as PreScission Protease. As informative as these results are regarding the kinetic characteristics of WT and MT His-PKM2 proteins, the question persists of what region/amino 
acids of PKM2 is required for binding to PSAT1. Importantly, while the preliminary data suggest that amino acids that make up MT3 aid in disassociating PSAT1, they may lead to overall structural changes in PKM2 and may not be directly involved in the interaction with PSAT1. This could also be addressed through computational programs, such as the Rosetta Online Server that Includes Everyone (ROSIE).

ROSIE uses a Monte Carlo based algorithm to predict the likelihood of two proteins interacting with one another using its structure-prediction based program [71]. Although ROSIE is capable of prediction protein: protein interaction, separate tools must be used to prepare the proteins of interest structure for ROSIE docking. Protein structures, attained in the form of protein data banks (PDB) files, are loaded into separate computer software for molecular visualization such as PyMol or Chimera. Within the software, users are capable of manipulating the protein structure through the removal, addition, or replacement of amino acids. When investigating possible protein: protein interaction, it is crucial that the regions that are believed to have a role in the interaction be positioned nearby one another. The purpose of this positioning becomes apparent when simulating protein: protein interaction through ROSIE, which performs local docking on the given starting conformation of the proteins involved. The resulting output from ROSIE is a list of possible protein conformations with the 10 lowest-energy needed structures being prominently displayed.

As these two proteins play essential roles in tumor metabolism, ultimately characterizing their functional association in the context of changing glucose 
and/or serine metabolism will provide a more comprehensive understanding of cellular changes during tumorigenesis. 


\section{REFERENCES}

1. Sreedhar, A. and Y. Zhao, Dysregulated metabolic enzymes and metabolic reprogramming in cancer cells. Biomed Rep, 2018. 8(1): p. 3-10.

2. Groheux, D., et al., Performance of FDG PET/CT in the clinical management of breast cancer. Radiology, 2013. 266(2): p. 388-405.

3. Bos, R., et al., Biologic correlates of (18)fluorodeoxyglucose uptake in human breast cancer measured by positron emission tomography. J Clin Oncol, 2002. 20(2): p. 379-87.

4. Woodward, G.E. and M.T. Hudson, The effect of 2-desoxy-D-glucose on glycolysis and respiration of tumor and normal tissues. Cancer Res, 1954. 14(8): p. 599-605.

5. Phelps, M.E., Positron emission tomography provides molecular imaging of biological processes. Proc Natl Acad Sci U S A, 2000. 97(16): p. 9226-33.

6. Volpi, S., et al., The role of positron emission tomography in the diagnosis, staging and response assessment of non-small cell lung cancer. Ann Transl Med, 2018. 6(5): p. 95.

7. Warburg, O., F. Wind, and E. Negelein, The Metabolism of Tumors in the Body. J Gen Physiol, 1927. 8(6): p. 519-30.

8. Hanahan, D. and R.A. Weinberg, Hallmarks of cancer: the next generation. Cell, 2011. 144(5): p. 646-74.

9. Kim, J.W. and C.V. Dang, Cancer's molecular sweet tooth and the Warburg effect. Cancer Res, 2006. 66(18): p. 8927-30.

10. Warburg, O., On respiratory impairment in cancer cells. Science, 1956. 124(3215): p. 269-70.

11. Fantin, V.R., J. St-Pierre, and P. Leder, Attenuation of LDH-A expression uncovers a link between glycolysis, mitochondrial physiology, and tumor maintenance. Cancer Cell, 2006. 9(6): p. 425-34.

12. Ramanathan, A., C. Wang, and S.L. Schreiber, Perturbational profiling of a cellline model of tumorigenesis by using metabolic measurements. Proc Natl Acad Sci U S A, 2005. 102(17): p. 5992-7.

13. Hsu, P.P. and D.M. Sabatini, Cancer cell metabolism: Warburg and beyond. Cell, 2008. 134(5): p. 703-7.

14. Chen, X.S., et al., Anticancer strategies based on the metabolic profile of tumor cells: therapeutic targeting of the Warburg effect. Acta Pharmacol Sin, 2016. 37(8): p. 1013-9.

15. Liberti, M.V. and J.W. Locasale, The Warburg Effect: How Does it Benefit Cancer Cells? Trends Biochem Sci, 2016. 41(3): p. 211-218. 
16. Valera, A., et al., Evidence from transgenic mice that myc regulates hepatic glycolysis. FASEB J, 1995. 9: p. 1067-78.

17. Gottlob, K., et al., Inhibition of early apoptotic events by Akt/PKB is dependent on the first committed step of glycolysis and mitochondrial hexokinase. Genes Dev, 2001. 15(11): p. 1406-18.

18. Osthus, R.C., et al., Deregulation of glucose transporter 1 and glycolytic gene expression by c-Myc. J Biol Chem, 2000. 275(29): p. 21797-800.

19. Clem, B.F., et al., Targeting 6-phosphofructo-2-kinase (PFKFB3) as a therapeutic strategy against cancer. Mol Cancer Ther, 2013. 12(8): p. 1461-70.

20. Bustamante, E., H.P. Morris, and P.L. Pedersen, Energy metabolism of tumor cells. Requirement for a form of hexokinase with a propensity for mitochondrial binding. J Biol Chem, 1981. 256(16): p. 8699-704.

21. Bennett, M.J., et al., Isoenzymes of hexokinase in the developing, normal and neoplastic human brain. Eur J Cancer, 1978. 14(2): p. 189-93.

22. Moreno-Sanchez, R., et al., Energy metabolism in tumor cells. FEBS J, 2007. 274(6): p. 1393-418.

23. Christofk, H.R., et al., The M2 splice isoform of pyruvate kinase is important for cancer metabolism and tumour growth. Nature, 2008. 452(7184): p. 230-3.

24. Rempel, A., et al., Glucose catabolism in cancer cells: amplification of the gene encoding type II hexokinase. Cancer Res, 1996. 56(11): p. 2468-71.

25. Vander Heiden, M.G., L.C. Cantley, and C.B. Thompson, Understanding the Warburg effect: the metabolic requirements of cell proliferation. Science, 2009. 324(5930): p. 1029-33.

26. Patra, K.C. and N. Hay, The pentose phosphate pathway and cancer. Trends Biochem Sci, 2014. 39(8): p. 347-54.

27. Jiang, P., W. Du, and M. Wu, Regulation of the pentose phosphate pathway in cancer. Protein Cell, 2014. 5(8): p. 592-602.

28. Cabezas, H., R.R. Raposo, and E. Melendez-Hevia, Activity and metabolic roles of the pentose phosphate cycle in several rat tissues. Mol Cell Biochem, 1999. 201(1-2): p. 57-63.

29. Riganti, C., et al., The pentose phosphate pathway: an antioxidant defense and a crossroad in tumor cell fate. Free Radic Biol Med, 2012. 53(3): p. 421-36.

30. Kolossov, V.L., et al., Inhibition of glutathione synthesis distinctly alters mitochondrial and cytosolic redox poise. Exp Biol Med (Maywood), 2014. 239(4): p. 394-403.

31. Kalhan, S.C. and R.W. Hanson, Resurgence of serine: an often neglected but indispensable amino Acid. J Biol Chem, 2012. 287(24): p. 19786-91.

32. Antonov, A., et al., Bioinformatics analysis of the serine and glycine pathway in cancer cells. Oncotarget, 2014. 5(22): p. 11004-13.

33. Renwick, S.B., K. Snell, and U. Baumann, The crystal structure of human cytosolic serine hydroxymethyltransferase: a target for cancer chemotherapy. Structure, 1998. 6(9): p. 1105-16. 
34. Tedeschi, P.M., et al., Contribution of serine, folate and glycine metabolism to the ATP, NADPH and purine requirements of cancer cells. Cell Death Dis, 2013. 4: p. e877.

35. Tehlivets, O., et al., S-adenosyl-L-homocysteine hydrolase and methylation disorders: yeast as a model system. Biochim Biophys Acta, 2013. 1832(1): p. 20415.

36. Pollari, S., et al., Enhanced serine production by bone metastatic breast cancer cells stimulates osteoclastogenesis. Breast Cancer Res Treat, 2011. 125(2): p. 421-30.

37. Possemato, R., et al., Functional genomics reveal serine synthesis is essential in PHGDH-amplified breast cancer. Nature, 2012. 476(7360): p. 346-350.

38. Li, C., et al., Metabolic reprogramming in cancer cells: glycolysis, glutaminolysis, and Bcl-2 proteins as novel therapeutic targets for cancer. World J Surg Oncol, 2016. 14(1): p. 15.

39. Atsumi, T., et al., High expression of inducible 6-phosphofructo-2-kinase/fructose2,6-bisphosphatase (iPFK-2; PFKFB3) in human cancers. Cancer Res, 2002. 62(20): p. 5881-7.

40. Zancan, P., et al., Differential expression of phosphofructokinase-1 isoforms correlates with the glycolytic efficiency of breast cancer cells. Mol Genet Metab, 2010. 100(4): p. 372-8.

41. El-Bacha, T., M.S. de Freitas, and M. Sola-Penna, Cellular distribution of phosphofructokinase activity and implications to metabolic regulation in human breast cancer. Mol Genet Metab, 2003. 79(4): p. 294-9.

42. Goldman, R.D., N.O. Kaplan, and T.C. Hall, Lactic Dehydrogenase in Human Neoplastic Tissues. Cancer Res, 1964. 24: p. 389-99.

43. Rizwan, A., et al., Relationships between LDH-A, lactate, and metastases in 4T1 breast tumors. Clin Cancer Res, 2013. 19(18): p. 5158-69.

44. Shim, H., et al., c-Myc transactivation of $L D H$-A: implications for tumor metabolism and growth. Proc Natl Acad Sci U S A, 1997. 94(13): p. 6658-63.

45. Yamada, K. and T. Noguchi, Nutrient and hormonal regulation of pyruvate kinase gene expression. Biochem J, 1999. 337 ( Pt 1): p. 1-11.

46. Morgan, H.P., et al., M2 pyruvate kinase provides a mechanism for nutrient sensing and regulation of cell proliferation. Proc Natl Acad Sci U S A, 2013. 110(15): p. 5881-6.

47. Wu, S. and H. Le, Dual roles of PKM2 in cancer metabolism. Acta Biochim Biophys Sin (Shanghai), 2013. 45(1): p. 27-35.

48. Noguchi, T., H. Inoue, and T. Tanaka, The M1- and M2-type isozymes of rat pyruvate kinase are produced from the same gene by alternative RNA splicing. J Biol Chem, 1986. 261(29): p. 13807-12.

49. Dombrauckas, J.D., B.D. Santarsiero, and A.D. Mesecar, Structural basis for tumor pyruvate kinase M2 allosteric regulation and catalysis. Biochemistry, 2005. 44(27): p. 9417-29.

50. Luo, W. and G.L. Semenza, Emerging roles of PKM2 in cell metabolism and cancer progression. Trends Endocrinol Metab, 2012. 23(11): p. 560-6. 
51. Wang, Z., et al., Exon-centric regulation of pyruvate kinase $M$ alternative splicing via mutually exclusive exons. J Mol Cell Biol, 2012. 4(2): p. 79-87.

52. Chen, M., C.J. David, and J.L. Manley, Concentration-dependent control of pyruvate kinase $M$ mutually exclusive splicing by hnRNP proteins. Nat Struct Mol Biol, 2012. 19(3): p. 346-54.

53. Dong, G., et al., PKM2 and cancer: The function of PKM2 beyond glycolysis. Oncol Lett, 2016. 11(3): p. 1980-1986.

54. Gui, D.Y., C.A. Lewis, and M.G. Vander Heiden, Allosteric regulation of PKM2 allows cellular adaptation to different physiological states. Sci Signal, 2013. 6(263): p. pe7.

55. Anastasiou, D., et al., Pyruvate kinase $\mathrm{M} 2$ activators promote tetramer formation and suppress tumorigenesis. Nat Chem Biol, 2012. 8(10): p. 839-47.

56. Chaneton, B., et al., Serine is a natural ligand and allosteric activator of pyruvate kinase M2. Nature, 2012. 491(7424): p. 458-462.

57. Yang, J., et al., Synergistic Allosteric Mechanism of Fructose-1,6-bisphosphate and Serine for Pyruvate Kinase M2 via Dynamics Fluctuation Network Analysis. J Chem Inf Model, 2016. 56(6): p. 1184-1192.

58. Kung, C., et al., Small molecule activation of PKM2 in cancer cells induces serine auxotrophy. Chem Biol, 2012. 19(9): p. 1187-98.

59. Christofk, H.R., et al., Pyruvate kinase $M 2$ is a phosphotyrosine-binding protein. Nature, 2008. 452(7184): p. 181-6.

60. Yang, W., et al., Nuclear PKM2 regulates beta-catenin transactivation upon EGFR activation. Nature, 2011. 480(7375): p. 118-22.

61. Yang, W., et al., PKM2 phosphorylates histone H3 and promotes gene transcription and tumorigenesis. Cell, 2012. 150(4): p. 685-96.

62. Jiang, Y., et al., PKM2 regulates chromosome segregation and mitosis progression of tumor cells. Mol Cell, 2014. 53(1): p. 75-87.

63. Lu, Z. and T. Hunter, Metabolic Kinases Moonlighting as Protein Kinases. Trends Biochem Sci, 2018. 43(4): p. 301-310.

64. Lee, J., et al., Pyruvate kinase isozyme type M2 (PKM2) interacts and cooperates with Oct-4 in regulating transcription. Int J Biochem Cell Biol, 2008. 40(5): p. 1043-54.

65. Zhang, Z., et al., Antigen presentation by dendritic cells in tumors is disrupted by altered metabolism that involves pyruvate kinase $\mathrm{M} 2$ and its interaction with SOCS3. Cancer Res, 2010. 70(1): p. 89-98.

66. Luo, W., et al., Pyruvate kinase M2 is a PHD3-stimulated coactivator for hypoxiainducible factor 1. Cell, 2011. 145(5): p. 732-44.

67. Possemato, R., et al., Functional genomics reveal that the serine synthesis pathway is essential in breast cancer. Nature, 2012. 476(7630): p. 346-50.

68. Locasale, J.W., Serine, glycine and one-carbon units: cancer metabolism in full circle. Nat Rev Cancer, 2013. 13(8): p. 572-83.

69. Pacold, M.E., et al., A PHGDH inhibitor reveals coordination of serine synthesis and one-carbon unit fate. Nat Chem Biol, 2016. 12(6): p. 452-8. 
70. Park, D.W., et al., Improved recovery of active GST-fusion proteins from insoluble aggregates: solubilization and purification conditions using PKM2 and HtrA2 as model proteins. BMB Rep, 2011. 44(4): p. 279-84.

71. Lyskov, S. and J.J. Gray, The RosettaDock server for local protein-protein docking. Nucleic Acids Res, 2008. 36(Web Server issue): p. W233-8. 


\section{APPENDIX}

\section{B.1-H is-PKM 2 W T}

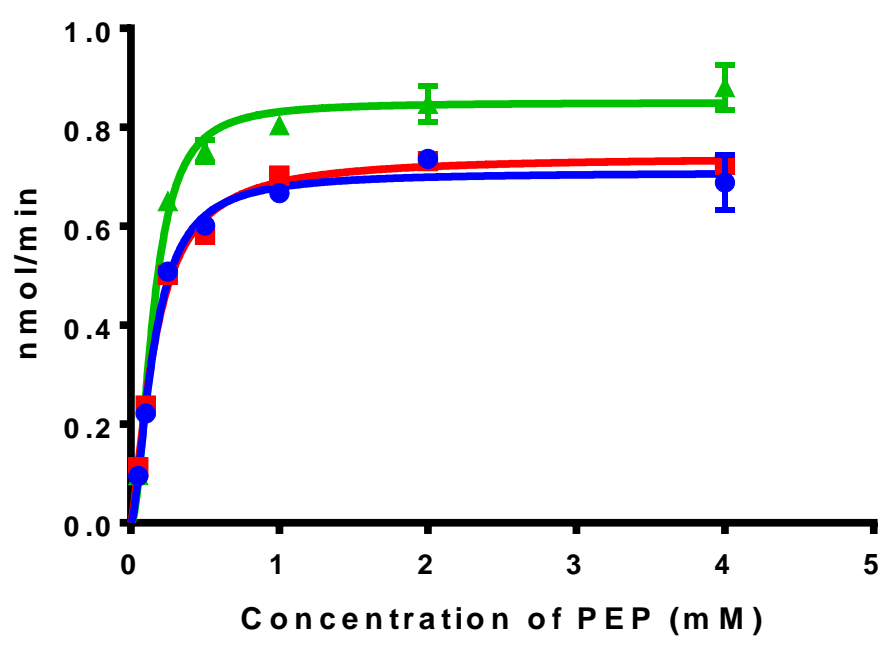

$P K M 2$

$=$ PKM2 + 400nM PSAT1

$=P K M 2+500 u M F B P$

\begin{tabular}{l|c|c|c} 
B1 & His-PKM2 WT & $\begin{array}{c}\text { His-PKM2 WT } \\
\text { +400nM PSAT1 }\end{array}$ & $\begin{array}{c}\text { His PKM2 WT } \\
\text { +500uM FBP }\end{array}$ \\
\hline $\boldsymbol{V}_{\max }$ & 0.7086 & 0.7401 & 0.8501 \\
& $(0.01431)$ & $(0.01189)$ & $(0.01489)$ \\
\hline$K_{\boldsymbol{m}}$ & 0.1548 & 0.164 & 0.1521 \\
& $(0.009587)$ & $(0.0081)$ & $(0.008032)$ \\
\hline
\end{tabular}

Figure 29. Effect of PSAT1 and FBP on WT His-PKM2 (Batch1) activity. Enzymatic activity of WT PKM2 (2.5nM) from Batch 1 was measured by an enzyme- coupled assay with increasing concentrations of PEP in the presence or absence of PSAT1 or FBP. Data is represented as $\mathrm{nmol} / \mathrm{min}$ and fitted to a non-linear regression model. Results are an average of two technical replicates. Table depicts average kinetic parameters $\left(V_{\max }\right.$ and $\left.\mathrm{K}_{m}\right)$ for each condition. SD is indicated within the parentheses. 


\section{B.1-H is-P K M 2 M T 1}

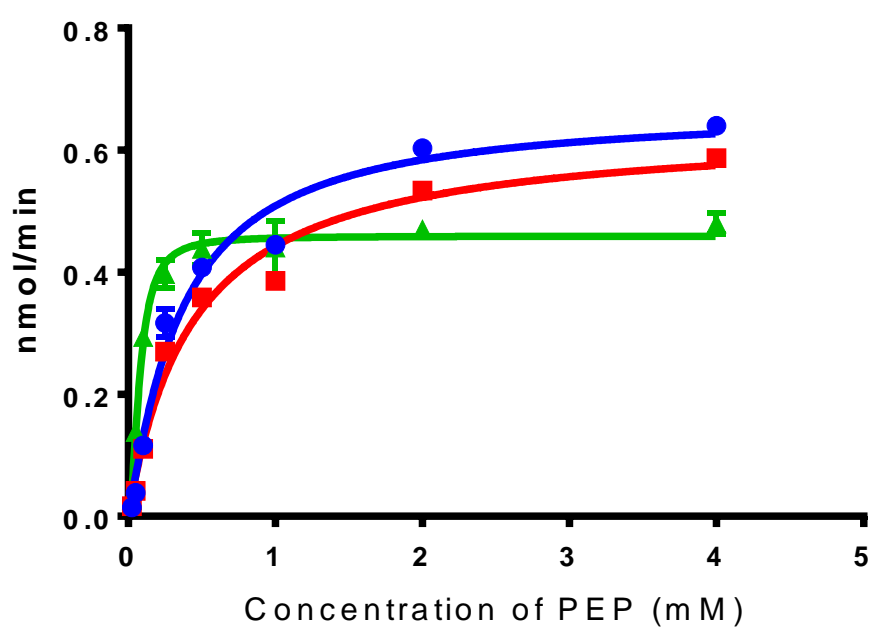

- PKM 2

$=$ PKM2 + 400nM PSAT1

\pm PKM2 + 500uM FBP

\section{B1} His-PKM2 MT1 His-PKM2 MT1 His-PKM2 MT1 +400nM PSAT1 +500uM FBP

\begin{tabular}{|c|c}
\hline $\boldsymbol{V}_{\max }$ & 0.6685 \\
& $(0.03888)$ \\
\hline $\boldsymbol{K}_{\boldsymbol{m}}$ & 0.3563 \\
& $(0.05821)$ \\
\hline
\end{tabular}

0.6394

$(0.04569)$

0.4423

$(0.09085)$

0.4592

$(0.008941)$

0.07875

$(0.004954)$

Figure 30. Effect of PSAT1 and FBP on MT1 His-PKM2 (Batch1) activity. Enzymatic activity of MT1 PKM2 $(2.5 \mathrm{nM})$ from Batch 1 was measured by an enzyme-coupled assay with increasing concentrations of PEP in the presence or absence of PSAT1 or FBP. Data is represented as nmol / min and fitted to a non-linear regression model. Results are an average of two technical replicates. Table depicts average kinetic parameters $\left(\mathrm{V}_{\max }\right.$ and $\left.\mathrm{K}_{\mathrm{m}}\right)$ for each condition. SD is indicated within the parentheses. 
B.1-H is-PKM 2 M T 2

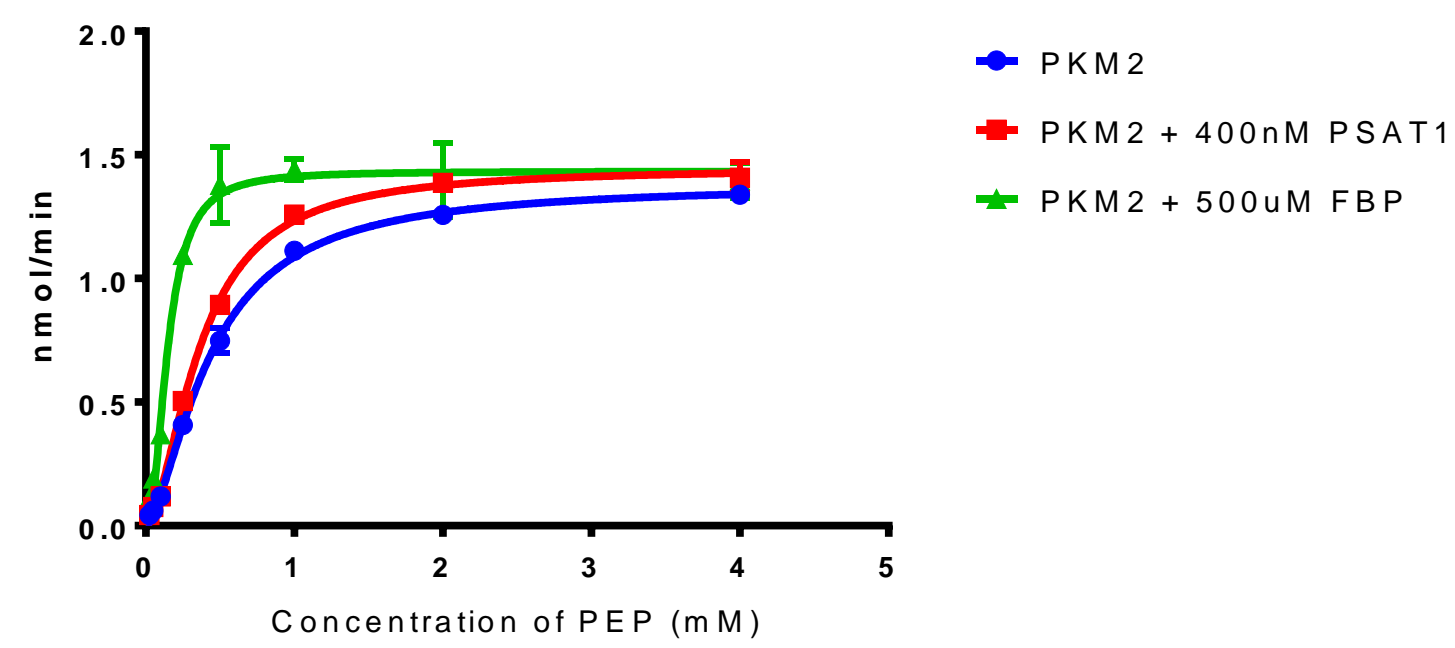

B1 His-PKM2 MT2 His-PKM2 MT2 His-PKM2 MT2 +400nM PSAT1 +500uM FBP

\begin{tabular}{l|c|c|c}
\hline $\boldsymbol{V}_{\max }$ & 1.381 & 1.448 & 1.433 \\
& $(0.02136)$ & $(0.02223)$ & $(0.03562)$ \\
\hline $\boldsymbol{K}_{\boldsymbol{m}}$ & 0.4361 & 0.3657 & 0.1485 \\
& $(0.01556)$ & $(0.01319)$ & $(0.01109)$ \\
\hline
\end{tabular}

Figure 31. Effect of PSAT1 and FBP on MT2 His-PKM2 (Batch1) activity. Enzymatic activity of MT2 PKM2 (2.5nM) from Batch 1 was measured by an enzyme-coupled assay with increasing concentrations of PEP in the presence or absence of PSAT1 or FBP. Data is represented as nmol / min and fitted to a non-linear regression model. Results are an average of two technical replicates. Table depicts average kinetic parameters $\left(\mathrm{V}_{\max }\right.$ and $\left.\mathrm{K}_{\mathrm{m}}\right)$ for each condition. SD is indicated within the parentheses. 
B.1-H is-P K M 2 M T 4

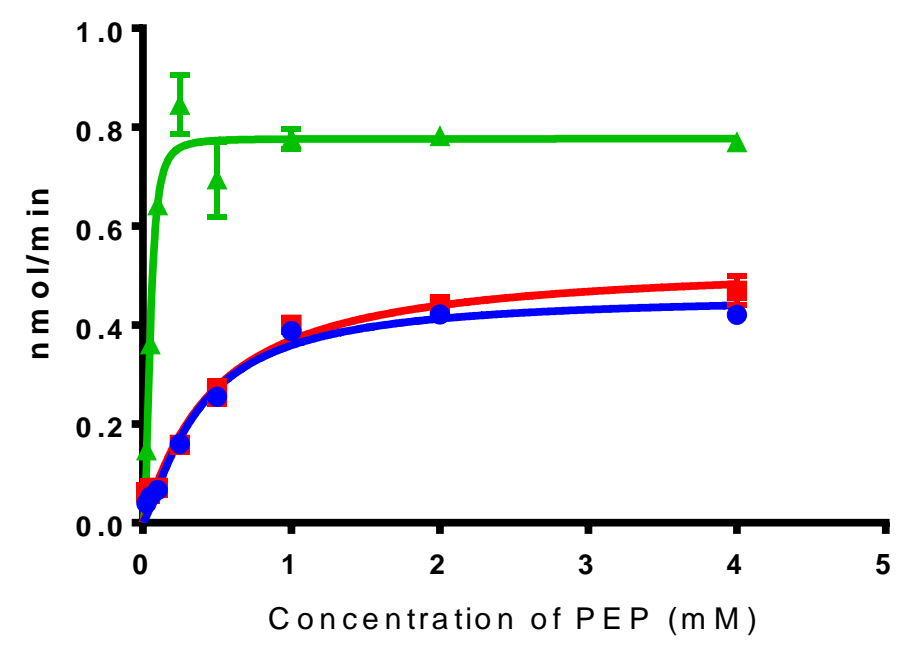

- PKM2

$\Rightarrow \mathrm{PKM} 2+400 \mathrm{nM}$ PSAT1

$\longrightarrow \mathrm{PKM} 2+500 \mathrm{uM}$ FBP

B1

\section{His-PKM2 MT4}

His-PKM2 MT4 His-PKM2 MT4 +400nM PSAT1 +500uM FBP

\begin{tabular}{l|c|c|c}
\hline $\boldsymbol{V}_{\max }$ & 0.4604 & 0.5274 & 0.7766 \\
& $(0.01947)$ & $(0.03599)$ & $(0.01855)$ \\
\hline $\boldsymbol{K}_{\boldsymbol{m}}$ & 0.3773 & 0.4621 & 0.05099 \\
& $(0.04146)$ & $(0.08492)$ & $(0.00375)$ \\
\hline
\end{tabular}

Figure 32. Effect of PSAT1 and FBP on MT4 His-PKM2 (Batch 1) activity. Enzymatic activity of MT4 PKM2 (2.5nM) from Batch 1 was measured by an enzyme-coupled assay with increasing concentrations of PEP in the presence or absence of recPSAT1 or FBP. Data is represented as nmol / min and fitted to a non-linear regression model. Results are an average of two technical replicates. Table depicts average kinetic parameters $\left(\mathrm{V}_{\max }\right.$ and $\left.\mathrm{K}_{\mathrm{m}}\right)$ for each condition. SD is indicated within the parentheses 


\section{B.2-H is-PKM 2 W T}

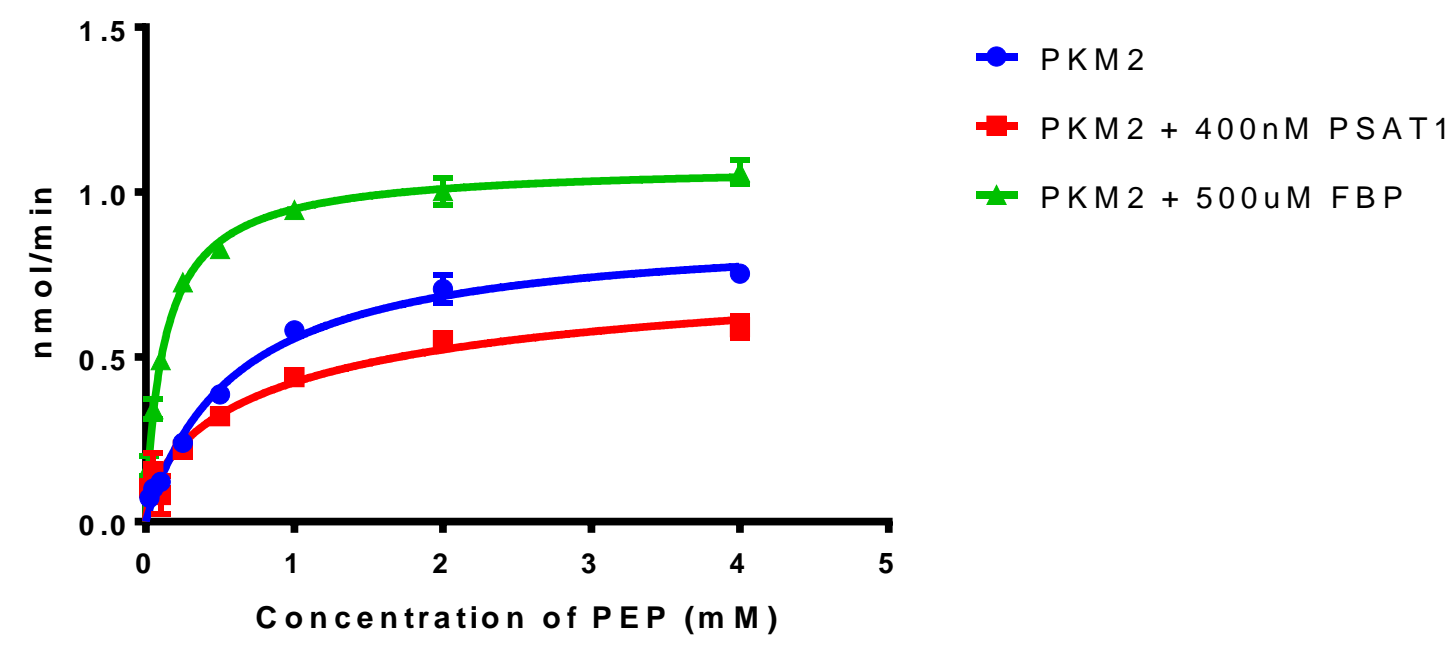

\begin{tabular}{l|ccc} 
B2 & His-PKM2 WT & $\begin{array}{c}\text { His-PKM2 WT } \\
\text { +400nM PSAT1 }\end{array}$ & $\begin{array}{c}\text { His-PKM2 WT } \\
\text { +500uM FBP }\end{array}$ \\
\hline $\boldsymbol{V}_{\max }$ & 0.8934 & 0.867 & 1.087 \\
& $(0.05763)$ & $(0.2191)$ & $(0.02343)$ \\
\hline$K_{\boldsymbol{m}}$ & 0.6041 & 1.076 & 0.126 \\
& $(0.1068)$ & $(0.917)$ & $(0.009584)$ \\
\hline
\end{tabular}

Figure 33. Effect of PSAT1 and FBP on WT His-PKM2 (Batch 2) activity. Enzymatic activity of MT4 PKM2 $(2.5 \mathrm{nM})$ from Batch 1 was measured by an enzyme-coupled assay with increasing concentrations of PEP in the presence or absence of recPSAT1 or FBP. Data is represented as $\mathrm{nmol} / \mathrm{min}$ and fitted to a non-linear regression model. Results are an average of two technical replicates. Table depicts average kinetic parameters $\left(\mathrm{V}_{\max }\right.$ and $\left.\mathrm{K}_{\mathrm{m}}\right)$ for each condition. SD is indicated within the parentheses 


\section{B.2-H is-PKM 2 M T 1}

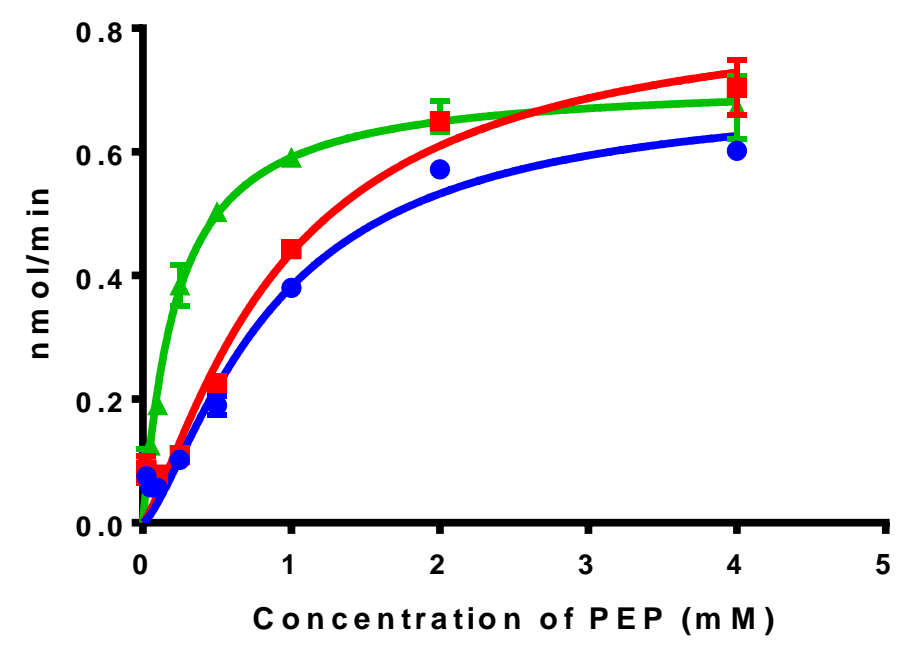

PKM2

$=P K M 2+500 u M F B P$

B2

His-PKM2 MT1 His-PKM2 MT1 His-PKM2 MT1 +400nM PSAT1 +500uM FBP

\begin{tabular}{l|c|c|c}
\hline $\boldsymbol{V}_{\max }$ & 0.7019 & 0.8449 & 0.7151 \\
& $(0.06659)$ & $(0.09603)$ & $(0.02305)$ \\
\hline $\boldsymbol{K}_{\boldsymbol{m}}$ & 0.8794 & 0.9467 & 0.2242 \\
& $(0.1725)$ & $(0.2311)$ & $(0.0229)$ \\
\hline
\end{tabular}

Figure 34. Effect of PSAT1 and FBP on MT1 His-PKM2 (Batch 2) activity. Enzymatic activity of MT4 PKM2 $(2.5 \mathrm{nM})$ from Batch 1 was measured by an enzyme-coupled assay with increasing concentrations of PEP in the presence or absence of recPSAT1 or FBP. Data is represented as $\mathrm{nmol} / \mathrm{min}$ and fitted to a non-linear regression model. Results are an average of two technical replicates. Table depicts average kinetic parameters $\left(\mathrm{V}_{\max }\right.$ and $\left.\mathrm{K}_{\mathrm{m}}\right)$ for each condition. SD is indicated within the parentheses 


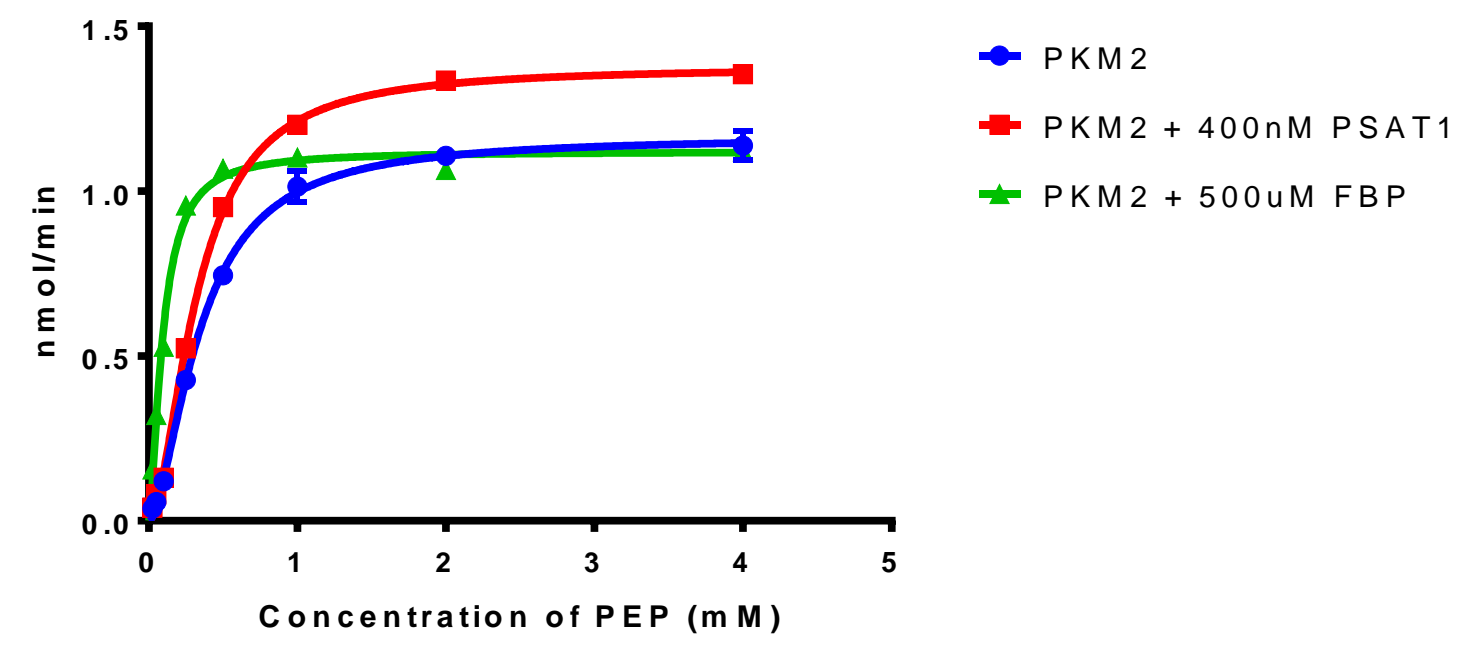

\begin{tabular}{l|c|c|c} 
B2 & His-PKM2 MT2 & $\begin{array}{c}\text { His-PKM2 MT2 } \\
\text { +400nM PSAT1 }\end{array}$ & $\begin{array}{c}\text { His-PKM2 MT2 } \\
\text { +500uM FBP }\end{array}$ \\
\hline $\boldsymbol{V}_{\max }$ & 1.165 & 1.376 & 1.12 \\
& $(0.01669)$ & $(0.3256)$ & $(0.01741)$ \\
\hline$K_{\boldsymbol{m}}$ & 0.3473 & 0.3256 & 0.09464 \\
& $(0.01222)$ & $(0.008292)$ & $(0.004654)$ \\
\hline
\end{tabular}

Figure 35. Effect of PSAT1 and FBP on MT2 His-PKM2 (Batch 2) activity. Enzymatic activity of MT4 PKM2 $(2.5 \mathrm{nM})$ from Batch 1 was measured by an enzyme-coupled assay with increasing concentrations of PEP in the presence or absence of PSAT1 or FBP. Data is represented as nmol / min and fitted to a non-linear regression model. Results are an average of two technical replicates. Table depicts average kinetic parameters $\left(\mathrm{V}_{\max }\right.$ and $\left.\mathrm{K}_{\mathrm{m}}\right)$ for each condition. SD is indicated within the parentheses 


\section{B.2-H is-PKM 2 M T 4}

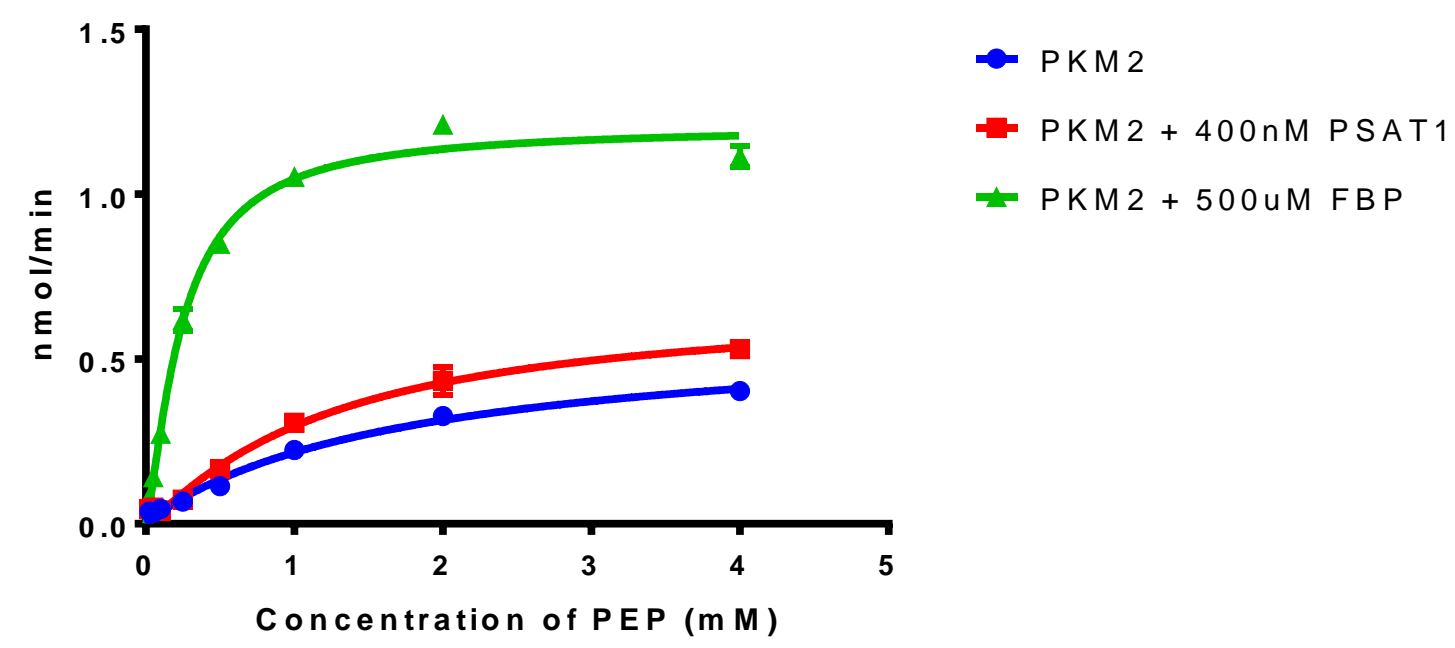

\begin{tabular}{l|ccc} 
B2 & His-PKM2 MT4 & $\begin{array}{c}\text { His-PKM2 MT4 } \\
\text { +400nM PSAT1 }\end{array}$ & $\begin{array}{c}\text { His-PKM2 MT4 } \\
\text { +500uM FBP }\end{array}$ \\
\hline $\boldsymbol{V}_{\max }$ & 0.6025 & 0.6741 & 1.206 \\
& $(0.1099)$ & $(0.07942)$ & $(0.03112)$ \\
\hline$K_{\boldsymbol{m}}$ & 1.825 & 1.236 & 0.2427 \\
& $(0.7758)$ & $(0.3186)$ & $(0.01812)$ \\
\hline
\end{tabular}

Figure 36. Effect of PSAT1 and FBP on MT4 His-PKM2 (Batch 2) activity. Enzymatic activity of MT4 PKM2 $(2.5 \mathrm{nM})$ from Batch 1 was measured by an enzyme-coupled assay with increasing concentrations of PEP in the presence or absence of recPSAT1 or FBP. Data is represented as nmol / min and fitted to a non-linear regression model. Results are an average of two technical replicates. Table depicts average kinetic parameters $\left(\mathrm{V}_{\max }\right.$ and $\left.\mathrm{K}_{\mathrm{m}}\right)$ for each condition. SD is indicated within the parentheses 


\begin{tabular}{|l|l|}
\hline Abb. & Name \\
\hline PKM2 & Pyruvate Kinase M2 isoform \\
\hline PSAT1 & PhosphoSerine AminoTransferase 1 \\
\hline recPKM2 & Recombinant PKM2 protein \\
\hline ATP & Adenosine TriPhosphate \\
\hline HK & Hexokinase \\
\hline G6P & Glucose 6-Phosphate \\
\hline PGI & PhosphoGlucose Isomerase \\
\hline F6P & Fructose 6-Phophate \\
\hline PFK1 & PhosphoFructoKinase-1 \\
\hline FBP & Fructose 1,6-BisPhosphate \\
\hline G3P & Glyceraldehyde 3-Phosphate \\
\hline GAPDH & $\begin{array}{l}\text { GlycerAldehyde 3-Phosphate } \\
\text { DeHydrogenase }\end{array}$ \\
\hline NAD & Nicotinamide Adenine Dinucleotide \\
\hline ADP & Adenosine DiPhosphate \\
\hline PEP & PhosphoEnolPyruvate \\
\hline PK & Pyruvate Kinase \\
\hline TCA & TriCarboxylic Acid \\
\hline FAD & Flavin Adenine Dinucleotide \\
\hline LDH & Lactate DeHydrogenase \\
\hline FDG & FluroDeoxyGlucose \\
\hline PET & Positron Emission Tomography \\
\hline CT & Computed Tomography \\
\hline HIF1 $\alpha$ & Hypoxia Inducing Factor 1 $\alpha$ \\
\hline PPP & Pentose Phosphate Pathway \\
\hline NADP & $\begin{array}{l}\text { Nicotinamide Adenine Dinucleotide } \\
\text { Phosphate }\end{array}$ \\
\hline ROS & Reactive Oxygen Species \\
\hline PHP & 3-PhosphoHydroxyPyruvate \\
\hline PHGDH & PHosphoGlycerate DeHydrogenase \\
\hline PLP & PyridoxaL 5'-Phosphate \\
\hline$\alpha K G$ & $\alpha$-KetoGlutarate \\
\hline P-ser & PhosphoSERine \\
\hline PSPH & PhosphoSerine PHosphatase \\
\hline THF & TetraHydroFolate \\
\hline SAM & S-Adenosyl Methionine \\
\hline hnRNP & HeterogeNous RiboNucleoProteins \\
\hline SRSF 3 & Serine-aRgenine Splice Factor 3 \\
\hline
\end{tabular}




\begin{tabular}{|l|l|}
\hline H3T11 & Tyrosine 11 on Histone H3 \\
\hline MTHF & methyl TetraHydroFolate \\
\hline MT1 & Mutant 1 \\
\hline MT2 & Mutant 2 \\
\hline MT3 & Mutant 3 \\
\hline MT4 & Mutant 4 \\
\hline WT & Wild-Type \\
\hline B.1 & Batch 1 \\
\hline B.2 & Batch 2 \\
\hline
\end{tabular}

\section{Table 1. Abbreviations}




\section{Assessment of interaction of His-PKM2 with Glutathione Beads}

The PSAT1:PKM2 association was originally identified through a GSTPSAT1 pulldown. To determine the feasibility of this strategy to investigate HisPKM2 association, I first wanted to test if His-PKM2 non-specifically bound to glutathione beads. For this, $0.1 \%$ of BSA was added to Glutathione beads and incubated overnight at $4{ }^{\circ} \mathrm{C}$. 500ng of His-PKM2 was added to the solution and incubated at $4^{\circ} \mathrm{C}$ for an additional 45 minutes. Beads were centrifuged, and supernatant was discarded. Beads were washed 3 times using 1x PBS, centrifuged, and supernatant was discarded. $25 \mu \mathrm{L}$ of $1 \mathrm{x}$ Laemmli Buffer was added to the beads and heated to $95^{\circ} \mathrm{C}$ for 5 minutes. Beads were then centrifuged, and supernatant was loaded onto $10 \%$ SDS-PAGE gel. Binding of His-

PKM2 to glutathione beads was assessed by immunoblotting using anti-His antibody. As depicted in Figure 37, no His-PKM2 was seen bound to GST beads. These data suggest that binding of His-PKM2 protein to GST-PSAT1 may be evaluated with this approach. 
Glutathione Beads

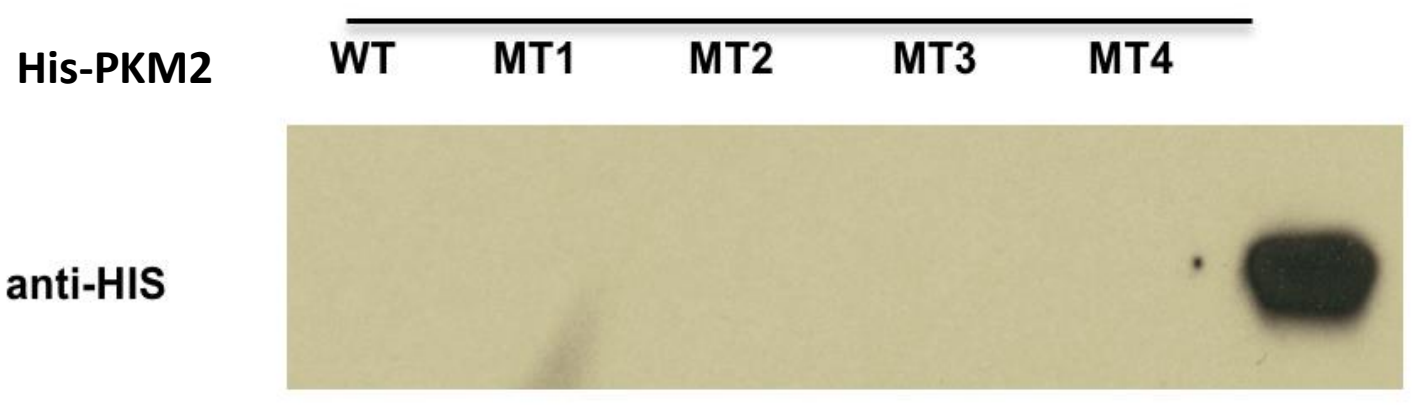

Figure 37. Analysis of His-PKM2 association with glutathione beads. His-tagged PKM2 proteins were incubated with glutathione beads alone. Elutions were ran on SDS-PAGE and shown is an individual Western blot assessing presence of PKM2 using an anti-His antibody. Aliquot of recPKM2 WT was used as positive control for immunoblot. 
Alexis Vega

744 E Madison St. 744A

Louisville, KY 40202

Telephone: (239)895-6213

aavega01@exchange.louisville.edu

\section{A. Education}

University of Louisville

$08 / 2016$

Louisville, $K Y$

Present

Master's in Science, Molecular Biology and Molecular Genetics

Florida Gulf Coast University

Fort Myers, FL

08/2011

Bachelor's in Science, Biotechnology

$04 / 2014$

Miami-Dade Community College

Miami, FL

Associate's in Arts, Biotechnology

$08 / 2009$

B. Academic Appointments

James Brown Cancer Center

Louisville, $K Y$

Lab Technician I

$01 / 2017$

PI: Dr. Brian F. Clem

$04 / 2011$

Investigating the interaction between recombinant PKM2 and

$05 / 2018$

PSAT1

C. Abstracts and Presentations

Graduate Student Regional Research Conference

$03 / 2018$

Louisville, $K Y$

PI: Dr. Brian Clem

Functional consequence of association of PKM2 and PSAT1 on their inherent enzymatic activity

Research! Louisville

09/2017

Louisville, $K Y$

PI: Dr. Brian Clem

Functional consequence of association of PKM2 and PSAT1 on their inherent enzymatic activity

BMG Retreat

Louisville, $K Y$

$08 / 2017$

PI: Dr. Brian Clem 
Functional consequence of association of PKM2 and PSAT1 on their inherent enzymatic activity

Florida Gulf Coast University Research Day

Fort Myers, FL

PI: Dr. Jan DeJarnette

$03 / 2014$

Determining Whether Certain Strains of Methicillin-Resistant

Staphylococcus aureus have Sexual Preferences

A. Research Funding

Graduate School Committee Research Award

University of Louisville, PI: Dr. Brian F. Clem

2017

Role: Project Investigator (90\%)

Funding amount: $\$ 500$ (Indirect) 